\title{
International Association of
}

Instructors and Investigators in Poultry Husbandry

\section{YOLUME I}

Proceedings of the Meetings for the Years 1908, 1909, 1910 
P. P. Itamas 




\section{International Association of}

Instructors and Investigators in Poultry Husbandry

VOLUME I

Proceedings of the Meetings for the Years 1908, 1909, 1910

Committee on Publication

JAMES E. RICE HOWARD C. PIERCE

RAYMOND PEARL

C. A. ROGERS, Editor

I T H A CA, N. Y . 


\section{Press of W. F. HUMPhrgy}

Geneva, N. Y.

Copyright, 1912, by

The International Association of Instructors and Investigators in Poultry Husbandry 


\section{CONTENTS}

Foreword.

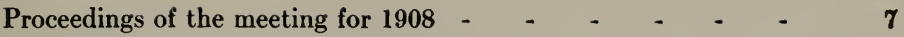

Proceedings of the meeting for $1909 \quad-\quad+\quad+\quad-\quad 12$

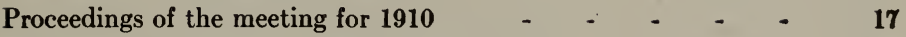

Address of Welcome for 1908-James E. Rice - - - 24

Response-James E. Rice - - - - - - - 24

The Field of Research in Poultry Husbandry-Horace Atwood - $\quad 27$

Inheritance of the Function of Egg Production in the Domestic

Fowl and its Influence on the Fertility and Hatching Power of Eggs-Raymond Pearl - - - - - - -

A Report of the Committee on Investigation for 1909-

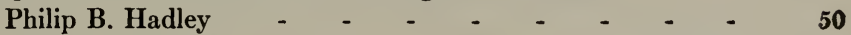

The Present Status of Investigation of the Problems of Poultry Culture for 1909-Philip B. Hadley - - - - -

The Present Status of Investigation of the Problems of Poultry

Culture for 1910-Philip B. Hadley - - - - -

Profitable Lines of Investigation in Poultry Diseases-

George Byron Morse - - - - - - -

The Relation of Intestinal Worms to Poultry Hygiene-

George Edward Gage - - - - - - -

Fowl Cholera (Cholera Gallinarum)-J. Willems, Translated by

Victor Fortier - - _ - _ - - - .

Present Condition of Experimental Work in Feeding-

R. R. Slocum - - - $\quad$ - $\quad$ - $\quad$ - - - -

Feeding Color-An Aid in Studying Physiological Development-

C. A. Rogers - - - - - - - - -

Influence of the Type of the House upon the Progeny-

L. C. Opperman - - - - - - - $\quad 8$

Some Recent Experiments in Incubation-James Dryden. - $\quad 85$

Comparison of Poultry Keeping in Europe, United States and

Canada-Wil Brown. - - - - - - -

An Outline for a Course of Study in Poultry Husbandry-

James E. Rice 
Teaching by Farm Trains and Educational Exhibits at FairsW. A. Brown. - - - - - - - - -

Teaching by Lectures, Recitations and Reference ReadingWm. A. Lippincott - - - - - - - - 108

Poultry Pathology. Its Place in the Curriculum-

George Byron Morse - - - - - - - 110

Study of Feeds and Methods of Instruction in Feeding-

W. G. Krum - - - - - - - - - 114

Instruction in Feeding Poultry-C. A. Rogers - - - 119

A Combined Report of the Committees on Bibliography-

Clara Nixon - - - - - - - - - 122

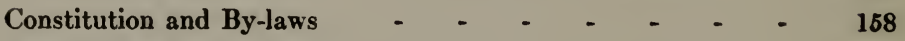

Members - - _ - _ _ - - - - 162 


\section{FOREWORD}

For a number of years previous to the formation of the International Association of Instructors and Investigators in Poultry Husbandry, there existed among several interested in Poultry work a desire to discuss common problems and various methods. A movement to accomplish this desirable end was set on foot as early as 1906 when several teachers of Poultry Husbandry met at the Madison Square Garden Show for an impromptu discussion.

A little later, in 1908 to be specific, others feeling that conditions were ripe for concerted action and organization united in an effort to assemble all teachers and investigators of Poultry Culture. After considerable discussion it was decided to hold a conference in connection with the course in Poultry at the Graduate School of Agriculture, meeting that year at Cornell University.

A regular organization was effected at this conference. The interest manifested induced the directors to hold a meeting of the Association annually. The second conference was held at the Ontario Agricultural College and Experiment Station and the third at the Iowa Agricultural College and Experiment Station.

This volume contains a report of the proceedings of the first three conferences of the International Association of Instructors and Investigators in Poultry Husbandry. No definite action was taken to publish the proceedings of this Association until the third annual conference. Consequently a large portion of the material of these first meetings is not available. This fact accounts for the publication in one volume of the proceedings of the first three meetings. 




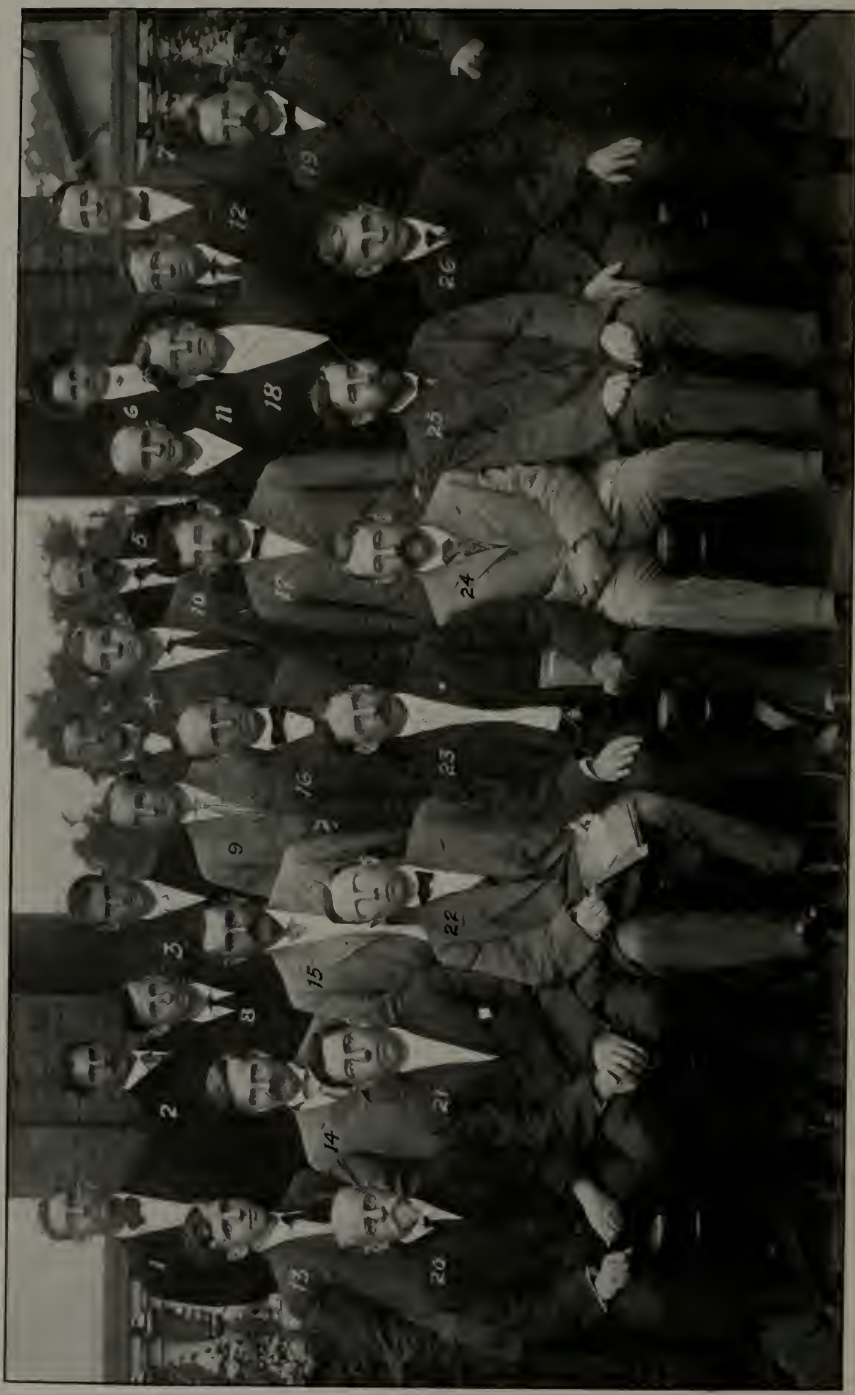




\section{PROCEEDINGS OF THF MFETING FOR 1908}

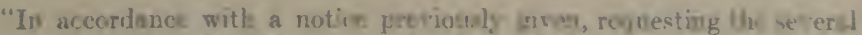
workers in poultry line from the Agricullural Colleges and Exporment

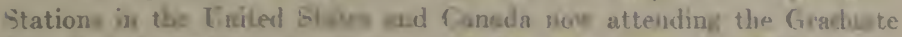

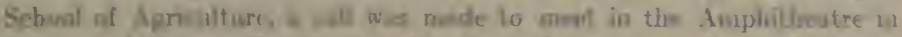

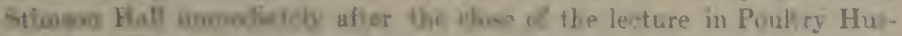

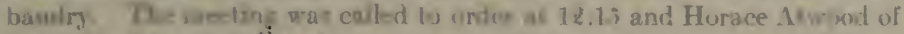
West Virtima elente Miss, was elected seetary. Jamen E Rile was called upon to state the

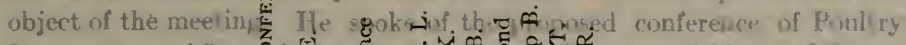

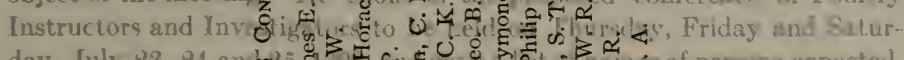

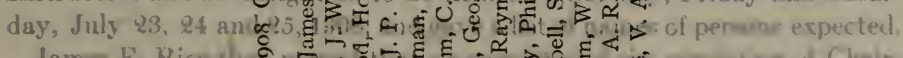
Jama E. Rice a

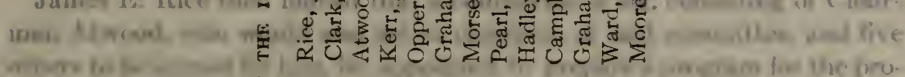

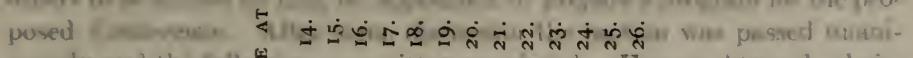

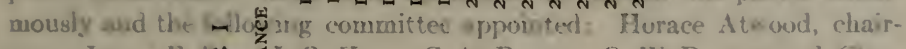
man; James E. ज. Nixon-"*

\section{The Procran}

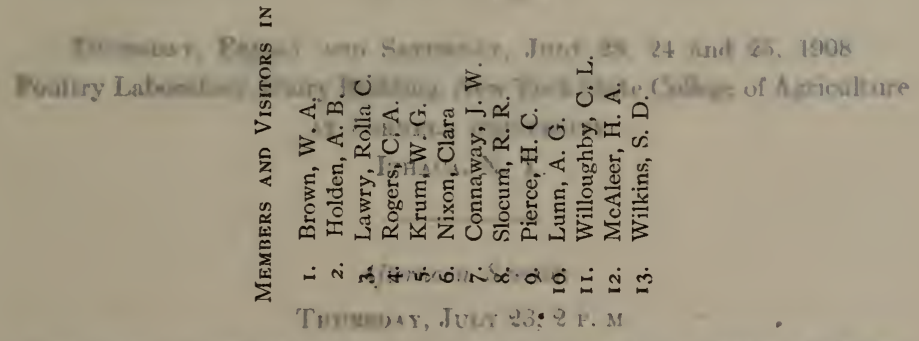

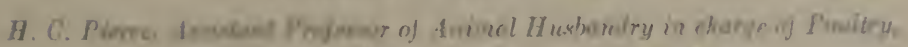

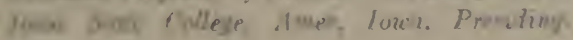

Adiress of Welcume, - - _ - _ - Jamin E Rice

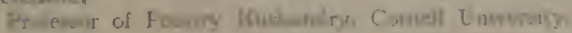

Greeting,

Dr. A C. True

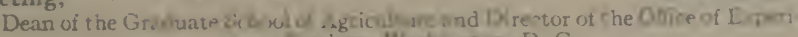
ment tation, Wist nites D C

Response

Juwrs I. Rice

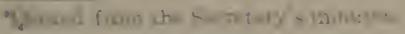




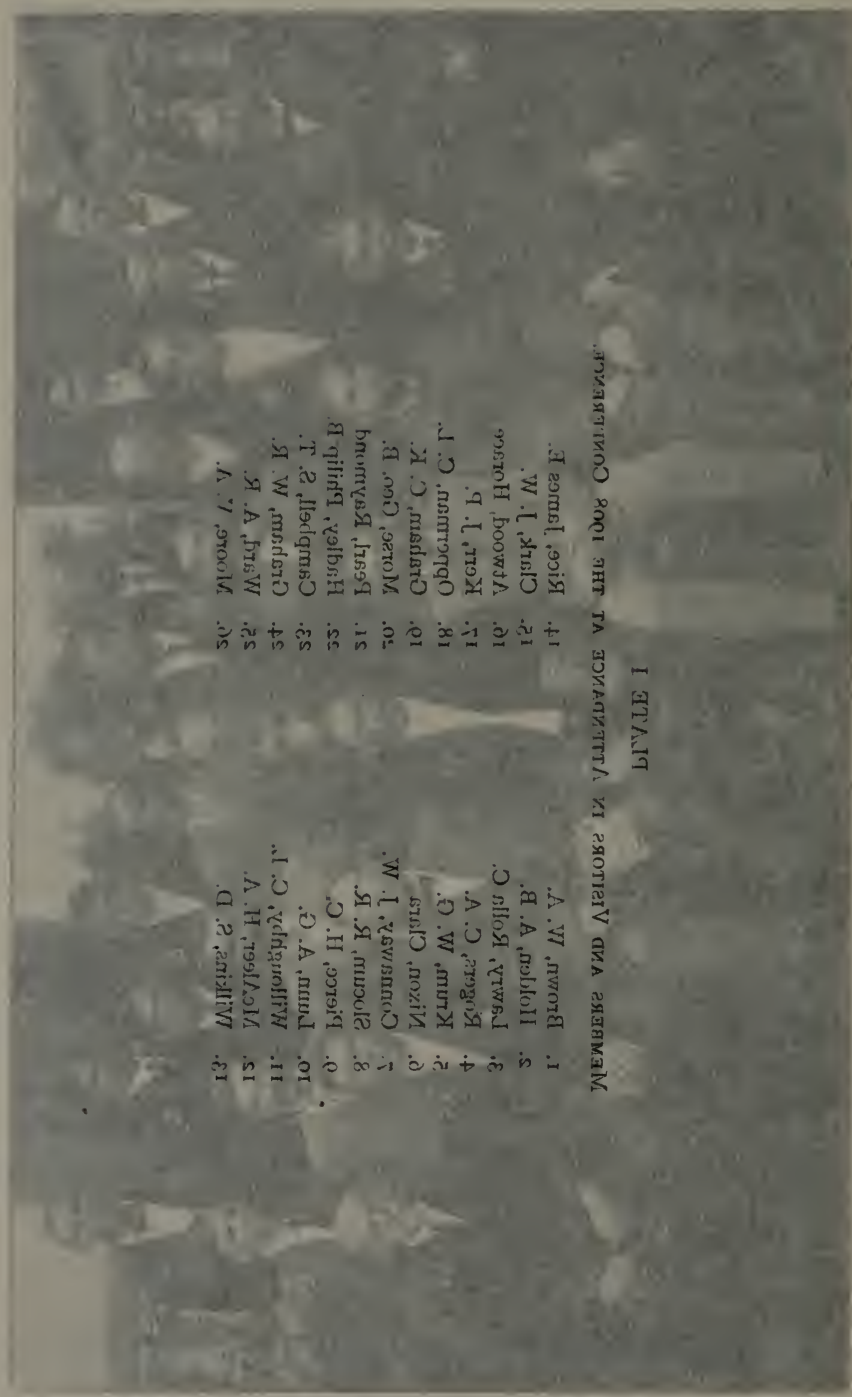




\section{PROCEEDINGS OF THE MEETING FOR 1908}

"In accordance with a notice previously given, requesting the several workers in poultry lines from the Agricultural Colleges and Experiment Stations in the United States and Canada now attending the Graduate School of Agriculture, a call was made to meet in the Amphitheatre in Stimson Hall immediately after the close of the lecture in Poultry Husbandry. The meeting was called to order at 12:15 and Horace Atwood of West Virginia elected chairman. James P. Kerr of Agricultural College, Miss., was elected secretary. James E. Rice was called upon to state the object of the meeting. He spoke of the proposed conference of Poultry Instructors and Investigators to be held on Thursday, Friday and Saturday, July 23, 24 and 25, 1908, and gave a list of names of persons expected.

James E. Rice then moved that a committee of six, consisting of Chairman Atwood, who would also act as chairman of said committee, and five others to be named by him, be appointed to prepare a program for the proposed Conference. After some discussion the motion was passed unanimously and the following committee appointed: Horace Atwood, chairman; James E. Rice, J. P. Kerr; C. A. Rogers, O. W. Dynes, and Clara Nixon."*

\section{The Program}

Thursday, Friday and Saturday, July 23, 24 and 25, 1908 Poultry Laboratory, Dairy Building, New York State College of Agriculture AT CORNELL UNIVERSITY
ITHACA, N. Y.

\section{Afternoon Session}

Thursday, July 23, 2 P. M.

H. C. Pierce, Assistant Professor of Animal Husbandry in charge of Poultry, Iowa State College, Ames, Iowa, Presiding.

Address of Welcome, - $\quad$ - $\quad$ - $\quad$ - $\quad-\quad$ - James E. Rice Professor of Poultry Husbandry, Cornell University.

Greeting,

Dean of the Graduate School of Agriculture and Director of the Office of Experiment Stations, Washington, D. C.

Response,

*Quoted from the Secretary's minutes. 
"Methods of Instruction in Poultry Husbandry," - - James E. Rico General Discussion, led by - $\quad$ - _ - - - C. K. Graham

Professor of Poultry Culture, Connecticut Agricultural College, Storrs, Conn.

Demonstrations: "Judging Eggs," and "Study of the Anatomy

of the Egg," - - - - - C. A. Rogers

Assistant Professor of Poultry Husbandry, Cornell University.

General Discussion, led by

- W. R. Graham

\section{Evening Session}

Thursday, July 23, 8 р. м.

James P. Kerr, in charge of Poultry Department, Mississippi State Experiment Station and Agricultural and Mechanical College, Agricultural

$$
\text { College, Miss., Presiding. }
$$

Demonstration: "Anatomy of Poultry," - - H. C. Pierce General Discussion, led by - - - - Dr. Geo. B. Morse Biologist, Bureau of Animal Industry, Washington, D. C.

Demonstration: "Study of Feeds" and "Methods of Instruction in

Feeding," - - - - - - - W. G. Krum Superintendent Poultry Plant, Cornell University.

General Discussion, led by - $\quad$ - $\quad$ - $\quad$ - $\quad$ - Alfred G. Lunn Assistant in Poultry Husbandry, Oregon Agricultural College and Experiment Station, Corvalis, Oregon.

General Discussion, led by _ - - - - - C. L. Opperman Poultryman, Maryland Agricultural College, College Park, Md.

\section{Afternoon Session}

Friday, JULY 24, 2 P. M.

R. R. Slocum, Poultryman, Bureau of Animal Industry, Washington, D. C., Presiding.

Demonstration: "Scoring Dressed Poultry," - $\quad W . R$. Graham General Discussion led by - $\quad$ - $\quad$ - $\quad$ - $\quad$ - $\quad$ R. C. Lawry Assistant in Poultry Husbandry, Cornell University.

Demonstration: "Judging Live Poultry for Utility," - $\quad$ R. C. Lawry General Discussion led by - $\quad$ - $\quad$ - $\quad$ - $\quad$ - W. A. Brown Demonstration: "Judging Exhibition Poultry,"

American Class, - - - - - - - J. P.Kerr Mediterranean Class, - _ $\quad$ - $\quad$ - $\quad$ - S. T. Campbell In charge of Poultry Course, Ohio State University, Columbus, 0. 
General Discussion led by

In charge of Winter Poultry Course, Pennsylvania State College, State College, Pa.

"Methods of Teaching the Principles of Laying Out and Constructing

a Poultry House,"

Assistant Professor Poultry Husbandry, Michigan Agricultural College, East Lansing, Michigan.

General Discussion led by

In charge of Poultry Experiments, West Virginia Experiment Station, Morgan-

- Horace Atwood town, W. Va.

Evening Session

Friday, JULY 24, 8 P. M.

Dr. C. B. Davenport, in charge of Carnegie Laboratory, Cold Spring Harbor, N. Y., Presiding.

"The Field of Research in Poultry Husbandry," - Horace Atwood

"Breeding Experiments and Methods of Keeping Records,"

Dr. Raymond Pearl

Biologist, Maine Experiment Station, Orono, Me.

Gestat

"Prof Dle Lines of Investigation in Poultry Diseases" Dr. Deo. B. Moroo General Discussion, led by - - - - - Dr. Archibald R. Ward Bacteriologist, University of California, Berkeley, California.

\section{Morning Session}

SATURDAY, JULY 25, 8 A .M.

W. R. Graham, Presiding.

"White Diarrhœa in Chicks," - _ _ - Dr. Geo. B. Morss

General Discussion, led by - - _ - Dr. Raymond Pearl

INTERMISSION 9 to $11 \mathrm{~A}$. M.

Inspection of the Cornell University Poultry Plant, 11 to 12 А. и.

\section{Afternoon Session}

Saturday, July 25, 2 P. M.

S. T. Campbell, Presiding.

"The Function of Carbondioxide in Incubation," W. R. Graham

"Influence of Varying Temperatures During the Early Periods of Incubation," 
"The Use of Moisture During Incubation,"

Horace Atwood

"Short talks on the Poultry Work in the Various States and Provinces,"

Introduced by

In charge of Poultry, North Dakota Experiment Station, Agricultural College, N. D.

"Ways and Means for Establishing and Maintaining Poultry Depart-

ments,"

Followed by "Round Table Discussion."

Papers from James Dryden, Professor of Poultry Husbandry, Oregon

Agricultural Experiment Station, Corvalis, Oregon, and by D. J.

Lambert, in charge of Instruction in Poultry Husbandry, Kingston,

Rhode Island.

Organization of an "International Association of Instructors and Investigators in Poultry Husbandry."

In response to a general demand, a meeting was called at 11:30 P. M., July 25th, to organize an International Association of Instructors and Investigators in Poultry Husbandry in the United States and Dominion of Canada.

W. R. Graham was elected chairman. S. T. Campbell was made secretary.

The objects of the meeting were stated by the chair. After a general discussion it was moved and carried that an organization of Instructors and Investigators in Poultry Husbandry be formed.

The chair then presented for consideration a proposed constitution and by-laws prepared by a self-constituted committee consisting of W. R. Graham, Horace Atwood, H. C. Pierce, J. P. Kerr and James E. Rice.

After general discussion it was moved and carried that the section relating to the election of officers be adopted and the matter of final adoption of constitution and by-laws be left to the Board of Directors after such changes had been made as in their judgment seemed best.

The following officers and directors were then elected: President, W. R. Graham; 1st vice-president, James Dryden; 2d vice-president, Raymond Pearl; secretary-treasurer, James E. Rice; directors for 1908-10, Horace Atwood, James P. Kerr, S. T. Campbell; directors for 1908-9, H. C. Pierce, R. R. Slocum.

Before adjourning the members in conference extended a hearty vote of thanks and appreciation to the Poultry Department at Cornell University for providing a meeting place and for other courtesies. 
Attendance

Atwood Horace Brown, W. A.

Campbell, S. T. Clark, J. W. Davenport, Dr. C. B. Dynes, O. W. Graham, C. K. Graham, W. R. Hadley, P. B.

C. K. Graham

P. B. Hadley

\section{A. A. Brigham}

D. J. Lambert

F. H. Stoneburn

F. C. Elford

Geo. Byron Morse

Clara Nixon
Halpin, J. G.

Holden, Arthur B.

Kerr, James P.

Krum, W. G.

Lawry, Rolla C.

Lunn, Alfred G.

McAleer, Harry A.

Morse, Geo. Byron

Nixon, Clara

Commitees for 1909

Legislation

O. W. Dynes

Investigation

James G. Halpin

Instruction

W. A. Brown

Breeding

C. B. Davenport

Feeding

A. W. Foley

Incubation

C. A. Rogers

Diseases and Parasites

$$
\text { Archibald Ward }
$$

Bibliography

Victor Fortier
Opperman, C. L.

Pearl, Raymond

Pierce, H. C.

Rice, J. E.

Rogers, C. A.

Slocum, R. R.

Williams, R. H.

Wilkins, Stanley D.

R. C. Lawry

J. P. Landry

W. G. Krum

J. S. Jeff rey

A. G. Gilbert

J. W. Clark

W. T. Kirkpatrick

Frank Surface 


\section{PROCEEDINGS OF THE MEETING FOR 1909}

The second annual conference of the International Association of Instructors and Investigators in Poultry Husbandry was held at the Ontario Agricultural College, Guelph, Canada, on August 13th and 14th, 1909.

The meeting was called to order at $1: 30$ P. м. by President Graham, who introduced Mr. G. C. Creelman, President of the Ontario Agricultural College. President Creelman gave a hearty and inspiring address of welcome.

The program, with a few exceptions, was carried out as printed.

At the business meeting, Saturday afternoon, August 14th, President W. R. Graham was in the chair. The minutes of the last meeting were read by the Secretary-Treasurer and approved.

The action of the Board of Directors in accepting new members was approved.

A formal ballot for President resulted in the election of Dr. Raymond Pearl.

At this point the election of officers was interrupted to adjourn to the lawn for the purpose of securing a group picture. Later the meeting re-assembled and the election of officers was continued with the following results: First vice-president, James Dryden; second vice-president, F. C. Elford; secretary-treasurer, H. C. Pierce; directors for 1909-11, James E. Rice and W. R. Graham.

The Secretary-Treasurer's report stated that practically all of the persons now qualified for membership in the Association had joined the organization. The membership now consisted of 54, with two applications yet to be considered. The books showed a balance of $\$ 38.28+$ dues collectable and due, $\$ 35.00$, making the total assets $\$ 73.28$. The books were submitted showing detailed statements of accounts, with signed vouchers for all bills which had been paid. The report was approved.

At the close of the conference the Association extended a hearty vote of thanks to President Creelman and Professor W. R. Graham for their hospitality and the splendid facilities with which they had provided the Association.

Respectfully submitted,

JAMES E. RICE, Secretary-Treasurer. 



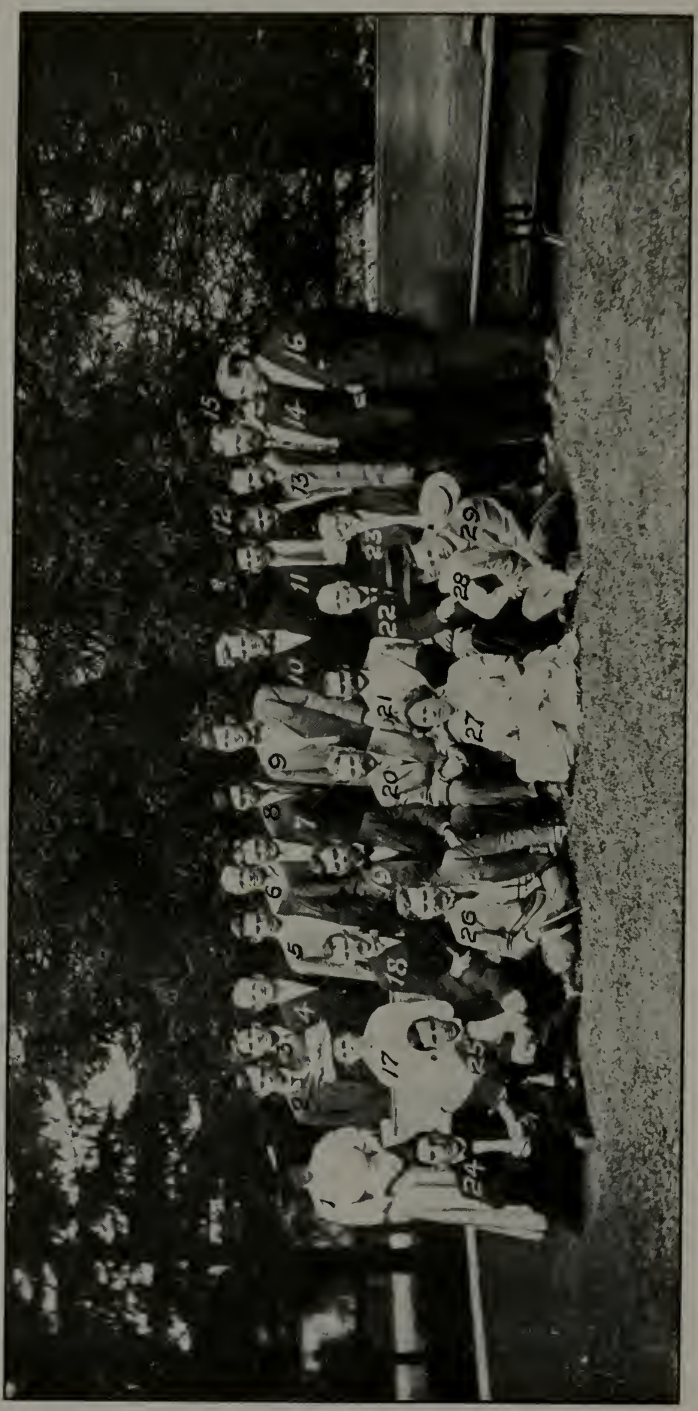




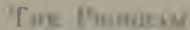

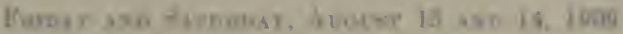

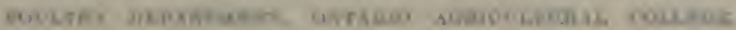
Tirsure Eavos

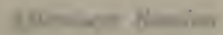

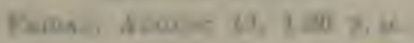

Arlares it the wate

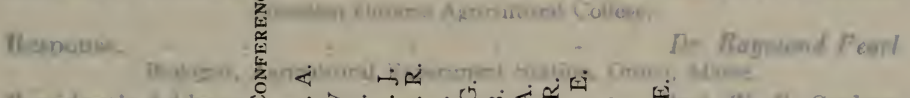

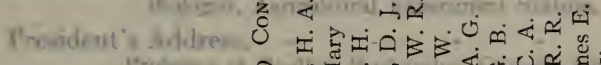

Provilad il A. Croilnus

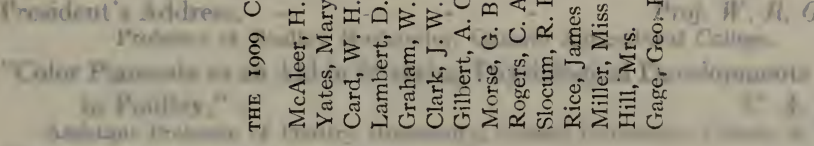

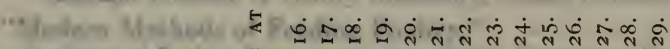

Whe The

Heroct of whe R

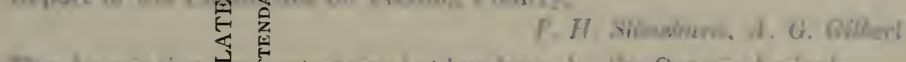

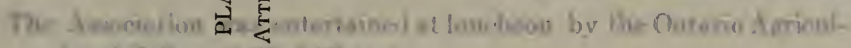

lu, I Collingt $z$

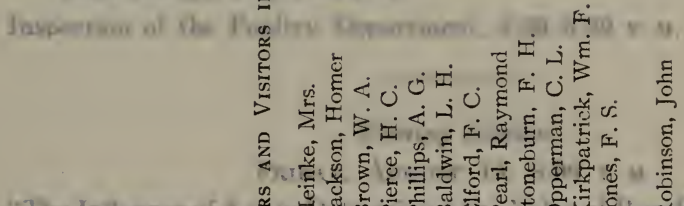

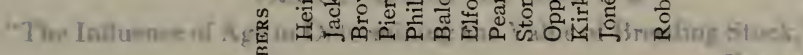

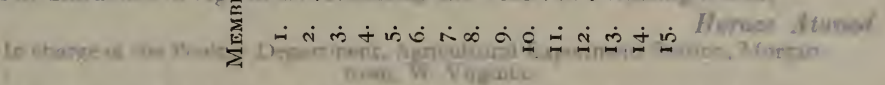

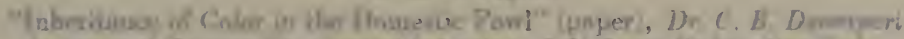

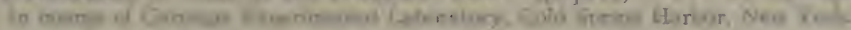

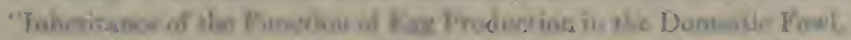

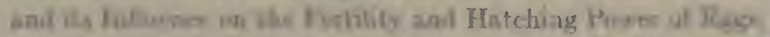

Dr. Hoxami Peart

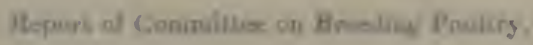

(I) J. Lumberl 


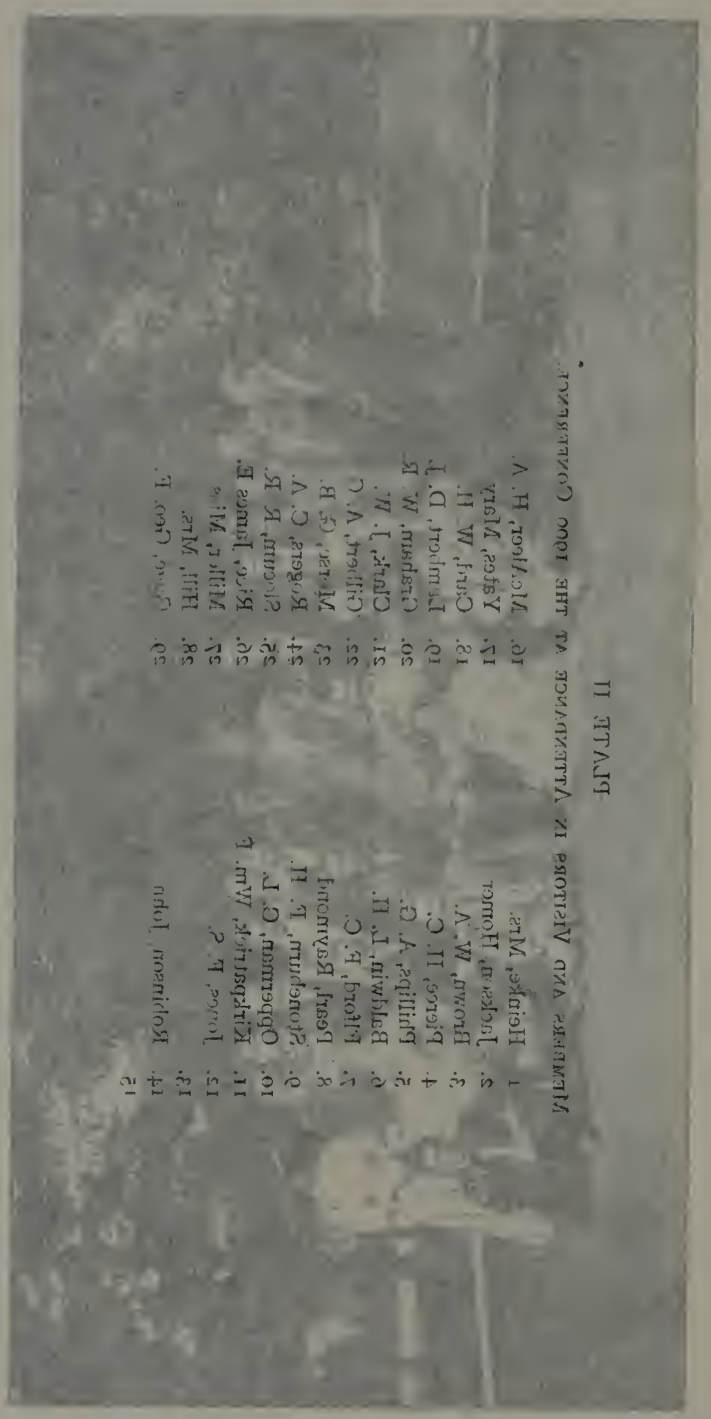


The Progr.am

Friday and Saturday, August 13 and 14, 1909

POULTRY DEPARTMENT, ONTARIO AGRICULTURAL COLLEGE Guelph, Canada

Afternoon Session

Friday, August 13, $1: 30$ P. м.

Address of Welcome, - _ - - - President G. C. Creelman President Ontario Agricultural College.

Response, - - - - - $\quad$ - $\quad-\quad$ Dr. Raymond Pearl Biologist, Agricultural Experiment Station, Orono, Maine.

President's Address, - $\quad$ - $\quad$ - $\quad$ - $\quad$ Prof. W. R. Graham Professor of Poultry Husbandry, Ontario Agricultural College.

"Color Pigments as an Aid in Studying Physiological Developments in Poultry," - - - - - - C. A. Rogers Assistant Professor of Poultry Husbandry, Cornell University, Ithaca, N. Y.

"Modern Methods of Feeding Poultry," - - - A. G. Gilbert

In charge of Poultry Department, Agricultural Experiment Station, Ottawa, Can.

Report of the Committee on Feeding Poultry,

F. H. Stoneburn, A. G. Gilbert

The Association was entertained at luncheon by the Ontario Agricultural College, $5: 30-6: 30$ P. M.

Inspection of the Poultry Department, 6:30-8:30 P. M.

\section{Evening Session}

Friday, August 13, 8:00 р. м.

"The Influence of Age in Determining the Value of Breeding Stock," Horace Atwood In charge of the Poultry Department, Agricultural Experiment Station, Morgantown, W. Virginia.

"Inheritance of Color in the Domestic Fowl" (paper), Dr. C. B. Davenport In charge of Carnegie Experimental Laboratory, Cold Spring Harbor, New York.

"Inheritance of the Function of Egg Production in the Domestic Fowl, and its Influence on the Fertility and Hatching Power of Eggs, Dr. Raymond Pearl

Report of Committee on Breeding Poultry, D. J. Lambert 


\section{Morning Session}

Saturday, August 14, 9:30 A. M.

Demonstration on "Trussing," with Remarks on English Table Poultry, Miss Mary Yates

"Recent Light on the Problems of Incubation," (paper) James Dryden Professor of Poultry Husbandry, Agricultural Experiment Station, Corvallis, Oregon

"Conditions Affecting Eggs Kept for Hatching," -

In charge of Poultry Department, Manhattan, Kansas.

Report of the Committee on Incubation,

$$
\text { F. C. Elford, C. A. Rogers, J.W. Clark }
$$

\section{Afternoon Session}

\section{Saturday, August 14, 2:00 P. м.}

"Comparison of Poultry Keeping in Europe, United States and Canada,"

(Paper) - - - - - - - - - Wil Brown In charge of Poultry Experiments, Reading, England.

"Co-operative Poultry Associations," - - - F. C. Elford

In charge of Poultry Department, McDonald College, Quebec, Canada.

"Mortality in Chickens," - - - - Dr. Geo. B. Morse Pathologist, Bureau of Animal Industry, Washington, D. C.

Dr. P. B. Hadley

Biologist, Agricultural Experiment Station, Kingston, R. I. (paper)

Report of Committee on Poultry Diseases,

Dr. Geo. B. Morse, Wm. F. Kirkpatrick

"Poultry Departments and Poultry Associations,"

F. H. Stoneburn

Professor of Poultry Husbandry, Connecticut Agricultural College, Storrs, Conn.

Evening Session

August 14, 8:00 P. м.

Report of Committee on Investigation, - - - - P. B. Hadley Report of Committee on Bibliography,

Miss Clara Nixon, Victor Fortier, F. M. Surface

Topics of General Discussion

(Speakers called upon impromptu by the presiding officer.)

What should be the attitude of the teacher on the question of large poultry farms? 
What is the scientific or practical value of the "Magic Egg Tester?" Cold versus warm brooding systems. Which is to be preferred?

Influences affecting fertility and hatching power of eggs.

What is the best method of feeding chicks from hatching to laying age?

The effect of meat food on the fertility and hatching power of eggs.

Effect of green food on egg yield and hatching power.

Conditions affecting constitutional vigor.

Headquarters: King Edward Hotel.

Attendance

Atwood, Horace

Baldwin, L. H.

Brown, W. A.

Card, W. H.

Creelman, G. C.

Clark, J. W.

Drew, J. M.

Edwards, S. F.

Elford, F. C.

Gage, G. E.

C. K. Graham

P. B. Hadley

James E. Rice

F. H. Stoneburn

C. A. Rogers
Gilbert, A. G.

Graham, W. R.

Herner, M. C.

Jackson, Homer

Jones, F. S.

Kirkpatrick, Wm. F.

Lambert, D. J.

McAleer, H. A.

Morse, Geo. B.

Opperman, C. L.

Committees for 1910

Legislation

T. E. Quisenberry

\section{Investigation}

James G. Halpin

J. P. Landry

\section{Instruction}

Homer Jackson

Geo. B. Morse

\section{Breeding}

C. B. Davenport

R. R. Slocum

\section{Feeding}
A. G. Gilbert
R. R. Slocum

W. A. Brown
Pearl, R.

Phillips, A. G.

Pierce, H. C.

Quisenberry, T. E.

Rice, J. E.

Rogers, C. A.

Slocum, R. R.

Spear, A. E.

Stoneburn, F. H. 
PROCEEDINGS OF THE INTERNATIONAL

\section{Incubation}

W. R. Graham

F. C. Elford

C. L. Opperman

Diseases and Parasites

Geo. B. Morse

P. B. Hadley

G. E. Gage

Bibliography

Clara Nixon Victor Fortier

Archibald Ward

Frank M. Surface 



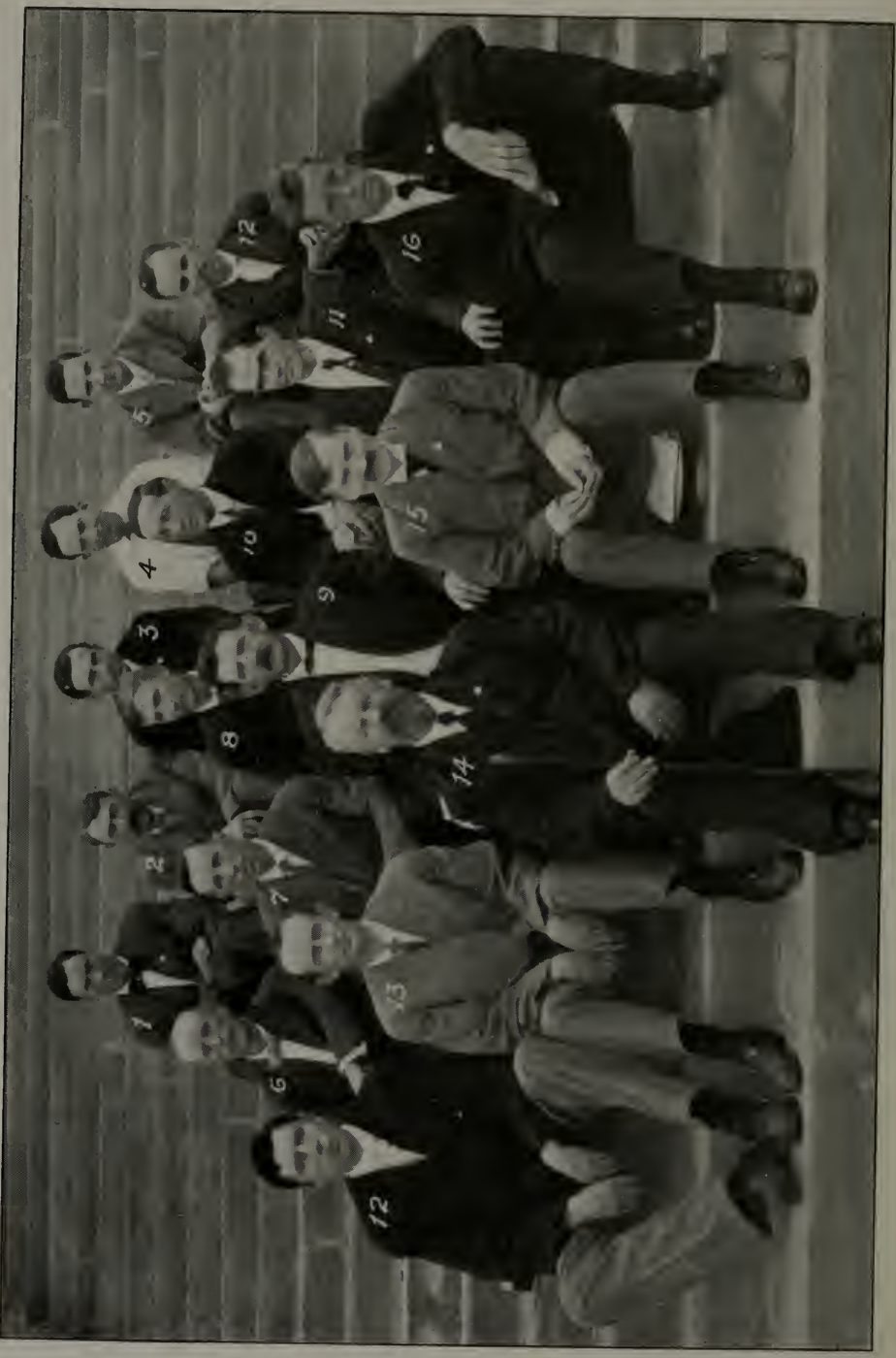




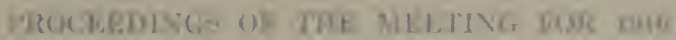

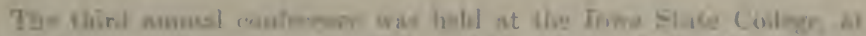

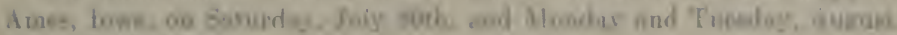
Is sud at. 11180

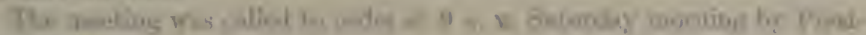
dert Mesh.

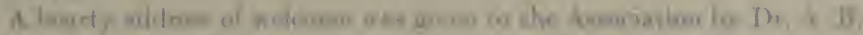

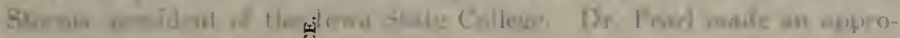
vriuk renowiace

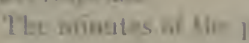

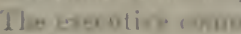

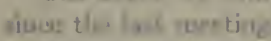

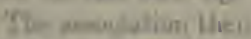

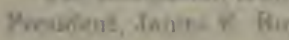

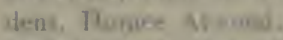

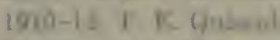
butang in wa ill he

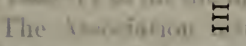
whis th the strondet the

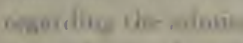

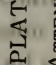

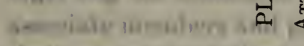

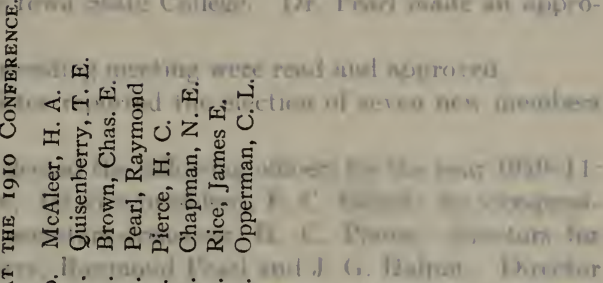

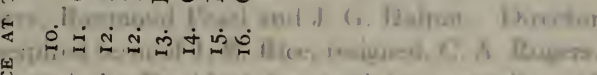

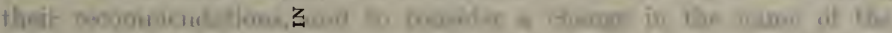

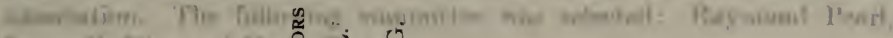
The: 15 the orat II

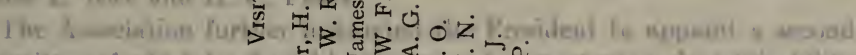
anmition of thintilu

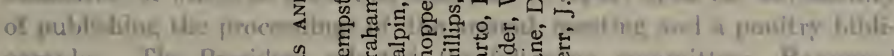

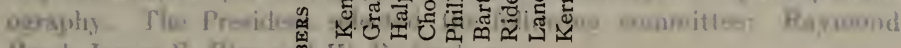

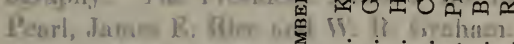

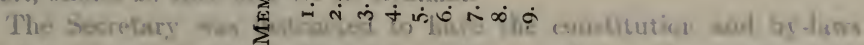

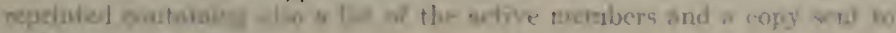
emah artipe anewle:

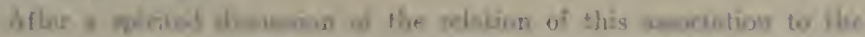

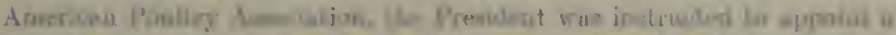

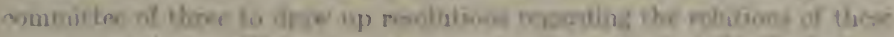

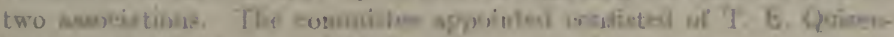

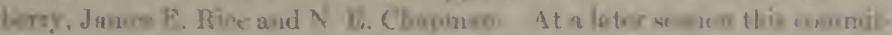
ues mod the following reselutiams which were adepteri. 


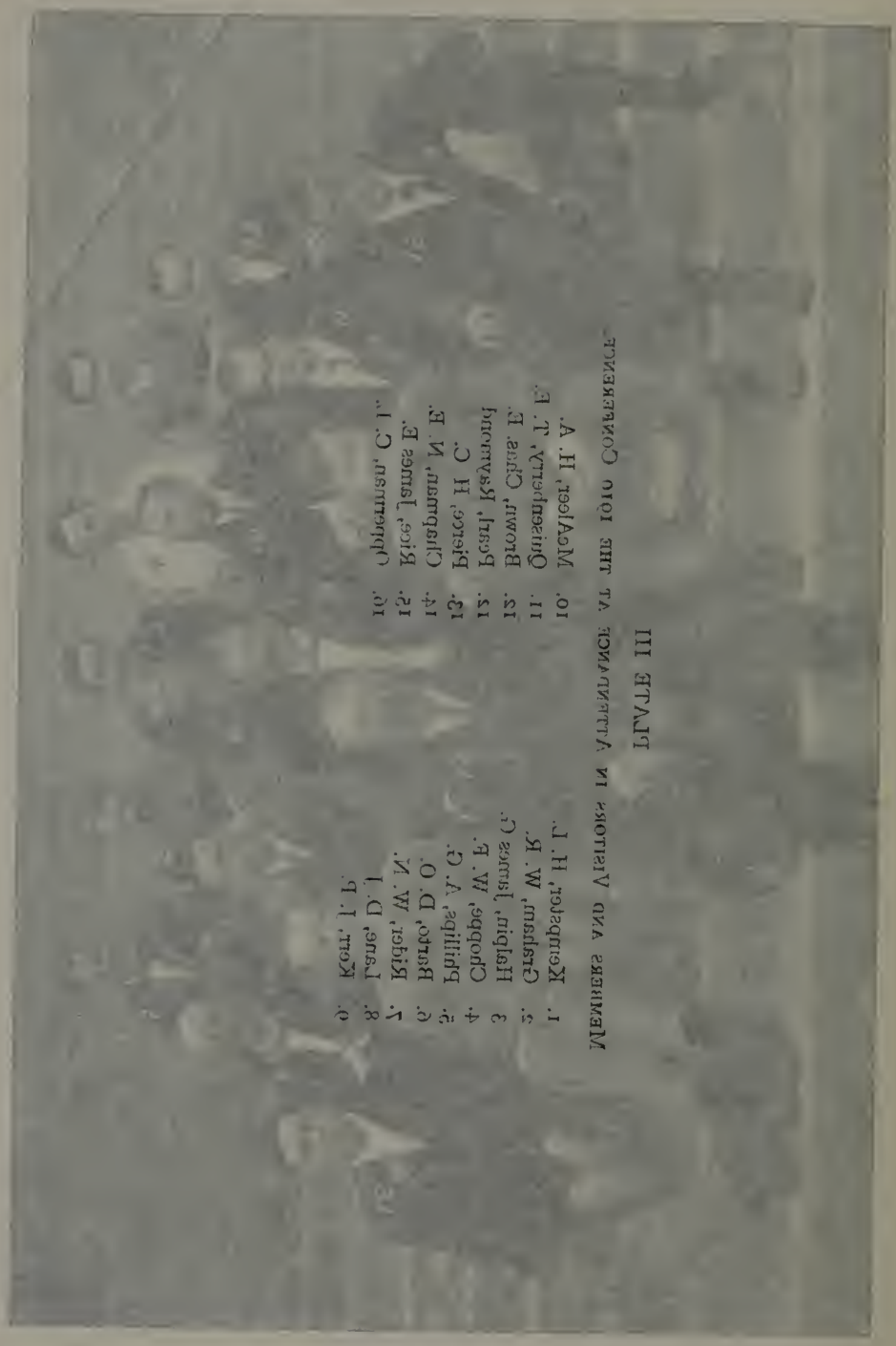




\section{PROCEEDINGS OF THE MEETING FOR 1910}

The third annual conference was held at the Iowa State College, at Ames, Iowa, on Saturday, July 30th, and Monday and Tuesday, August 1 st and $2 \mathrm{~d}, 1910$.

The meeting was called to order at 9 A. M. Saturday morning by President Pearl.

A hearty address of welcome was given to the Association by Dr. A. B. Storms, president of the Iowa State College. Dr. Pearl made an appropriate response.

The minutes of the preceding meeting were read and approved.

The executive committee reported the election of seven new members since the last meeting.

The association then elected the following officers for the year 1910-11: President, James E. Rice; 1st vice-president, F. C. Elford; 2d vice-president, Horace Atwood; secretary-treasurer, H. C. Pierce; directors for 1910-12, T. E. Quisenberry, Raymond Pearl and J. G. Halpin. Director for 1909-11 to fill the unexpired term of J. E. Rice, resigned, C. A. Rogers.

The Association instructed the President to appoint a committee of which he should be chairman to submit an amendment to the constitution regarding the admission of honorary members, to consider the admission of associate members and prepare an amendment to the constitution covering their recommendations, and to consider a change in the name of the Association. The following committee was selected: Raymond Pearl, James E. Rice and H. C. Pierce.

The Association further instructed the President to appoint a second committee of which he should be chairman to report upon the advisability of publishing the proceedings of the annual meeting and a poultry bibliography. The President selected the following committee: Raymond Pearl, James E. Rice and W. R. Graham.

The Secretary was instructed to have the constitution and by-laws reprinted containing also a list of the active members and a copy sent to each active member.

After a spirited discussion of the relation of this association to the American Poultry Association, the President was instructed to appoint a committee of three to draw up resolutions regarding the relations of these two associations. The committee appointed consisted of T. E. Quisenberry, James E. Rice and N. E. Chapman. At a later session this committee read the following resolutions, which were adopted. 
Appreciating the fact that the ultimate aims of the American Poultry Association and the International Association of Instructors and Investigators in Poultry Husbandry are identical, namely, the upbuilding of Poultry Husbandry as a profession, and believing that this end can best be attained by the mutual co-operation and support of the two organizations:

Therefore, we, the members of the International Association of Investigators and Instructors in Poultry Husbandry, 42 per cent. of whom are also members of the American Poultry Association, suggest the following means of co-operation and request favorable action on the part of the American Poultry Association at its annual meeting in St. Louis, August 15th to 20th, 1910 , namely,

That the Secretary of the American Poultry Association be instructed to arrange, without expense to the American Poultry Association, or without charge on the part of the American Poultry Association, for preserving the type and cuts of such portions of the proceedings as relate to the work of the poultry departments of the Agricultural Colleges and Experiment Stations and matters pertaining to State aid for Poultry Departments and Poultry Organizations. Such part of the proceedings as is deemed desirable shall be designated by a special legislative committee of three members of the American Poultry Association to be appointed by the President for the purpose of assisting Branch Associations and members of this Association in territory where Branches do not exist.

And, be it further resolved, that upon the request of a Branch president or three members of the American Poultry Association in any State, Province, or Territory, the President shall appoint a member from that State, Province or Territory, who shall be delegated to represent the American Poultry Association and shall work with the special legislative committee herein provided for in promoting campaigns of education for the advancement of Poultry Husbandry through the poultry departments and poultry associations.

$$
\begin{aligned}
& \text { T. E. Quisenberri, Missouri, } \\
& \text { James E. Rice, New York, } \\
& \text { N. E. Chapman, Minnesota, } \\
& \text { Committee. }
\end{aligned}
$$

The resolution was adopted by unanimous vote.

This resolution was also adopted by the American Poultry Association at its 35th Annual Meeting at St. Louis, Mo., August 16-18, 1910.

The committee on publications made the following report, which was adopted:

SEC. 1.-This association shall publish the proceedings of its meetings, including the reports of the several standing committees and such 
papers and addresses as shall in the judgment of the editorial board be worthy of permanent preservation and record.

SEC. 2.-The editing of the proceedings shall be under the control of an Editorial Board of four members as follows: (a) The President and Secretary-Treasurer $e x$-officio; (b) one director to be chosen by the directors of the association. These three members of the Editorial Board thus provided for shall serve during the entire term of the office to which they are elected; (c) The fourth member shall be an Editor-in-Chief and shall be elected annually by the other three members of the Editorial Board.

SEc. 3.-Each member of the Association in good standing shall be entitled to one copy of all publications issued.

The committee on honorary and associate membership and change of name reported that they believed it advisable to attempt to make this association international in fact as well as in name, and recommended that it be continued to perfect such an organization if possible.

After a brief but hearty discussion, in which all present were in favor of the proposal, it was moved and seconded and passed that the committee on International Organization, consisting of Raymond Pearl, J. E. Rice and H. C. Pierce, be continued, and endeavor to perfect an international organization of instructors and investigators in poultry husbandry.

The Secretary was instructed to send, each year, a copy of the program of the annual meetings to all presidents, deans and directors of Agricultural Colleges and Experiment Stations and the Principals of Agricultural High Schools and secondary schools of agriculture.

The Treasurer's report was read as follows and adopted:

RECEIPTS

Check from Prof. J. E. Rice outgoing treasurer - _ - _ - $\$ 38.28$

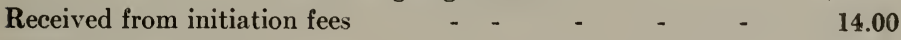

Received from dues - $\quad$ - $\quad$ - $\quad$ - $\quad$ - $\quad$ - $\quad-41.00$

$\$ 93.28$

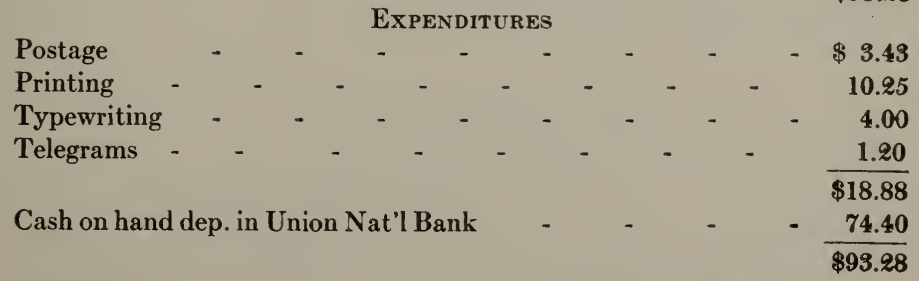

Respectfully submitted,

H. C. Pierce, Secretary-Treasurer. 
The Program

Saturday, July 30 and Monday, and Tuesday August 1 and 2,1910 IOWA STATE COLLEGE

Ames, Iowa

\section{SATURDAY}

9:00 A. m. Room 117 Hall of Agriculture

Address of Welcome, - $\quad$ - $\quad$ - $\quad$ - $\quad$ - D D. A. B. Storms Response, President Iowa State College.

Business Meeting

Roll Call

Minutes of Last Meeting

Election of New Members

Report of Executive Committee

Unfinished Business

Election of Officers

New Business

Under the head of New Business it is proposed to discuss tentatively certain topics such as Relation of the International Association of Instructors and Investigators in Poultry Husbandry to the American Poultry Association.

Publication of Transactions

Publication of Poultry Bibliography

Admission of Honorary Members

Final action on these topics to be deferred until a later meeting.

\section{Saturday Afternoon 2:00 P. m.}

Report of Committee on Incubation.

Effect of Housing on the Domestic Fowl, - - $\quad$ C. L. Opperman Bureau of Animal Industry, Washington, D. C.

Report of Committee on Investigation, - - - Dr. P. B. Hadley Rhode Island Agricultural College.

\section{Saturday Evening 8:00 P. M.}

Address-“Poultry Co-operation and Extension,"

Prof. N. E. Chapman, Minn.

Paper, "Farm Trains and Educational Exhibits," Prof. W. A. Brown University of Maine, Orono, Maine.

Read by - - - - - - - Geo. Browon 
Paper-"Relation of the International Association of Instructors and Investigators in Poultry Husbandry to the American Poultry Association," - $\quad-\quad$ - $\quad-\quad$ - $\quad$ S. T. Campbell

Secretary American Poultry Association, Mansfield, Ohio.

Read by - - $\quad-\quad-\quad-$ H. C. Pierce

Monday Morning, 9:00 A. M.

Report of Committee on Instruction and Outline for Courses in Poultry

Husbandry, - - - - - Prof. James E. Rice Cornell University, Ithaca, N. Y.

Discussion led by - - - - - - - H. L. Kempster Michigan Agricultural College, East Lansing, Mich.

Methods of Teaching Poultry Husbandry.

Lectures, Recitations and Reference Reading, Iowa State College, Ames, Iowa.

Laboratory, Practice Courses and Demonstrations, University of Wisconsin, Madison, Wis.

W. A. Lippincott

Prof.J.G. Halpin

Monday Afternoon, 2:00 P. M.

Report of Committee on Legislation,

Secretary Missouri State Poultry Board.

Report of Committee on Bibliography, Miss Clara Nixon Cornell University, Ithaca, N. Y.

T. E. Quisenberry

Monday Evening, 8:00 P. M. Report of Committee on Feeding, - - -
Cornell University, Ithaca, N. Y.

Address-"Poultry Research and Instruction in Europe,"

University of Maine, Orono, Maine.

Dr. Raymond Pearl

Tuesday Morning, 9:00 A. M.

General Discussion

What type of Poultry House shall we recommend?

What method of Feeding shall we recommend?

Method of Conducting Examinations:

Honor system, exempt marks, advance questions, examination of note books.

What shall be our attitude toward the so-called poultry systems? 
Tuesday Afternoon 2:00 P. M.

Marketing of Eggs,

Purdue University, LaFayette, Ind.

- A. G. Philips

Killing, Dressing and Marketing Poultry, - - $\quad$ H. C. Pierce

U. S. Department of Agriculture, Bureau of Chemistry.

Discussion of Deferred New Business

$\begin{array}{ll} & \text { Attendance } \\ \text { Barto, D. O. } & \text { MeAleer, H. A. } \\ \text { Brown, C. E. } & \text { Opperman, C. L. } \\ \text { Chapman, N. E. } & \text { Pearl, Raymond } \\ \text { Graham, W. R. } & \text { Phillips, A. G. } \\ \text { Halpin, J .G. } & \text { Pierce, H. C. } \\ \text { Kempster, H. L. } & \text { Quisenberry, T. E. } \\ \text { Kerr, James P. } & \text { Rice, J. E. } \\ \text { Lane, D. J. } & \text { Rider, W. M. } \\ \text { Lippincott, W. A. } & \text { Schoppe, Wm. F. }\end{array}$

Committees fOR 1911

Instruction

J. G. Halpin

D. J. Lambert

Horace Atwood

W. A. Brown

Homer Jackson
W. R. Graham

Feeding

A. A. Brigham

H. L. Kempster

W. A. Lippincott

Miss Clara Nixon

C. A. Rogers

L. J. Cole

Breeding

C. B. Davenport

Raymond Pearl

W. R. Graham

A. G. Phillips

Legislation

T. E. Quisenberry

A. G. Phillips

S. T. Campbell

F. H. Stoneburn

H. C. Pierce

F. C. Elford

Marketing

C. L. Opperman

F. S. Jacoby 


\section{Houses}

C. A. Rogers

C. L. Opperman

Horace Atwood

J. S. Jeffrey

D. J. Lambert

Bibliography

Miss Clara Nixon

R. R. Slocum

Victor Fortier

J. M. Turpin

Diseases and Parasites

Geo. B. Morse

G. E. Gage

P. B. Hadley

S. F. Edwards

International Organization

Raymond Pearl

H. C. Pierce

J. E. Rice

P. B. Hadley

Investigation

A. G. Phillips

Incubation

W. R. Graham

James Dryden

Horace Atwood

Publication

Raymond Pearl

H. W. McAleer

James E. Rice

H. C. Pierce

C. A. Rogers 


\section{ADDRESS OF WELCOME FOR 1908}

\section{Fellow Workers:}

BY JAMES E. RICE

It is a matter of regret to all of us that Director Bailey is unable to be here to extend to you a welcome on behalf of Cornell University and the New York State College of Agriculture. We, who are familiar with Director Bailey's educational policies, know that he is heartily and enthusiastically in favor of developing strong poultry departments that shall rank in scope and efficiency with other departments in connection with the agricultural colleges and experiment stations. He believes that Poultry Husbandry offers special pedagogical advantages because of the large number of persons who are interested in keeping poultry as a business occupation. This enables the colleges to appeal to the people, as he expresses it, "in terms of their daily lives."

If Director Bailey were here it is certain that he would have commended the motive that has inspired this meeting. He believes in the principle of "getting together," of co-operation and of organization. In his absence I am glad to extend to you a cordial welcome. There are no traditional latch strings to our doors. If there were any, they would hang on the outside. You are invited, instead, to turn the knob and "push" wherever you desire to go. The freedom of our campus and buildings, our gardens and our fields is extended to you. We are at your service. We welcome you to Cornell.

\section{RESPONSE}

\section{Fellow Workers:}

BY JAMES E. RICE

It is not often that a person is called upon to occupy the unique and embarrassing position of being asked, with only a few minutes warning, to give an address of welcome and then to respond to his own welcome. It was expected that Professor W. R. Graham would be present to respond to an address of welcome from Director Bailey. A response to the address of welcome would have been very appropriate from Professor Graham because it was he who issued the call for a meeting of teachers and investigators in poultry husbandry to meet at Madison Square Garden last year to talk over matters of mutual interest.

Speaking now for those who have assembled here for this meeting, I am certain that I roice the sentiment of all when I say that the time has come in the development of poultry departments when it is absolutely impera- 
tive that we who are charged with the responsibilities of teaching and investigating the subject of poultry husbandry must co-operate for mutual development.

Poultry Husbandry is old as an art but new as a science. Our methods are largely those of rules applicable to special use, rather than of principles for general application. We need more facts rather than more opinions, more results of experiment and research, and better classification of our present knowledge in order that we may deduct natural laws. This can best be brought about by getting together. We are now trying to work out our own salvation in our own way without knowing what others in the same occupation are doing. The sum total of our combined knowledge of poultry husbandry is far greater than our individual knowledge. The conclusion is obrious. We must compare our experiences, combine our knowledge, pool our interests, and join hands, hearts and heads for mutual help.

Poultry Husbandry is one of the last of the important branches of agriculture to be given attention by the agricultural colleges and experiment stations. We have made great progress in the few years since the first departments were established. This has been accomplished, in most instances, under trying and discouraging circumstances. The results, however, have justified the effort. Here and there, persons who are responsible for the organization and development of the agricultural colleges and experiment stations are coming to recognize the importance of poultry husbandry and are endearoring to give it proper support. Our meeting can accomplish much by discussing the needs of poultry departments. We should agrec, among ourselves, as to what constitutes adequate facilities as to land, stock, buildings, equipment and teaching or investigating staff, etc. We will accomplish more if we present a united front. We will command respect only in proportion as we respect ourselves and show that we deserve support and that we know what we require to make a department efficient. In order to do this we must fraternize and organize.

Inspiration always should result when right minded people in a similar calling confer to learn of each other's successes and failures. This should always be one of the most important purposes of such a meeting.

The purposes of this meeting, therefore, I take it, are:

First: To arrive at a hetter understanding as to how we should teach and investigate and extend the knowledge of better poultry husbandry.

Second: To decide upon questions of policy and practice.

Third: To endeavor to organize as workers for greater unity and efficiency; and 
Fourth: To receive inspiration which will enable us to press forward with greater courage and hopefulness.

Whether or not we shall accomplish all of these desirable purposes will depend upon ourselves. A meeting will rise only as high as the quality of its membership. We are assured of a gratifying attendance. We are bound to have a valuable meeting. 


\section{THE FIELD OF RESEARCH IN POULTRY HUSBANDRY}

BY HORACE ATWOOD

Research in poultry husbandry is concerned with an industry whose importance and extent most of us fail to appreciate. This lack of appreciation is due principally to the fact that the individual units of production are generally small and widely scattered. But when the aggregate is considered and it is found that, in 1907 for example, the value of the poultry products of the United States exceeded the value of the wheat crop by $\$ 100,000,000$ then we can properly value the importance and magnitude of the industry that we are seeking to promote.

Not only is the industry whose problems we are studying a large and important one, but poultry husbandry as carried on at the present time, with its artificial methods and appliances, is a development of recent years and there is behind this business no such accumulation of facts and experiences as is the case in the other branches of live stock industry that have been carried on for a nuch longer time. Consequently there are numerous new problems awaiting solution, and new difficulties arising which demand the attention of investigators in this line of work. In fact, the problems which we may select for study are so numerous that there is some danger that we may spread our energies over too wide a range, thus interfering with the quality of our work. The ideal is to concentrate effort on a few specific problems until final results are achieved and presented to the public.

In this field of research we may rear many stately edifices, but if the foundations of these structures are not well built they will tumble down and we shall not only have lost the result of our labors, but we shall be obliged to clear away the wreckage and clean up the ruins before we can begin once more our efforts for progress.

It is annoying both to ourselves and to our constituents to be obliged to clear away a wreck due to building a house upon the sand. Therefore, let us be doubly careful in this matter and resist with all our power any pressure which may be brought to bear on us for quick results, and when we do publish the results of an investigation let us be sure, not only of the facts involved, but also that our interpretation of the facts is the most logical and consistent that can be given. For sometimes a set of facts resulting from an investigation can be explained in two or more ways.

In poultry experiments we are dealing with life and its development, an extremely difficult and intricate subject, and one easily affected by what 
sometimes seem small and insignificant factors, and if the actual carrying on of the experiment is turned over to an assistant the experiment may be affected by secondary factors so that the results of the work may be of little or no permanent value. It is true that as a rule poultry experiments are extremely tedious and time consuming and it is sometimes necessary to turn over some of the details to an assistant, but this is never really desirable. An experimenter should be close to his experiments.

In this brief paper I shall not attempt to point out the particular problems in poultry husbandry that are of especial importance. Questions of this nature must be settled to a large extent by each investigator according to his equipment, local conditions, and his ability to carry out a certain line of work. But, speaking generally, it would seem that the main lines of improvement lie somewhat in the following directions:

1. Investigations should be conducted in the production of eggs better suited for incubation than those generally produced. A large amount of money is lost in this country each year in the incubation of eggs wholly infertile or with weak germs. This should be remedied.

2. Investigations are needed in incubation and brooding, so that a larger percentage of chicks can be brought to maturity.

3. Further studies are needed in the theory of feeding fowls for the production of meat and eggs, as most of our knowledge in this respect is vague, and based on insufficient evidence.

4. The production and handling of market eggs should be studied with reference to the quality of the egg; egg preservation, and cold storage.

5. Investigations should be carried on concerning diseases and parasites, and those more general factors which have to do with the efficiency of fowls, including the subjects of housing and management.

In closing, permit me to quote a few words from the Report of the Committee on Education and Experimentation of The American Poultry Association, regarding the importance of investigations in poultry husbandry.

"The practical poultryman encounters difficulties at every turn. Why are so many of the eggs infertile? Why do so many chicks die in the shell? Why do so many chicks die after incubation and what is the remedy? How should little chicks be fed for best results? How should one feed various breeds during different seasons for egg production? What is the best type of house for winter egg production-for summer use in hot climates? What is the cause and remedy for White Diarrhoea, for roup and other serious ailments? How should one mate fowls in order to obtain certain desired qualities in the offspring? How do the constituents in various poultry foods differ in digestibility? 
How many hens can be kept in one flock to best advantage? How many chickens can be reared in one flock most profitably? How does food effect the color and flavor of eggs? Of flesh? What is the best combination of foods, and most economical ration and method for fattening? What is the comparative value of poultry foods and various by-products? Is grit essential? How should fowls be fed during the moulting season? What is the importance of green food and free range as compared with bare yards?

Who knows the chemical and embryological changes that take place within the egg during incubation? Who knows the chemical and physical changes which occur in the keeping of poultry products inside or outside of cold storage? Who knows whether poultry will keep better and be more wholesome when drawn or undrawn? Who knows the life, history and the rapidity of multiplication of external and internal poultry parasites, several hundred of which have been discovered and named?"

These are a few of the more important practical problems now before us. They are all capable of solution." 


\title{
INHERITANCE OF THE FUNCTION OF EGG PRODUCTION IN THE DOMESTIC FOWL AND ITS INFLUENCE ON THE FERTILITY AND HATCHING POWER OF EGGS
}

\author{
BY RAYMOND PEARL
}

\section{Introductory Note}

The address which was given under the above title was based upon investigations which have been reported in two papers. That portion of the address which dealt with the inheritance of egg producing capacity sensu strictu is discussed in a paper which was given before the American Society of Naturalists in 1910 and is here reprinted in full. That portion which dealt with the results then in hand respecting the inheritance of the fertility and hatching power of eggs has been printed as Bulletin 168 of the Maine Agricultural Experiment Station, with the title "Data on Certain Factors Influencing the Fertility and Hatching of Eggs." Since this material is, and has been for some time, available to the members of the Association there is no reason for reprinting it in whole or in part here.

The paper which follows was originally published in the American Naturalist, Vol. XLV, pp. 321-345, June, 1911.

\section{INHERITANCE OF FECUNDITY IN THE DOMESTIC FOWL ${ }^{1}$}

There are under discussion at the present time two general views regarding certain fundamental points in heredity. Each of these points of view has its zealous adherents. On the one hand, is what may be designated the "statistical" concept of inheritance, and on the other hand, the concept of genotypes. By the "statistical" concept of inheritance is meant that point of view which assumes, either by direct assertion or by implication, that all variations are of equal hereditary significance and consequently may be treated statistically as a homogeneous mass, provided only that they conform to purely statistical canons of homogeneity. This assumption of equal hereditary significance for all variations is tacitly made in deducing the law of ancestral inheritance, when individuals are lumped together in a gross correlation table. ${ }^{2}$ The genotype concept, on the other hand, takes as a fundamental postulate, firmly grounded on the basis of breeding ex-

${ }^{1}$ Papers from the Biological Laboratory of the Maine Experiment Station, No. 25. This paper was read at the meeting of the American Society of Naturalists at Ithaca. December, 1910.

2 For a more detailed discussion of this point see a paper by the present writer entitled "Biometric Ideas and Methods in Biology; their Significance and Limitations," in the Revista di Scienza (in press). 
perience, that two sorts of variations can be distinguished, namely those (a) that are represented in the germinal material and are inherited without substantial modification, as in "pure lines," and those $(b)$ that are somatic and are not inherited. By anything short of the actual breeding test it is quite impossible to tell whether a particular variation observed in the soma belongs to the one category or to the other. As I have tried to emphasize in other places, it is both to be expected on this view of inheritance, and is also the case in actual fact, that the somatic manifestation or condition of any character is a most uncertain and unreliable criterion of the behavior of that character in breeding. Finally under the genotype concept, of course, the whole array of facts brought out by Mendelian experiments find their place.

Now while certain adumbrations of the genotype concept have long been current in biological speculations in regard to heredity, this general viewpoint owes its grounding in solid facts primarily to Johannsen's work with beans and with barley. It is to be noted that in these cases, as well as in most of the investigations of the pure line theory which have followed Johannsen's work, the organisms used have been such as reproduced either by self-fertilization, or by fission, or by some vegetative process. This brings us to the consideration of a question of great importance, both theoretical and practical. In cases of diœcious organisms, where a "pure" pedigree line in the sense that such lines are found in beans or in Paramecium by definition can not exist, has the genotype concept any bearing or significance? In a general way it obviously has. Probably no one (except possibly some of the ultra-statistical school) could be found who would deny that in general a distinction is to be made between variations having a gametic and those having merely a somatic basis. But specifically how far has the genotype concept any application in case of "non-selfed" organisms? Johannsen in his "Elemente" has thoroughly analyzed Galton's material and shown that it is capable of a satisfactory and reasonable interpretation on the genotype hypothesis, and East and Shull have gone far in the analysis of genotypes in maize. This, however, is only a beginning. There is the greatest need for careful, thorough investigations of the inheritance of characters showing marked fluctuating variation in organisms having the sexes separate. Here lies one of the crucial fields in the study of inheritance to-day. Through the brilliant results in Mendelian directions and from the study of really "pure" lines we are getting clear-cut ideas as to the inheritance of qualitatively differentiated characters, such as color, pattern and the like, on the one hand, and in regard to the inheritance of quantitative variation in self-fertilized or non-sexually reproducing 
organisms, on the other hand. But beyond all these lie the difficult cases where in diøecious forms quantitative variations must be dealt with. If these ean be cleared up and brought harmoniously into a general scheme or view-point regarding inheritance, we shall have gone a long way in the solution of this world-old biological problem.

For some four years past the writer has been engaged in a study of the inheritance of fecundity in the domestic fowl. The problem presented here is an important one from the practical as well as the theoretical standpoint. If definite and sure methods of improving the average egg production of poultry by breeding can be discovered it will mean much to the farmers of the nation. At the same time egg production is a character in some ways well adapted to furnish definite and crucial data regarding inheritance. Variations in egg production are readily measured, and can be directly expressed in figures.

The general results of this study of the inheritance of fecundity may be said, in a word, to be, so far as they go, in entire accord with the genotype concept, and not to agree at all with the "statistico-ancestral" theory of inheritance. Indeed, so ill is the accord here that the chief exponent of the latter doctrine has recently attempted to throw the whole case out of court ${ }^{3}$ by asserting that fecundity is not inherited in fowls, and that the present writer's investigations show essentially nothing more than that. It will be the purpose of this paper to present some figures sufficient to indicate with some degree of probability, I think, first that egg production in fowls is inherited, and second that it is probably inherited in accord with the genotype concept, in spite of the fact that we do not and can not here have "pure lines" in the strict sense of Johannsen's definition. In the present paper, owing to limitations of space, the whole of the data in hand obviously can not be presented. Only a few illustrative cases can be given here.

Before entering upon the discussion of the evidence it is necessary to call attention to two points. The first is in regard to the unit of measuring egg production used in the work. For reasons which have been discussed in detail elsewhere ${ }^{4}$ the unit of study has been taken as the egg production of the bird before March 1 of her pullet year. This "winter production" is a better unit for the study of the inheritance of fecundity than any other which can be used practically. All records of production given in this paper are then to be understood as "winter" records, comprising all eggs laid up to March 1 of the first year of a bird's life. It may be said that the

'Pearson, K., "Darwinism, Biometry and some Recent Biology, I," Biometrika, Vol. 7, pp. 368-385, 1910. Part II.

1 Bull. Me. Agr. Exp. Sta., No. 165. U. S. Dept. Agr. Bur. Anim. Ind., Bul. 1 1o, 
"normal" mean winter production of Barred Plymouth Rocks (the breed used in this work) is fairly indicated by the 8-year average of the Maine Station flock. This average November 1 to March 1 production is 36.12 eggs. $^{5}$ This figure is based on eight years continuous trap-nesting of the flock with which the present work was done, carried out before these investigations were begun.

In the second place it is desirable to call attention to some of the difficulties which attend an attempt to analyze the inheritance of the character egg production. The most important of these is the fact that this character is not visibly or somatically expressed in the male. A male bird may carry the genes of high fecundity, but the only way to tell whether or not this is so is to breed and rear daughters from him. All Mendelian workers will agree that it is sometimes difficult enough to unravel gametic complexities in the case of characters expressed somatically. It is vastly more difficult when only one sex visibly bears the character. In the second place a very considerable practical difficulty arises from the fact that egg production is influenced markedly by a whole series of environmental circumstances. The greatest-of care is always necessary, if one is to get reliable results, to insure that all birds shall be kept under uniform and good conditions. Further, on this account, it is necessary to deal with relatively large numbers of birds. Some of the important conditions to be observed in work on fecundity have been discussed elsewhere ${ }^{6}$ and need not be repeated here.

Turning now to the results we may consider first

\section{The Effect of Selection for Fecundity in the General Population}

On the "statistico-ancestral" view of inheritance it would be expected that if fecundity were inherited at all this character would respond to continued selection. That is, it would be expected, if the highest layers only were bred from in each generation, that the general flock average would steadily, if perhaps slowly, increase and that any level reached would be at least maintained by continued selection. In 1898 an experiment in selecting for high egg production was begun at the Maine station. In this experiment only such females were used as breeders as had laid over 150 eggs in their pullet year (corresponding roughly to an average winter production of 45 or more eggs) and the only males used were such as were out

${ }^{B}$ It should be said that up to and including the winter of 1907 only the November I to March I records are available as a "winter" record. Since that time the small number of eggs laid before November I (on the average two or three per bird) are included in the "winter" totals. These, then, give, as stated, the total production up to March 1.

- Me. Agr. Exp. Sta. Ann. Rept. for 1910, p. Ioo. 
of birds laying 200 or more eggs in the year. This experiment was continued until the end of 1908 . The selection, be it understood, was based on the egg record alone, and no account was kept of pedigrees or of genotypes. Every female with a record higher than $150 \mathrm{eggs}$ in the year was used as a breeder regardless of whether her high fecundity was genotypic or phænotypic.

The results of this selection experiment covering a period of nine years have been fully reported elsewhere. ${ }^{7}$ Here it needs only to be said that the net outcome of the experiment was to show that there was no steady or fixed improvement in average flock production after the long period of selection. There was no permanently cumulative effect of the eight (in the last year) generations of selected ancestry. So far from there having been an increase there was actually a decline in mean egg production concurrent with the selection, taking the period as a whole. During parts of the selection period, however, as for example the years 1899-1900 to 1901-02, inclusive, and the years 1902-03 to 1905-06, inclusive, an improvement from year to year was to be noted, but in each case the flock dropped back in intervening years. This is an important point, the meaning of which is now clear. The flock average from year to year depended largely upon whether the breeders of the year before had had their high fecundity genetically represented or only somatically. In some years the selection was fortunate in getting nearly all the breeders from good (i. e., "high production") genotypes or from good combinations of genes. In other years just the opposite thing happened: the high layers chosen as breeders came from low genotypes or combinations of genes. The general upshot was that while the selection of high layers merely as such was systematic year after year the result attained in the general flock production was entirely haphazard and uncertain. This is exactly what would be expected on the genotype hypothesis, but not on the "statistico-ancestral."

TABLE I

Mean Winter (November i to March I) Egg Production During the Selection EXPERIMENT

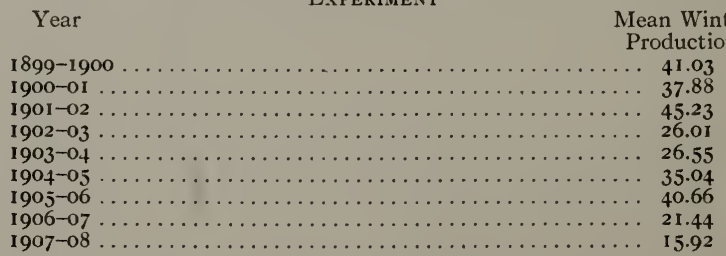

${ }^{7}$ U. S. Dept. Agr. Bur. Anim. Ind., Bul. I Io, Parts I and II, I909 and I9I r. Zeitschr. f. indukt. Abst. u. Vererb.-Lehre, Bd. 2, 1909, pp. 257-37.5. 
The actual course of the average winter egg production (not hitherto published) during the period is given by the figures of Table I and shown graphically in Fig. 1.

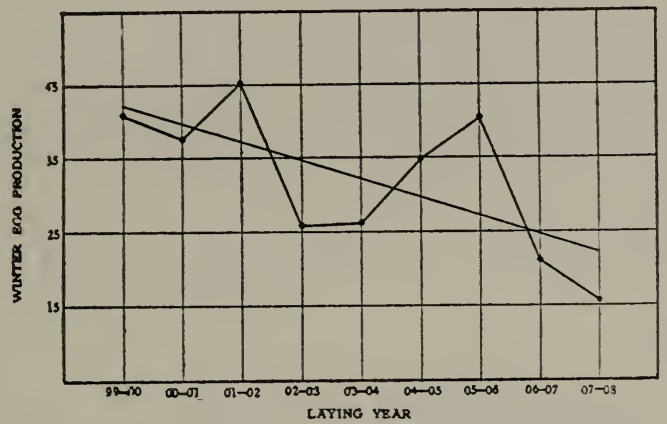

FiG. 1. Dlagram showing the course of arerage winter egg production durlaz the period covered by the mass selection experiment.

Certainly the first line of evidence, derived from a long-continued experiment, involving more than 2,000 individuals, gives no support to the "statistico-ancestral" theory and indeed is in flat contradiction to one of the most fundamental tenets of that faith.

Let us next consider the question,

\section{Are Somatically Equal Variations in Fecundity of Equal Hereditary Significance?}

In the spring and summer of 1907 were reared 250 pullets, all of which were the daughters of hens that had laid approximately 200 or more eggs in the first year of their life. This group of mothers was reasonably homogeneous in respect to records of egg production. All had laid about the same number of eggs. Their daughters were, however, far from a homogeneous lot with respect to egg production. ${ }^{8}$ It is plain from the results obtained in that experiment that the egg record of a hen is a most unreliable criterion of the probable number of eggs which her daughters will lay. This is demonstrated by examination of individual cases. Thus consider the two mothers nos. 253 and 14. Their winter production records were nearly identical ( 65 and 66 eggs, respectively). Their daughters' average winter productions were 23.87 and 2.40 eggs, respectively! Certainly it seems reasonable to conclude that the gametic constitutions involved in the

\footnotetext{
${ }^{8} \mathrm{Full}$ details regarding this experiment have been published as Bull. $166, \mathrm{Me} . \mathrm{Ag}$. Exp. Sta., 1909. See particularly Table I.
} 
breeding of 253 and 14 were quite different, though both these hens laid the same number of eggs. Again, take birds nos. 386 and 911. One had a winter record of 55 and the other of 52 eggs. Yet their daughters' average winter productions were, respectively, 4.88 and 27.33 eggs. Many more instances of this kind could be brought forward. Taken together, the whole evidence shows beyond the shadow of a doubt that the presence of high fecundity in an individual, and that factor which makes high fecundity appear in the progeny, are two very different things, either of which may be present in an individual without the other. We plainly have here the basis for the distinction of phænotypes and genotypes just as in beans.

The Inheritance of Egg Production in Pedigree Lines

Let us now consider some of the evidence that such things as genotypes of fecundity really exist in fowls. We may first examine some representative pedigrees covering four generations and showing the occurrence of high and low fecundity lines.

As a typical example of a high fecundity pedigree line in which the high fecundity is genotypic, line D5D39 may be considered. In the presentation of this and other pedigree tables the following conventions are adopted. The band numbers of the birds are in bold-faced type, and following the band number of each female, her winter egg record is given in italic figures enclosed in parenthesis. The band numbers of males are given in italics.

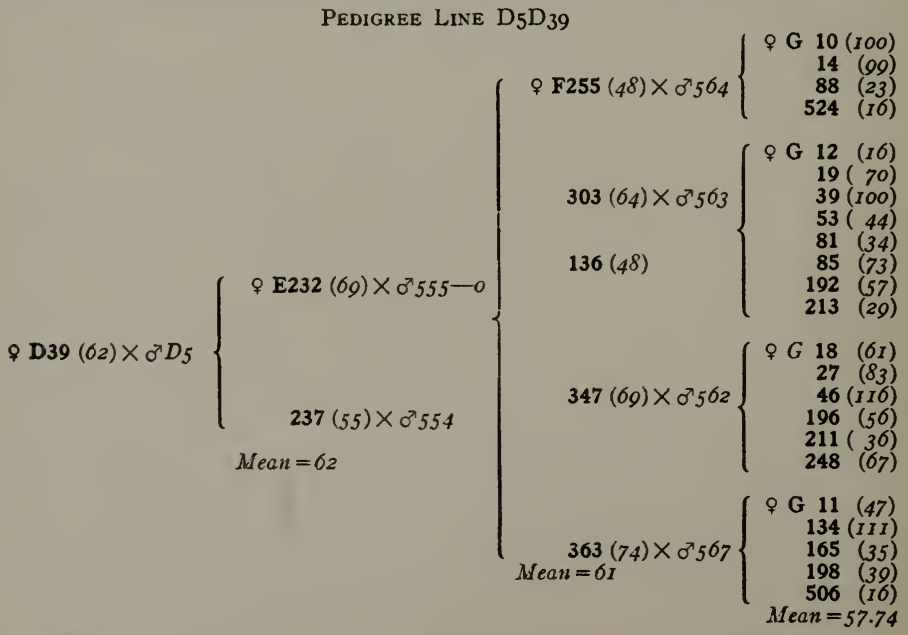


This line is shown graphically in Fig. 2.

Little comment on this pedigree line is necessary. We see a certain high degree of fecundity faithfully reproduced generation after generation. Different males were used with different females, but in every case the males used were from high fecundity lines and were believed to carry this quality in their germ cells either in homozygote or heterozygote condition.

In marked contrast to the last example let us consider the low fecundity line $\mathrm{D} 61 \mathrm{D} 168$. It is a troublesome matter to propagate the low fecundity lines, because of the difficulty of getting a sufficient number of eggs during the early part of the breeding season. The line D61D168 is of interest not alone as an illustration of a typical low line, but also because there appeared in it a mutation, or something very like one. We will consider here only the main line and not the mutant.

Pedigree Line D6iDi68

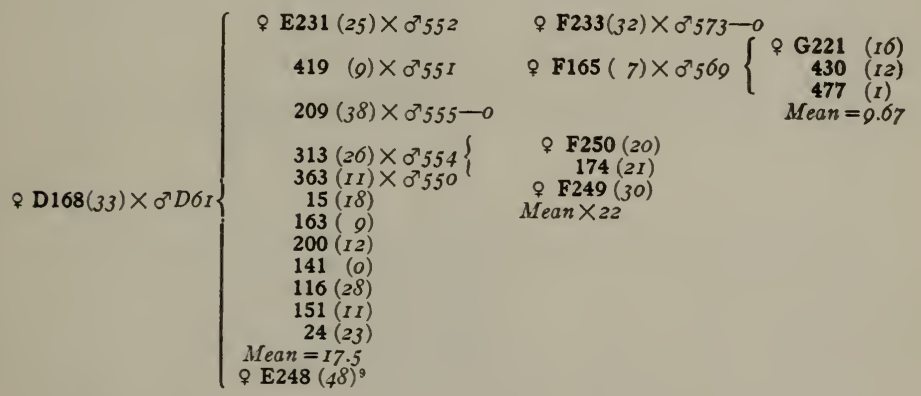

This line is shown graphically in Fig. 4, in which the mutant and its progeny are also shown.

A low line in which no mutant has appeared, but in which also the mean production is not so low as in line D61D168 is D65D366. Since the egg production has not been so low in the early part of the breeding season with this line it has been easier to propagate it.

This was the mutant referred to. Its progeny will be considered later. See p. 335. 


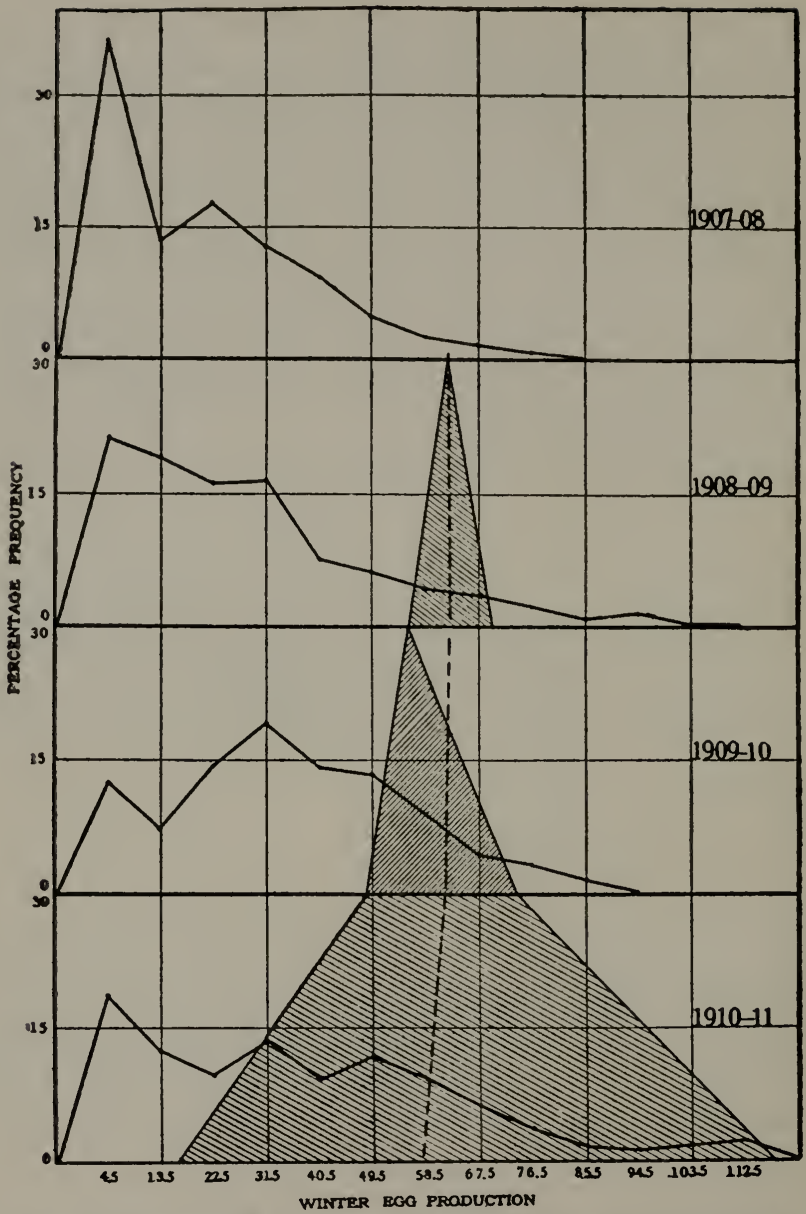

Fio. 2. Dlagram ahowing range of variation and mean fecundity in each generation of llne D5D39. The main polygons of variation give the distribution of fecundity in the general flock in each generation. The cross-batched areas represent the pedigree line, and the heavy dotted lines through theae areas represent the mean fecundity of the line in each generation. 


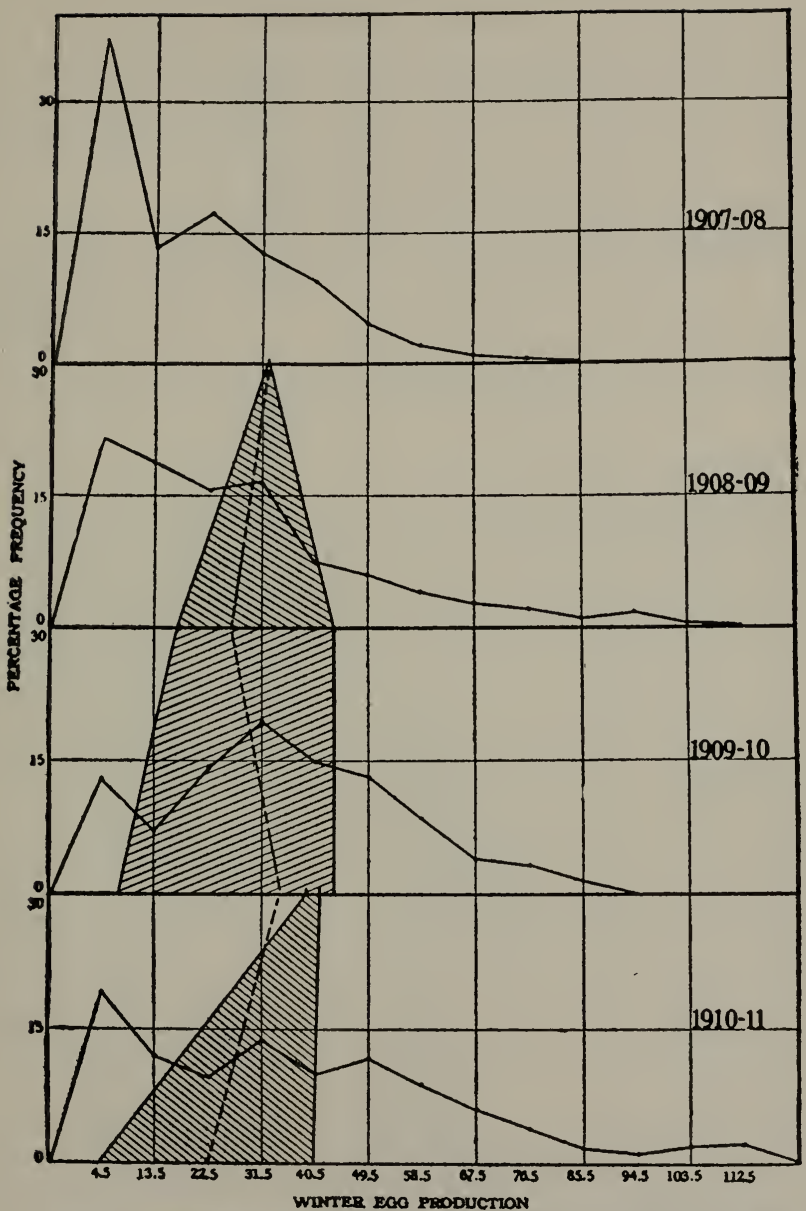

DiG. 3. Dlagram showing range of variation and mean fecundity in each generation of line D65D366. Sigulfeance of lines and cross hatching as in Bนg. 2, Q.v. 
Pedigree Line D65 D366

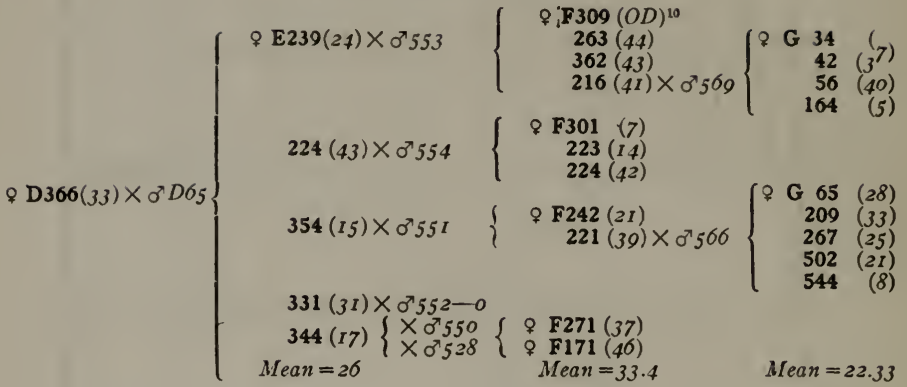

This line is shown graphically in Fig. 3.

In the examples thus far given we have had to do with pedigree lines in which a given degree of fecundity reappeared from generation to generation with practically no change. In two instances quite certainly, and possibly in several others, a new and distinct variation has suddenly appeared within a line and thereafter bred true, thus presenting the characteristic phenomena of mutation. The most striking instance of this sort occurred in line D61D168 and may be given here in detail. The main part of this line has already been discussed (p. 331). It will be recalled that it is a line of low fecundity. In 1908 there appeared in it one individual of distinctly higher fecundity than any other bird in the large family of that year. This individual when bred produced only high layers. In the next generation two of these daughters were bred to males known to belong to high fecundity genotypes $\left(\sigma^{7} \sigma^{x} 554\right.$ and 566$)$. One of these matings unfortunately produced no adult female offspring. The other led to the production of six adult daughters, all of which are relatively high layers, with the single exception of G495, which has a record of only one egg, and that record is doubtful. This bird has probably never laid an egg, and almost certainly is pathological.

Leaving this bird out of account because pathological, the mean winter production of the family is 52.8 eggs, very strikingly different from the average (9.67 eggs) of the birds of the same generation in the main low line in which the mutation appeared.

Two other daughters of the mutant E248 were mated to o D31,a bird known not only to belong to a genotype of mediocre to low fecundity, but to

${ }^{\mathrm{r}} \mathrm{Bird}$ died during winter period. 


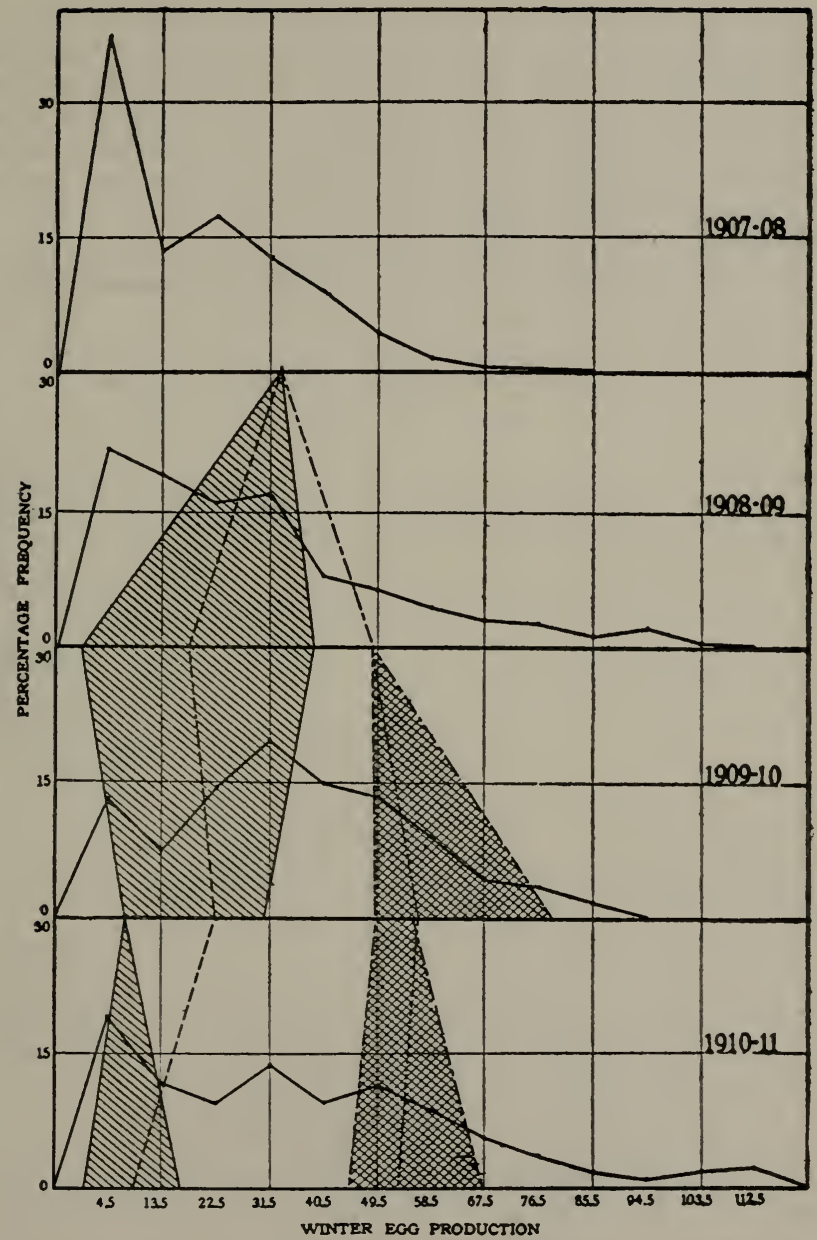

Fig. 4. Diagram of pedigree line D61D163. The signiflance of lines is the sume as in Figs. 2 and 3 , except that the mutant line is double cross hatched. For the sake of simplicity E495 and the daughters of D32 are omitted in the 1910-11 generation. 
be remarkably prepotent in respect to this character, so that practically regardless of the females with which he has been mated the get has been uniformly poor in respect to egg production. Four adult females resulted from the two matings under discussion. They have an average winter production of 23.75 eggs. There are several possible explanations of this result, but the most probable is that we have here simply one more instance of the extraordinary prepotency of o'D31.

The last of the daughters of the mutant was mated to a cross-bred male, no. 578 , and consequently the progeny can not fairly be compared with the pure Barred Plymouth Rocks in respect to fecundity.

Pedigree line D6iDi68 (Complete)

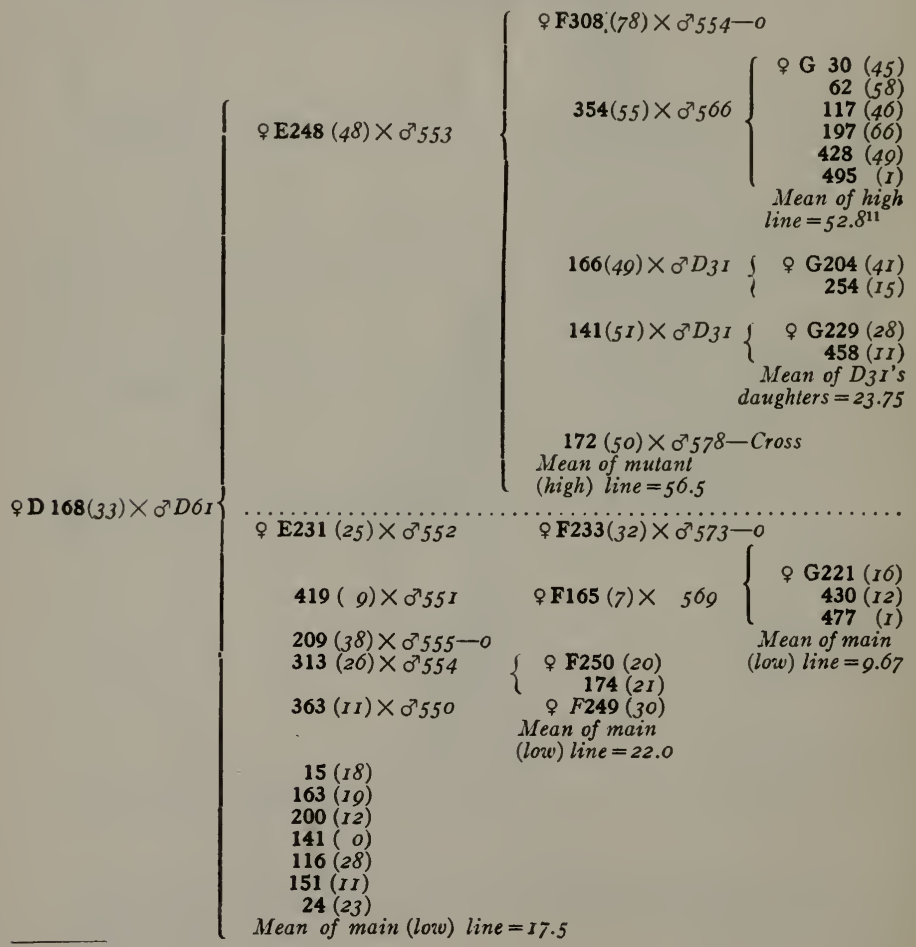

"Omitting $\mathrm{G}_{495}$. See texs. 
The facts here briefly discussed are shown in the following table and graphically in Fig. 4.

It is apparent from the table and the diagram that the main line and the "mutant" line are entirely distinct. Indeed they do not overlap in their ranges even excepting only the pathological individual G495. The "mutant" pullet E248, for some reason or other, possessed the capacity both to lay a relatively large number of eggs, and the genes necessary to make this quality appear in her progeny. Whether this individual is to be regarded as a true "mutation" would appear to be largely a question of definition. In the writer's opinion the nost probable explanation is that E248 is a Mendelian segregation product. That is, let it be supposed that both D168 and D61 were heterozygous with respect to degree of fecundity, and were producing in some (unknown) ratio both "high fecundity" and "low fecundity" gametes. Then E248 may be supposed to have originated from the union either of two "high fecundity" gametes or one high and one low fecundity gamete. She then would be either a DD or a DR bird, on the assumption, which the facts seem to support, and which $I$ have more fully discussed elsewhere, ${ }^{12}$ that high fecundity is dominant over low.

The subsequent breeding history of E248 indicates that it was probably a DD bird, though the reasons for this opinion can not be fully gone into here. The general view, recently emphasized by Nilsson-Ehle, ${ }^{13}$ that phenomena of mutation are, in many cases at least, merely cases of Mendelian segregation has much evideuce in its favor.

The pedigrees which have been given are merely illustrations. Many other similar ones might be cited from the records in hand did space permit. In the experiments during the last three years the attempt has been made to propagate separately lines of high, medium and low fecundity. In the course of this work it has been found that lines of high fecundity were nearly if not quite as likely to have originated with individuals of a low record of production as with those of a high record. Similarly, many low fecundity lines have originated with individuals which were themselves exceedingly high layers. Indeed one of the highest winter layers which have ever appeared in the stock evidently belonged to a genotype of very low fecundity, since it has never been able to produce progeny of anything but the poorest laying capacity. The breeding history of this bird (D352) is indeed so interesting that it may be briefly discussed here. This bird in her pullet year laid 98 eggs between November 10 and March 1 and made a record for

12 'Inheritance in 'Blood Lines' in Breeding Animals for Performance, with Special Reference to the '200-egg' Hen," Rept. Amer. Breeders' Assoc., Vol. VI, I9I I.

13 Nilsson-Ehle, H., "Kreuzungsuntersuchungen an Hafer und Weizen," Lunds Univ. Arsskr., N. F., Afd. 2, Bd. 5, Nr. 2, 1909, pp. 1-122. 
the year of over 200 eggs. She was mated and produced plenty of eggs during the hatching season, but they hatched very badly. Only one female worth putting in the house was obtained. This pullet (E356) made a winter record of only 39 eggs, just about the general flock average. E356 was not mated. Her mother (D352) was kept over and bred to another male the next year, in the hope that as a fowl she might produce more and better chickens than she had as a pullet. As a matter of fact she was again able to produce during the whole breeding season only one pullet worth putting into the laying house. This pullet (F163) made a winter record of but 11 eggs. F163 was bred in 1910, but produced only one daughter worth saving. This daughter, G429, has made a winter record of 18 eggs. It would be hard to get clearer evidence than that afforded by this breeding history that D352 belonged to a low fecundity genotype, in spite of her individual high laying record.

\section{The Effect of the Selection of Fecundity Genotypes}

Let us now consider the bearing of the results so far set forth on the problem of selection. Taking first the question of the effect of selection for fecundity within a population, it is plain that if different degrees of fecundity have a genotypic basis, as the facts above presented and a considerable mass of data of a similar kind, which owing to lack of space can not be given here would appear to indicate, then the results following selection will depend entirely upon the genotypic constitution of the population. If high fecundity genotypes are present they can be isolated by selection. If they are not present selection of high laying hens will not change the average production of the flock.

The aim of the selection experiments since 1907 has been to discover and propagate separately genotypes of high fecundity and genotypes of low fecundity, all the birds being taken from the same general flock. The results of this work are shown in the following table and in Fig. 5. This table is to be regarded as a continuation of that given on p. 327, supra, which shows the results of mass selection for high fecundity in the same stock.

Effect of Selection for Fecundity within the Population

1907-08. Mean winter production of general population $\ldots \ldots \ldots \ldots \ldots \ldots \ldots \quad \mathbf{1 5 . 9 2}$

1908-09. Mean winter production of all high fecundity lines......... 54.16

1908-09. Mean winter production of all low fecundity lines . . . . . . . . 22.06

1909-10. Mean winter production of all high fecundity lines. . . . . . . 47.57

1909-10. Mean winter production of all low fecundity lines $\ldots \ldots \ldots \ldots \ldots \ldots .25 .05$

I9I0-I I. Mean winter production of all high fecundity lines.......... 50.58

1910-11. Mean winter production of all low fecundity lines $\ldots \ldots \ldots \ldots \ldots \ldots .17 .00$ 


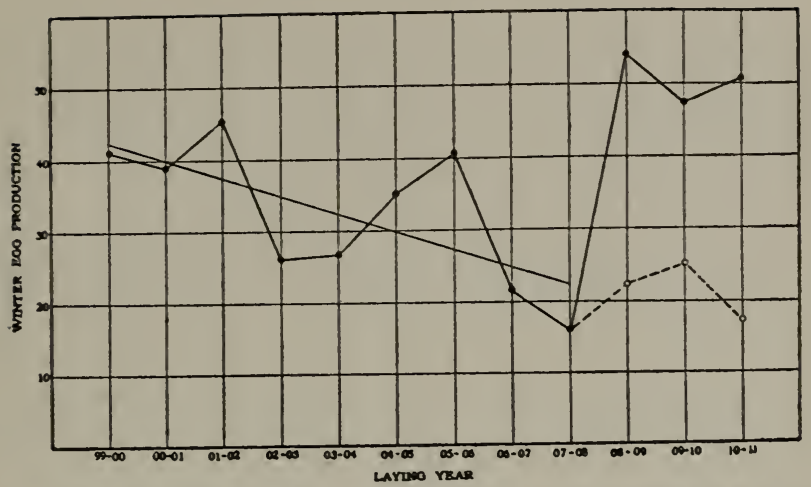

Fig. 5. Showing the effect of selecting high and low fecundity on a genotspic basis. The solid line denotes means of all "high lines"; the dotted line means of all "low lines." Up to $1907-08$ the attempt bad been to Increase eg8 production by breeding merely from the bighest layers. regardless of pedigrees. In 1907 and subsequent years the attempt has been to isolate genotypea of high and low fecundity whlch ahall breed true, each to Its own type.

The results indicate the effectiveness of this method of selection. It should be understood, of course, that only those pedigree lines are included in the high line averages which uniformly in each generation show high fecundity. A similar consideration applies to the low line averages.

Let us now consider briefly the question of the effectiveness of selection within the genotype. According to the "pure line" concept we should not expect selection of high or low individuals belonging to the same genotype to produce any effect, except in cases where segregation has occurred and the selected individuals are really gametically different, though having the same pedigree. An example of this sort has been given in the case of line D61D168 (cf. p. 331, supra). The ineffectiveness of selection within the line when something of this sort does not occur is illustrated by line D56D407. In the $F_{1}$ generation in this line there were four birds, of which three were good layers and one was a poor layer. Two of the good layers and the poor layer were bred. Large families were reared in $F_{2}$ and $F_{3}$. The average results in the three generations are given in the following table:

Effect of Selection of Good and Poor Winter Layers in the Same LiNe, D56D 407

$\begin{array}{cccc}\text { Generation } & \mathbf{F}_{1} & \mathbf{F}_{2} & \mathbf{F}_{3} \\ \text { Mean winter record of good layers and their progeny ......... } & 76.0 & 46.7 & 35.57 \\ \text { Mean winter record of poor layers and their progeny...... } & 26.0 & 5^{2.0} & 36.75^{14}\end{array}$

IIf one family of four birds, which ought not in fairness to be included here because they were extremely inbred (brother-sister mating) in connection with another experiment, is excluded, this average becomes 49.0. 
It is evident that selection within the line here was quite without effect.

Another example of the same thing from line D31D447 may be given by way of further illustration. In this line there was in the $F_{1}$ generation a family of ten daughters. Of these some were very good and some were poor layers. All were bred. The mean results are shown in the next table.

\begin{tabular}{|c|c|c|c|}
\hline $\begin{array}{c}\text { Generation } \\
\text { Gen }\end{array}$ & $F_{1}$ & $F_{2}$ & $\mathbf{P}_{3}$ \\
\hline Mean winter record of good layers and their progeny & 62.5 & 23.75 & 22.00 \\
\hline Mean winter record of poor layers and their progeny. & 32.0 & 28.75 & 14.75 \\
\hline
\end{tabular}

Here again it is plain that selection within the line was without effect. Many more examples of the same sort might be given from the records did space permit. In general there is no evidence whatever that the selection of individuals of different laying records, but belonging to the same fecundity genotype, produces any definite or permanent effect whatever.

\section{Discussion AND Conclusions}

Taking into consideration all the facts which have come out of this study, one is led to the following view as to the composition of a flock of fowls in respect to fecundity. In the average flock we may presume that there will probably be represented a number of fecundity genotypes, some high, some low, and some intermediate or mediocre. In an ordinary flock these genotypes will be greatly mixed and intermingled. Further, the facts in hand indicate that the range of variation in fecundity within the genotype is relatively very large, nearly as great, in fact, as in the general population. Thus while fecundity genotype means may be and usually are perfectly distinct, there is much overlapping of individuals in the different lines. In consequence it results that the egg record of an individual bird is of almost no value in helping to tell in advance of the breeding test to what fecundity genotype it belongs. Essentially this same fact has been brought out in all of the work which has been done with pure lines. The only difference in the present case lies in the fact that the range and degree of variation within the line appears to be relatively greater in the case of fecundity than in the case of most characters hitherto studied, as, for example, size relations in beans or Paramecium.

The most serious difficulty which confronts one in the attempt to analyze the inheritance of a character like fecundity lies in the almost inextricable mingling of genotypes in the great majority of individuals. This, of course, is a direct consequence of the manner of reproduction. The germ plasm of two separate individuals must unite to form a new individual. By 
prolonging incestuous mating one may in theory come indefinitely close to reproductive purity, but in practise even this is extremely difficult, if not impossible of accomplishment on any large scale or through any long period of time. The fact simply is that a "pure line" in the strict sense of Johann$\operatorname{sen}^{15}$ can not by definition exist in an organism reproducing as the domestic fowl does. This, however, by no means indicates that the inheritance of fecundity does not rest on a genotype basis, or, in other words, that fowls do not carry definite genes for definite degrees of fecundity.

We touch here upon an important point; namely, the relation of the mode of reproduction to the mode of inheritance. As one reflects upon the matter it becomes clear that it is only in the sense of a reproductive line that we can not, by definition, have pure lines in organisms where the sexes are separate. It is perfectly possible to have a line of such organisms in which all the individuals are gametically pure with reference to any particular character. For example, it is the simplest of matters to establish a line of horses pure in respect to chestnut coat color. Any individual in such a line mated to any other will never produce anything but chestnut offspring. So similarly with any other character, it is only necessary to obtain homozygous individuals in respect to any character in order to form a gametically pure strain with reference to that character.

It must further be kept clearly in mind that a reproductive "pure line" (in the sense of Johannsen's definition) may be made up of individuals not gametically pure (i.e.), homozygous. Thus suppose one crosses a yellow and $a$ green pea and then takes an $F_{2}$ heterozygote individual seed which originated from a self-fertilized $F_{I}$ individual as the "single, self-fertilized individual" with which to start a line. The individual which starts such a line arose by self-fertilization and is selfed to produce progeny and would thus fulfil every requirement of a reproductive "pure line" as defined by Johannsen. Yet it would produce both yellow and green offspring. On the other hand, as already pointed out, a line which is not, and from the nature of its mode of reproduction never can be, reproductively "pure" may be gametically so $(i$. $e$. , have none but homozygous individuals with respect to any character).

We then see that the fact that in fowls the sexes are separate and we therefore can not have reproductive "pure lines" gives, per se, no reason to suppose that fecundity is not inherited on a genotypic basis. We have to consider the problem of genetic or gametic purity. Do we have homozy-

${ }^{15} \mathrm{Johannsen's} \mathrm{definition} \mathrm{is} \mathrm{as} \mathrm{follows:} \mathrm{"Mit} \mathrm{einer} \mathrm{reinen} \mathrm{Linie} \mathrm{bezeichne} \mathrm{ich}$ Individuen, welche von einen einzelnen selbstbefruchtenden Individuum abstammen." ("Ueber Erblichkeit in Populationen und reinen Linien," p. 9.) 
gote lines in such cases as those discussed in this paper? It plainly is the fact that one can get lines of birds which, broadly speaking, will breed true (perhaps throwing occasionally a few individuals not true to the type of the line) to definite degrees of fecundity. The same thing is true of milk production in dairy cattle, speed in race horses, etc. What are these lines gametically? Theoretically the formation of gametically pure (homozygote) lines with respect to definite degrees of fecundity is simple. Practically it is exceedingly difficult to do this, owing to the fact that $(a)$ the character studied is not expressed in the male, and $(b)$ it is subject to a wide fluctuating variability caused by environmental conditions. The question as to the gametic constitution of the fecundity lines here discussed obviously can not be answered finally now. It is a matter for much further research. One may, however, form a general conception of the probable gametic constitution of such lines, which has much evidence in its support. The essential points in such a conception are:

1. Probably no line yet obtained is absolutely pure gametically in respect to fecundity. It represents a mixture of a greater or less number of fecundity genes.

2. Lines which breed reasonably true to a definite degree of fecundity may in most cases be taken to be made up of individuals bearing a preponderant number of genes of the particular degree of fecundity to which the line breeds true, so that in gametogenesis a great majority of the gametes formed carry only these genes. They also carry some genes of higher, or lower fecundity, or both kinds. When individuals of a definite $(e . g$., "high") line thus constituted are bred together the majority of the off spring will, purely as a matter of chance, be produced by the union of two high fecundity gametes. It is quite possible that with families of the size obtained with poultry nearly or quite every individual produced in the line for several successive generations may be of this kind. In the long run, however, it is to be expected that a small number of "off" individuals will appear in the line. These originate by the chance union of two low fecundity genes, or by the union of a "high" gene with a "low" gene of great potency (as in the case of D31, cf. p. 335).

3. The degree to which such a line will breed true will depend ujon the proportion of genes of one type (or of very similar types) present. The higher such proportion the less frequently will the "off" individual segregate out. The practical goal to be worked towards is, of course, to obtain several lines not closely related, but all made up only of individuals homozygous with respect to either high or low or any other definite degree of fecundity. 
Whether a given degree of fecundity is to be regarded as a single unit character, in the Mendelian sense, or, on the other hand, as a complex dependent upon a particular combination of separately segregable unit characters, can not yet be determined. Every one must recognize the fundamental importance of the investigations of Nilsson-Ehle, Baur and East, which have shown that many characters which at first glance do not appear to conform to any determinate law of inheritance are really complexes, formed by the combination of a number of unit characters, each of which segregates and otherwise behaves in a perfectly regular and lawful manner. There are some facts which indicate that high fecundity is a character of this kind, but it will require prolonged analysis to decide this, because of the numerous practical difficulties which attend the study of fecundity.

A great help in this analysis, as well as a contributory line of evidence of much weight in supporting the general conception of the manner of inheritance of fecundity set forth above, is derived from the study of crosses between breeds of poultry in which high and low degrees of fecundity are definite breed characters. Studies of this sort carried out at the Maine station indicate that the relatively high fecundity characteristic of the Barred Plymouth Rock breed is inherited as a sex-limited character. In this respect it behaves like a simple unit character, but this does not necessarily prove that it is not a complex. More data are needed to settle this point. Of much significance is the fact that, whether simple or complex, fecundity is shown by these experiments in cross breeding to be a character resting on a definite gametic basis.

In conclusion, I think it may fairly be said that the investigations here reported show in the first place that different degrees of fecundity are inherited in the domestic fowl, and in the second place, that in all respects wherein it has been possible, considering the inherent difficulties of the material and the character dealt with, to make the test, the method of this inheritance is in entire accord with Johannsen's concept of genotypes. 


\title{
REPORT OF THE COMMITTEE OF INVESTIGATION, AUGUST, 1909
}

\author{
PRESENTED BY PHILIP B. HADLEY
}

READ BY WM. F. KIRKPATRICK

The Comnittee of Investigation has attempted to ascertain the nature and distribution of poultry investigation throughout the United States, chiefly with reference to the work of the Agricultural Colleges and Experiment Stations. Reports were not received from five stations. The details ascertained from the others are as follows ${ }^{1}$ :

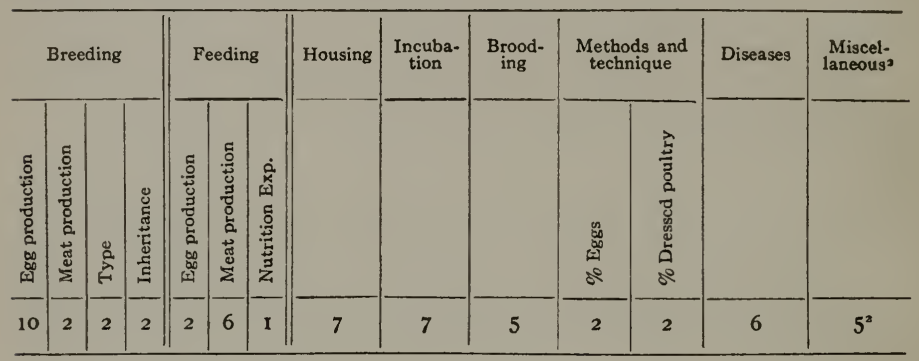

Respectfully submitted,

Philip B. Hadlet,

JaMes G. Halpin,

J. P. LANDRY.

June $30,1909,25$ of the 49 Experiment Stations were investigating poultry problems; of the remaining 24,9 signified their intention of taking up such work the following year.

'Under this heading comes the following problems each of which is being studied by a single station:

(I) The value of the male in the (scrub) flock.

(2) Moulting of poultry, rate of feathering, etc.

(3) A study of vitality in stock.

(4) Influence of feeding upon color of stock.

(5) Influence of light upon (a) laying; (b) development of chickens. 


\title{
PRESENT STATUS OF INVESTIGATION OF THE PROBLEMS OF POULTRY CULTURE*
}

\author{
PRESENTED BY PHILIP B. HADLEY
}

\author{
READ BY WM. F. KIRKPATRICK
}

Since the time when the investigation of poultry problems was first taken up in connection with Experiment Station work, the field of experimentation and of research has been greatly extended. At the present time the subjects of investigation are numerous, but every year are being increased in number as well as made more valuable by reason of greater intensity of effort.

In view of these facts, it has appeared desirable to your Committee on Investigation to make an attempt to obtain concise data regarding the general nature of the poultry investigation which is being carried on in the different experiment stations of the United States and Canada; and to ascertain, if possible, the nature of the distribution of these problems in different parts of the country. This has been done with the belief that the acquisition of such data might serve as a basis for more valuable co-operation and united effort between individual investigators. It appears unfortunately true that such co-operation or unity has not, in the past, characterized a great amount of the work of widely separated investigators of poultry problems. On the other hand there has often appeared a lamentable narrowness of horizon on the part of many who have appeared to be actuated by the belief that, the surest way to secure advantageous results from their investigational efforts, was to closely foster their own problems, and to mention them in detail only to those who did not have an actual working interest in them. Such pettiness in work of a broadly scientific character is not uncommon, and is especially to be avoided; indeed, it must be avoided if the investigations in poultry problems are to result in the fullest measure of benefit to the poultry industry on the one hand, and to pure science on the other.

As being placed against this attitude it is the belief of your Committee that one of the highest aims in the formation of this association is to stimulate the free interchange of ideas on subjects which are of fundamental interest to the poultrymen of this country.

In attempting to outline the field of poultry investigations, it is first necessary to distinguish between different types of investigational work.

${ }^{*}$ Report of the Committee on Investigation for the year ending June 30, 1909. 
At the outset, although this classification has certain disadvantages, we may separate the whole field into, first, that of pure experimental work; secondly, that of pure research; and betwcen these two there is a sort of investigation which may be either experimental, or research, depending upon the point of view and the ultimate aims of the investigator. It should not be inferred from this distinction that, as is so often said, one is necessarily a higher type of investigation than the other. In all cases the pursuit of true research problems must involve much work which is of the experimental order. Indeed, the majority of so-called "research problems" must have their basis in the results of a greater or small number of single experiments. Whether or not such experimentation can be built up into a piece of research depends largely upon what the aims of the investigation as a whole, may be; and to what degree the results of the single experiments are used as the means for reaching these ends, and for advancing toward the solution of still deeper problems. To state an example: To ascertain, by means of feeding broiler chicks several different nitrogenous feeding stuffs, what combination produces the quickest growth, or the highest eggproduction is experimentation. But to ascertain what the reasons for such differences may be, for instance whether they are due to mineral constituents, to the difference in fats, or to the peculiar proteids, this constitutes research.

It is difficult to say at the present time in which category most of the investigational work, to be mentioned in this report, belongs. For the sake of convenience the fields have been first divided, as already stated, into the purely experimental and into the true research work. Into the former class has been placed work in incubation, brooding, housing, feeding, much of the work in breeding, and investigations regarding methods and technique in poultry husbandry.

In the latter group may be placed the study of definite problems in regard to inheritance, nutrition, poultry diseases, and other problems dealing with subjects of a physiological nature, such as those of egg fertility, the vitality of stock, the physiology of reproduction and digestion.

It must be borne in mind, however, that those distinctions are by no means rigid; and that the work in feeding, for instance, while appearing to be only of the experimental order, may in certain cases, be the basis of other work which is more closely allied to true research; and that similarly work on poultry diseases, while it should represent true research, is frequently nothing more than purely experimental.

As a result of reviewing the answers to the questions which your Committee has sent to the various experiment stations, it is often impossible to 
state which order of investigation is represented by the work in question, although it is apparent that at present more belong to the purely experimental than to the research group.

With this brief introduction we may then, turn our attention to the various branches of investigational work in poultry husbandry that are being conducted by the experiment stations at the present time. First it should be said that notwithstanding persistent effort, no replies regarding the position of poultry investigations have been received from several states. All the others have responded promptly, though in many instances too briefly.

In the survey of these replies, the first point of interest lies in the number of institutions in the United States, that are carrying on any definite investigation of poultry problems. It here appears that slightly more than half-or twenty-five- of the forty-eight stations are at the time of writing actively engaged in work along these lines. The states that are, so far as can be ascertained, carrying on no work with regard to poultry include the following: Alabama, Arkansas, California, Delaware, Florida, Georgia, Idaho, Illinois, Kentucky, Louisiana, Montana, Nebraska, New Hampshire, New Jersey, New Mexico, Ohio, Oklahoma, South Carolina, South Dakota, Tennessee, Texas, Vermont, Washington, Wisconsin, and Wyoming.

In connection with this point, it is gratifying to note that of these twenty-four stations, in which at the present time, no poultry investigations are being conducted, nine, including Arkansas, Colorado, Idaho, Montana, New Jersey, Mew Mexico, Oklahoma, Wisconsin and Wyoming, have expressed an intention of taking up such work either as soon as funds are available for the purpose, or a suitable man can be found. In most cases it appears, however, that it is funds, not men, that are not available. The fact that these nine institutions thus signify their intention of undertaking the study of poultry problems in the near future is surely suggestive of the increasing interest that is now being taken in poultry husbandry; and of the weighty significance of many of the problems included therein.

Omitting for the present, the work of the five stations, from which it has been impossible to secure data regarding the poultry work, attention may be turned to a review of what is being done in other institutions.

Of course most of the work which is now being done centers about the subjects of breeding, feeding and housing. In most instances, however, there is some definitely ulterior aim in the work; and this is usually to observe the influence of these factors upon vitality, egg-production, meat production or type. 
It is at once apparent that more work is being accomplished under the head of breeding and feeding experiments, than in all the other divisions of poultry investigation combined. It appears, moreover, that while the breeding for egg production is the subject of investigation in ten instances, breeding for meat production is being investigated at only two stations, although one other station is studying the correlation between conformation and meat production as affected by breeding.

In the case of feeding experiments, on the other hand, it is apparent that six stations are engaged in feeding for meat production, but that, so far as can be learned at the present time, only two institutions are breeding for type. It should be said that the work of Davenport, at Cold Springs Harbor, is not included in this list. Furthermore, at one other station, although no definite poultry investigations are under way, the horticulturist is carrying on independently some very interesting experiments in making reciprocal crosses between fowls, with a view to throwing more light upon some of the problems of sex heredity. Generally speaking, it may be said that most of the work which is now being done in poultry breeding and feeding belongs to the purely experimental order; that is, very little of it is of a sort calculated to throw light upon the deeper principles which underlie the phenomena referable to both these subjects. This cannot, by any means, be called a regrettable condition, as some would have us believe. There is room in the whole field of poultry investigation for work of a simple testing character for a long time to come. What we need first is facts upon which we can rely, facts regarding feeding stuffs and feeding methods, regarding definite crosses and their result, facts about diseases and disease parasites. A substantial body of facts, from which to work upward is the surest basis for all higher types of scientific investigation.

There appears to be, however, in the field of poultry investigation relating to breeding and feeding, ample opportunity for the study of problems of heredity in poultry. It is true that many of these problems are more easily studied with other birds and mammals, but there are many problems of heredity, for the working out of which, poultry is especially well adapted. Furthermore, as has been shown, another phase of poultry investigation is especially open and promising, that is, breeding for meat production. It is probable that the next few years will see much valuable work accomplished by the small number engaged in this line of work.

When we come to the subjects of incubation and brooding, it appears that, while seven institutions are engaged in studying the former, only five are working at the latter. This indicates a diminishing interest in this line of investigational work, much of which has undoubtedly been forsaken 
for the more alluring problems in breeding and feeding. It cannot be believed, however, that all that can be said about incubation and brooding, has been said. With the greater increase in the poultry industry in this country, and the necessity of winter production of immense numbers of birds to supply city markets, the problem of artificial brooding is becoming of an ever increasing importance to all large poultry raisers.

Closely related to this subject, since so great mortality is often present among artificially brooded chicks, is that which we may call, for the lack of a better term, Poultry Hygiene; and we may define this as the science which deals with the laws of health of the chicks. It is a study of the young birds' surroundings, with a view to ascertaining in what measure these are conducive to health or to disease. Disease is not, strictly speaking, caused by micro-organisms. In most instances, whether in human beings or in chicks, disease is due as much to a weakened vitality as to outside infectious agents or materials. Disease is merely an offset to the normal equilibrium of physiological conditions, which we call health, either because the vitality is too weak, or because some outside stimulus is too strong. In a great number of cases young birds in a weakened condition succumb to the action of organisms which are constantly present in well birds. The problem of practical poultry hygiene would, then, have for its aim the study of all those conditions which make for or against the vitality and health of poultry. It is a problem whose aspects extend into every phase of poultry work, from the formation of the egg in the oviduct to the final disposal of the bird in the market. It has to do, first, with the problem of egg infection, either with the coccidia which cause Blackhead and White Diarrhea, or with other microörganisms which cause the rotting of eggs and the premature death of young chicks in the shell. It may have to do with the questions of incubation including the effect of moisture, of carbon dioxide, of ventilation, of intermittant versus steady heat. Later, it includes consideration of methods of brooding; and the relation thereto of different methods of feeding and heating; also questions of infection through dust or through contaminated food or water. Furthermore, the practical poultry hygiene should include a study of the hygiene of the poultry yard, its location, drainage, its constant or intermittent use, methods of cleansing, disinfecting, etc., together with methods (especially in large poultry plants) whereby certain divisions of the yard can be quickly and effectively isolated from the rest in the case of such an epidemic as fowl cholera. The writer has recently been called to inquire into a certain poultry epidemic in a neighboring state in which a large poultryman lost three thousand birds within two months through fowl cholera, and was advised to kill the balance 
of a flock of forty-five hundred. If, at the time this epidemic broke out, one single section of the poultry plant could have been effectively isloated from all the rest, the loss would probably have been less than five hundred, or at most, a thousand birds. Such methods could have been devised and put into effect for fifty dollars. The poultryman has now lost five thousand fowls and also his trade. It is the part of Poultry Hygiene to study into all these matters which make for the well being of poultry, both to maintain their own vitality and by all possible means to guard it against the invasion of hostile microorganisms. There is excellent opportunity, and eminent need, for station investigators to enter into this field of work.

This brings us at once to a consideration of the distribution and nature of the work on poultry diseases among the experiment stations. It is a regrettable fact that of the forty-eight experiment stations in the United States, only six are, at the present time engaged in the study of poultry diseases, or disease parasites; and only four of these are making a definite study of the infectious or communicable diseases. Efforts in this country to establish etiological relations of poultry diseases, have not, as a rule, yielded fruitful results, either in benefit to the poultry industry as a whole, or to pure science. Indeed, it is only within a comparatively short time that the pathological anatomy and etiology of poultry diseases, as a whole, has begun to be placed upon a scientifically accurate basis. Ever since the painstaking and productive researches of Pasteur upon fowl cholera, scientifically trained investigators in this country have avoided, to a greater or less extent, the field of poultry diseases, either believing that the field was too far removed from the study of mammalian diseases to make their investigation really of value, or convinced that the subject of poultry diseases was too limited in its scope, and too narrow in its suggestiveness, to furnish the researcher with problems worthy of his steel. And for these reasons the work in the investigation of poultry diseases in this country has until within the last five years, been practically at a standstill compared with the progress made along similar lines in Germany, France, and Russia. As a result, our text books are full of data on diseases which do not exist, and when we wish to obtain definite information on some of those that do exist in this country, we are forced to go to the works of German, French, or Italian investigators.

The nature of the replies from the various experiment stations, together with the loose, and often unreliable, quality of the majority of the few bulletins that have been published by the stations upon the subject of poultry diseases, are decidedly suggestive of the strenuous effort that should be made to raise the standard of this line of investigation in the institutions of this country. 
It is not the function of the present paper to indicate what subjects of investigation in poultry diseases may be especially desirable or profitable at this time, but it may be said that the field is a wide one, and the need for such work great.

The next most important branch of poultry investigations, at least the one in which a large number of stations are interested, is that of Housing. Seven institutions are now investigating the merits of different housing systems, upon egg production, fertility, etc. Much of the experimental work in this line has already yielded good results. One of the aspects of this subject which has not, however, received so much attention, is the hygienic conditions of the poultry house, especially with reference to the nature of the flooring, the presence of many deep, open cracks, and the supply of sunlight. All these points are directly referable to the larger subject of Poultry Hygiene, already mentioned.

Most of the remaining subjects of poultry investigation may be grouped under the heading of Methods and Technique, especially with reference to handling the fowls themselves. This group included experiments in caponizing, in preparing birds for market, in methods of shipping and of storing dressed fowl. Under this head may also be placed the method of handling and preserving eggs; and methods of storing them for the market. All these subjects are of value, and it is somewhat surprising that only four stations are interested in definite work of this nature, although several others are making casual observations.

The remaining subjects which are receiving attention are of a miscellaneous nature. They include for instance experiments calculated to show the value of the male in the flock, especially with reference to bringing up the grade of a scrub flock; also studies of the moulting of birds, the rate of feathering, etc. One station is making a special point of the study of the vitality of the stock, believing that this is one of the most important considerations for the poultryman. Other subjects include color feeding, the influence of light upon the egg-production of a flock, the influence of light upon the development of chicks, all of which problems are being investigated by one or two stations. And besides all these, there are probably still other problems which, as the writer has stated, have not, for one reason or another, been brought to the attention of your committee.

In conclusion it may be said that we have some reason to be proud of the quality of the investigation of poultry problems, which is now being conducted in this country. However much has been written on some of the subjects in investigation given above, very few problems are as yet, settled. What is needed primarily in poultry investigations at the present time is a 
greater body of substantial facts on all phases of the subject concerned. When these facts have been secured, it will be time enough to read into them, and out of them, the principles of breeding, the principles of poultry feeding, and the principles of the causation and treatment of poultry diseases. With respect to the fundamental principles which underlie all these branches, we are still very much in the dark, but the increasing enthusiasm for work in solving the problems of poultry, if united with a wise discretion as to what problems an investigator or an institution is best fitted to take up, will assuredly, in the near future, yield results of rich profit. 


\title{
THE PRESENT STATUS OF INVESTIGATION OF THE PROBLEMS OF POULTRY CULTURE ${ }^{1}$
}

\author{
PRESENTED BY PHILIP B. HADLEY \\ READ BY WM. F. KIRKPATRICK
}

In the previous report of your committee on investigation it was stated that of forty-eight Experiment Stations in the United States and Canada, sending replies to circular letters, slightly more than half, or twenty-five, were engaged in the investigation of poultry problems, leaving twenty-three which were carrying on no poultry work. It has been ascertained at the present time, that twenty-seven institutions out of forty-eight, are carrying on investigational work with poultry, while twenty-one are not. In other words, two institutions have during the past year initiated poultry investigations. Two institutions among the twenty-one, not at present carrying on poultry investigation, signify their intention of doing so within the coming year.

As to the subjects of investigation, the following points are to be noted. As was the case one year ago, nore energy is being expended under the head of breeding and feeding than in all the other divisions of poultry investigation combined. However, while one year ago ten Stations were engaged in breeding experiments for egg production, at the present time the number has diminished to seven, and one of these instances is the first initiative. This indicates that four institutions have abandoned either permanently or temporarily this phase of breeding work.

One year ago breeding for meat production was being carried on at two institutions. This year the number has increased to three.

A year ago there were six stations feeding for meat production. At the present time only four are engaged in this line of investigation; and whereas one year ago six stations were feeding for egg production, at the present time only five are engaged in this investigation, although two more signify their intention of entering this field.

Another phase of the work in animal feeding is to be considered under the head of Investigation in Nutrition. This work has in view the utility of particular materials, and seeks the reason for it in the chemical composition of the substances concerned. Three stations are engaged in this line of work.

When we come to the subject of incubation, we find that there are five stations interested in incubation problems against seven of a year ago.

${ }^{1}$ Report of the Committee on Investigation for the year ending June $30,1910$. 
Moreover, while five stations were attacking brooding problems a year ago, at the present time only one institution is apparently still consistently inquiring into problems of this nature.

The number of stations studying the diseases of poultry remains the same as a year ago, that is, six. One station, however, has apparently dropped out of this line of work, and one new one has entered the field. Still one other station promises to enter upon this line of work in the autumn The fact that each year the experiment stations are entering more fully into the study of the cause and prevention of poultry diseases is surely encouraging.

The number of stations investigating the merits of certain housing systems has increased one over last year. The number is now eight.

Although breeding work does not appear to have advanced over last year, it is interesting to observe how much more attention is being devoted to the study of the egg, together with conditions affecting its fertility and hatchability; also of conditions affecting the vigor of young chicks. All of these problems are being attacked more strongly than ever from the bacteriological, and physiological and chemical points of view.

Other important and more fundamental lines of investigation which are being taken up by only one or two stations are the physiology of reproduction, and the physiology of digestion in poultry. The practical results of these investigations are not quick to appear, but their value is yet a basic one. Outside of breeding work, which has for its object either meat production or egg production, certain other studies in inheritance are being carried on with poultry, one station is studying the behavior of weight in inheritance, and one the possible method of fixing heterozygous characters in poultry.

Most of the remaining subjects of poultry investigation can be grouped under the head of "Methods and Technique," This group includes caponizing, preparing birds for market, methods of shipping and storing dressed fowl, methods of handling and preserving eggs, effect of free range upon egg production, factors influencing the size and weight of eggs, the effect of the male in the flock, the analysis of eggs, the effect of feeding animal food upon the hatching power of eggs, etc. Not more than one station, as a rule is interested in any one of these problems.

One point is brought out strongly as a result of observing the scheduled lines of poultry investigations of the same institutions for two or three successive years. This is the arbitrary way in which certain lines of investigation are taken up and dropped. The value of the majority of the lines of investigations with poultry depend to a great measure upon continuity of effort, and this is especially true of all breeding work. Probably 
the condition is not so serious as it is made to appear through more or less hurried replies to circular letters, but the fact remains that continuity of effort does not characterize the investigational effort of the institutions in this country as a whole.

Respectfully submitted,

Philip B. Hadley,

James G. Halpin,

J. P. LANDRY. 


\section{PROFITABLE LINES OF INVESTIGATION IN POULTRY DISEASES}

BY GEORGE BYRON MORSE

In the last analysis all truly scientific investigation looks toward the practical. The pure bred scientist is by nature a utilitarian. One would not be, therefore, far astray in answering the implied question of this paper's title by saying that all lines of investigation in poultry diseases are profitable. Surveying the field of poultry diseases for the first time one is astounded that so little really final work has been accomplished. We have positive knowledge as to the causative relation of a few infectious agents to certain epizootic diseases. But when it comes to the question of the normal habitat of these supposedly well identified microbes, of how best to attack them before they attack the flock, of the surest weapons with which to repel an attack, of what kind of a certificate of health can be awarded a so-called cured bird, I do not fear contradiction when I assert that we are largely in the dark.

Suppose we take the embryo. Why do chicks die in the shell? Your weak-germs and lack-of-moisture theories have been worked a long while but they do not fit all cases. Why do hens surpass incubators in securing a manifestation of fertility in the eggs? Are there microbes or enzymes at work within the egg that throttle the embryo on the very threshold of life? And if they do not die in the shell what is that spirit of spite that makes them "cripples" at the time of hatching?

Suppose we take the chick. On the headstone orer an infant's grave in an English churchyard are the words:

If I was so soon to be done for, What in the world was I begun for?

Many a poultryman has probably said, as he viewed the sickening mass of feathered remains of what had appeared to be a good hatch, "Them's my sentiments." The cause of white diarrhea in chicks has been recognized and announced by the writer, but the problems connected with this fatal plague of coccidiosis are many and difficult of solution. The same may be said of all the diseases that sweep epizootically through a flock.

Intestinal troubles in chicks offer a most interesting subject of investigation. Probably no subject presents better inducements for careful and extensive research than that of the diarrheas of chicks and chickens. Relaxation diarrhea must be taken into account. Physical agencies, such as 
heat or its lack, moisture or its lack, play a prominent role in the causation of this form of diarrhea. Foreign body diarrheas must also be recognized. Under this head I would place those diarrheal conditions arising from overfeeding, too frequent feeding or the feeding of wrong material, all of which might be placed under the general title of improper feeding. Parasitic diarrheas, using the term "parasitic" in its widest sense, offer the greatest field for research on the line we are now considering, especially to the pathologist. The macroparasites deserve attention whether they be supposedly harmless worms acting injuriously only by the greatness of their numbers or as I am inclined to think we shall come to believe, through their toxins, or the hooked forms which at once act as irritants and possibly frequently as inoculating needles for intestinal bacteria that are only waiting to enter through the abraded mucous membrane. Then there are the microparasites, microorganisms, which divide into two general classes: protozoa which are the lowest animal forms, and microscopic vegetable forms such as bacteria and molds.

Among the protozoa as agents of intestinal disturbances, the coccidia and the flagellates are to be studied. Whereas there is but one coccidium, Coccidium tenellum, it is very likely that we shall have to take account of different flagellates, the Cercomonas and the Trichomonas, as causing diarrheas and other forms of intestinal disturbance not only in chicks but in adult poultry as well.

In this connection it must be remembered that intestinal disturbances do not invariably manifest themselves by diarrhea. In the Bureau of Animal Industry Circular No. 128, which presents in a preliminary way, the subject of coccidiosis in poultry, the writer calls attention to the fact that he believes that many cases of limberneck and leg weakness are caused by the coccidium. Maggots have long had the unenviable reputation of causing limberneck in chickens but, without doubt, it is not the maggots per se that cause that nervous phenomenon. The poisons from the decaying meat containing the maggots are producing their toxic effects upon the bird. Hence it is not too much to expect that the toxins developed in the intestinal tract by bacteria and by digestive changes in the food, gain entrance into the body of the bird through abrasions caused by any intestinal parasites and so produce limberneck. As a therapeutic test of the correctness of this diagnosis try the administration of a teaspoonful of castor oil containing 10 to 15 drops of turpentine, repeated every two or three days, or purgative doses of Epsom salt. We have already learned in human medicine that intestinal toxemia may be the cause of many cases of arthritis, often called rheumatism, and one of the commonest methods of 
the development of intestinal toxemia in chickens is through the presence of intestinal parasites. And so, in leg weakness or rheumatism or paralysis or whatever you choose to call it, purgation results in a most beneficial confirmation of the diagnosis.

The bacterial diseases of chicks demand investigation. Shortly after the appearance of Circular 128, Rettger and Harvey presented a detailed study of a speticemia of young chicks which had been studied earlier by Professor Rettger himself. The authors have seen fit to attach to their title the words "White Diarrhea" although the disease bears all the ear marks of a septicemia. For this reason and because diarrhea is apt to be one of the symptoms of the young chick's infection with this bacterium discovered by Professor Rettger, the disease calls for mention at this point. It seems to the writer that nothing could offer a more interesting and fruitful field of investigation than a most careful study of the bacterial flora of the fowl's intestine, starting, of course, with the chick. Those who enter deeply into the microbiologic investigation of chick diseases will find, as has the writer, that various bacteria play a part in the production of death even when the diseased condition has been induced by coccidia, flagellates or worms. This is true not only for chicks but also for fowls. Hence the importance of a knowledge of the bacteria that are likely to come to light from time to time in connection with these different ailments, for instance, Bacillus coli, Bacterium aerogenes, Bacterium sanguinarium Moore, the bacillus of fowl cholera, Bacillus pyocyaneus otherwise known as the bacillus of green pus, and some of the variants of Bacillus proteus.

The molds that produce disease in chicks should be studied. It is probable that but one, Aspergillus fumigatus, calls for special study. This is known to be quite troublesome especially among water birds and pigeons. The writer within the last few months in attempting to distinguish between the various diarrheas of chicks has come to recognize that what is called "pasting" or "pasting up behind" is oftener associated with a lung affection than with coccidiosis, although it may occur in this latter disease. Brooderpneumonia or, as it is sometimes called, incubator penumonia is an affection of young chicks in which the lungs are studded with pinhead yellowish or whitish nodules. Sometimes a large portion of one or both lungs are transformed into a cheesy mass. Such chicks have been called "lungers." This lung disease according to the writer's findings is due to the presence of the mold, Aspergillus fumigatus. The recognition of this organism in this affection and the development of the disease at such an early date suggests also the possibility of egg infection from the hen's diseased eggtube or by being retained for some time in a musty locality before incubation. It has 
long been known that this particular mold infects the inside of eggs and it is easily conceivable that the incubation of the egg would furnish the necessary heat and moisture required for the development of the mold. Any pure-blood researcher would easily think up a dozen lines of investigation to be pursued in connection with this mold infection.

The gape worm, although well studied, can still furnish us with some interesting matter for investigation. For instance, we should have a better treatment than that of slowly digging out the worm from the windpipe by means of a horsehair or a timothy head. Then, too, is it the earth worm or the old hen that keeps up the supply?

Suppose we take the chicken or fowl. Here we still find coccidiosis, flagellosis, aspergillosis and several of the bacterial infections. The gape worm and Rettger's bacillus drop out, but in their place we find fowl cholera, meat poisoning or infection with the so-called hog cholera organism and sereral bacilli that have been recognized in association with roup. Here comes up also the investigation of the treatment of roup. Is it actually worth while to attempt to treat a flock when once the infection has secured a good start? Can the birds be successfully treated? Would it not be best, when once the disease is recognized, before it has produced symptoms in the exposed birds, to kill them off for market, disinfect the premises thoroughly and start fresh?

There is a rather large group of diseases of the liver that are popularly classed under the designation "spotted liver," "liver disease," etc. These should be differentiated and studied, placed upon their proper ground as infectious diseases as most of them are, and classified as to their curability, the desirability of attempting a cure or the necessity of undertaking most radical measures for their eradication. Instead of calling them all tuberculosis and saying that they are caused by overfeeding, let us at least recognize that there are tuberculosis, aspergillosis, coccidiosis, (especially if the blackhead disease of turkeys be completely demonstrated to be a coccidiosis and the subject is sure to receive most careful researching at the hands of our talented fellow member Dr. P. B. Hadley, of the Rhode Island Agricultural Experiment Station), cercomoniasis, and liver invasions by the two malignant tumor formations, sarcoma and carcinoma, to say nothing of a disease apparently a blood disorder, known as leukemia which also produces minute spots in the liver.

It would be a splendid thing for the poultry industry if we could during the coming year run down even a fourth of the lines of investigation suggested. Should any one fear a dearth of work after all the foregoing has been accomplished, I would simply remind him that the field is unlimited. 


\section{THE RELATION OF INTESTINAL WORMS TO POULTRY HYGIENE}

BY GEORGE EDWARD GAGE

Poultry hygiene today embodies all those factors which are conducive to the maintenance of poultry in a healthy, vigorous condition. To the average layman this simply means attending to the general outward appearance of the different housing and yarding conditions, as to neatness and general cleanliness. The term, however, has a far broader meaning when applied in the purely scientific sense. It means, among other things, are intestinal worms and other parasites present on the poultry premises? Are they a constant menace to the general well being of the birds which are to furnish produce for the market? The statement that some of the birds are harboring intestinal worms may sound simple, but, if it is true, great may be the consequences from the standpoint of breeding and finance.

The question of worms is of far greater importance than the poultry investigator is apt to believe. In the southern states these parasites are undoubtedly responsible for more disease than simply those ailments which are designated as tæniade infestations. The relation of these intestinal parasites to the fundamental principles of poultry hygiene is paramount. Their powers of depleting nourishment supply, of injuring the intestinal epithelium and of invoking a nervous condition are only a few instances of their work in starting the course for other infectious diseases in which they prepare the path for either pathogenic hacteria or other deadly parasites which, by their bacterial action or poisons, may ultimately cause the death of the fowl.

It has been my experience in Maryland to observe the autopsy of many birds in which the intestinal mucosa was greatly damaged either by the presence of tapeworms or round worms. They caused an intestinal catarrh which formed denuded areas infested with animal parasites and thus caused the death of the birds.

In reviewing literature on the various parasitic diseases, it is interesting to note the importance which many pathologists attach to worm infestation. It may be a complication in fowl cholera, blackhead in turkeys, and in several others of the intestinal diseases of domestic birds. When the intestinal tract is invaded by Tænia infundibuliformis, a tapeworm common in Maryland, Virginia and West Virginia, or by round worms of the Heterakis type, common in Maryland, undoubtedly they play a great part in hastening a fatal issue in any bird suffering from any other intestinal 
infection or infestation. Worm infestation plays a most important role in emaciation, causing faulty assimilation and resulting in a deranged metabolism. These parasites destroy the absorbing epethilium.

The importance of eliminating these parasites from birds has been clearly demonstrated at the Maryland Experiment Station. On several occasions birds have been selected for experimental work and after two or three weeks the presence of round worms has been detected in the droppings and in several instances death has resulted from large numbers of tapeworms being harbored in the alimentary tract, causing general weakness, marasmus and ultimately the death of the subject in question. If experimental work of a strictly scientific character is to be conducted in the southern states, where intestinal worms abound, the observance of hygienic methods in experimental pens should include the careful examination of the droppings for evidences of tapeworm and round worm infestation and the elimination of the factors which may contribute to any pathological condition and cause disturbances in the general physiology of the birds. When conducting experiments in poultry pathology these considerations are evidently of fundamental importance.

Frequently people who keep poultry on a small scale do not understand why their poultry does not yield profits comparable with the other farm animals. In nine cases out of ten it is the result of trying to raise poultry as an adjunct to the farm without considering the necessary precautions for their well being. The crops and other live stock receive first attention and the chickens last. When disease infects the flocks it is allowed to run its course without interruption until nearly all the birds die. Then the poultryman becomes discouraged.

To return to our definition of poultry hygiene it may be stated that it is a branch of poultry husbandry which is concerned with the maintenance of the health of poultry. Perhaps the poultryman is not impressed, but if the fact is mentioned that every year there die from infectious diseases, thousands and thousands of valuable birds which could have been saved and produced a handsome income for the owner. Then these principles of hygiene may become of interest.

In consideration of the relation of the intestinal worms to poultry hygiene and as an example of rapidity of infestation, it may be well to state something concerning the life history of the tapeworm.

The life history of a very few forms of tapeworms is definitely known. It is generally believed that the infestation of these parasites is transmitted through an intermediate host. They are adapted to a life of parasitism. They have no digestive system, but are nourished through the general 
surface. The soft liquid nourishment is derived from the material within the digestive canal of the host. The tape or flat-band worm is not continuous but is made up of segments or proglottides, each of which contains vital organs, and in the posterior end of the worm each segment contains a complete set of reproductive organs. As rapidly as the ova are fertilized they are received into a uterus which is distended with eggs. The segmeuts drop off one by one and reach the exterior in the feces of the host. In this way the upper surface of the soil over which the poultry range becomes infested. Each egg contains an embryo, consisting of a round mass of cells, bearing chitinous hooks. As soon as the egg has been discharged it is necessary that it reach the intestinal canal of a second kind of animal which is the intermediate host. This is necessary in order that the embryo may enter the next phase of its life history.

The six-hooked embryo known as an oncosphere or hexacanth embryo, bores its way from the intestines into the body cavity of the intermediate host. In the case of tapeworms in poultry, this is thought to be a true worm, snail, crustacean or an insect. In this intermediate host it develops into a larval form known as a cysticeroid. In turn this larva develops into an adult worm when swallowed by a chicken and causes the formation of the denuded areas along the intestinal tract. Grassi and Rovelli state that the larva of Drepidotænia infundibuliformis may be transmitted to birds through the house fly as an intermediate host. According to Piana in 1882 the larva of Tænia tetragona was found in snails of the genus Helix. He holds that this is a common means of the infestation of tapeworms among domestic fowls.

If intestinal worms are detected in the droppings this is indicative that there is great probability that the land over which the birds range may be infested with the worms in some stage of their life. If this be the case, and our experience here at Maryland has shown it to be so, then the first hygienic principle to be employed is a primary and fundamental one in the science of hygiene, namely: prevention.

Every part of the poultry house should be thoroughly disinfected with a 5 to $10 \%$ solution of zenolium or some other good disinfectant. If these birds appear badly infested every individual bird should receive a purgative dose of Epsom salts followed by a few drops of turpentine. Finally, every part of the poultry yards should be plowed, thus bringing the eggs or larva of the infectious parasites to the surface and destroy them as far as possible by the disinfecting action of the sun. Lime should be used freely and if possible the land sweetened by vegetation. These few principles observed will greatly correct the conditions which have existed during infestation of the premises with intestinal worms. 
After the rehearsal of such rigid preventative methods the poultryman will ask, "Did it pay?" It can be definitely stated that in all our experiments in which an intestinal worm infestation appeared when all these careful disinfecting methods were strictly observed the results were most gratifying. Among a small flock in which worm infestation had been evident, this method of disinfection has been followed during the past few months with the result that at the present time the flock is absolutely free from the infestation.

These facts hold true for young chicks as well as for older birds. Many of the intestinal disturbances which young chicks exhibit may be attributed to the harboring of intestinal worms. This gives evidence of faulty assimilation which results in an unbalanced metabolism. These conditions may obtain in young birds suffering from any of these parasites which injure the intestinal epithelium.

The greatest role of intestinal worms is the part played in complication of other diseases and for this reason alone every effort should be made to keep the premises free from them. There are several factors which are favorable to their existence. If the farm is poorly drained, if the birds have access to dirty drinking water, and if birds which have harbored the parasites die and are allowed to remain on the grounds, hygienic principles are not being observed. And if in the summer months the eggs of the worms or worms in any stage of growth are about the place, infestation of the poultry will occur sooner or later. When these parasites infest premises affording such unsanitary environment they multiply rapidly and in a very short time are transmitted from bird to bird. The droppings containing the infection are deposited on the surface of the land, over which the birds range, resulting in a general dissemination of infectious material thus contaminating the poultry grounds with the different stages of these infesting parasites.

Under such conditions how can the farmer or poultryman expect to raise birds which are to maintain vigor and that kind of vigor which is necessary for breeding purposes? If young birds are harboring these parasites they can never be expected to be strong, mature birds and the poultryman will not be able to maintain a strain of birds which will be capable of performing all the functions of healthy fowls.

The importance of these intestinal worms in relation to hygienic conditions for poultry should receive considerable investigation. The life histories, modes of transmission, and the action of the various disinfectants upon them are subjects which need much study. The facts that they may be present in apparently healthy birds, that they may infest the 
grounds and houses, that birds may harbor them all their lives and be a menace to the production of ideal breeders, and that they may make lesions which may be the starting point of more serious troubles, are enough to emphasize the necessity of their elimination from the bodies of the birds and from the ground of any well conducted poultry plant. This is a principle that is quite as fundamental in poultry hygiene as the cleanliness and neatness of the houses and yards themselves.

In the warfare against the conditions produced by these intestinal parasites a most rational hygiene of the poultry houses and yards must be observed. It is no less a fact that domestic birds as well as human beings may receive infection through contaminated food. All the means of communication may be recognized, and just as the spreading of human disease is held to be a matter of public concern, and preventative measures instituted by experts, and in view of the facts that intestinal worms may be associated with other diseases, that they destroy the intestinal epithelium and cause emaciation, and general intestinal disorders, together with deranged metabolism, it is clear that the elimination of these parasites is absolutely necessary if poultry hygiene is to be considered in the rearing of poultry. The relation of these intestinal worms to poultry hygiene should be of great concern to the poultryman if he is desirous of maintaining his birds in a healthy condition. Careful consideration, however, of the elimination of these parasites is a fundamental principle, and if thoroughly and consistently executed will do a great deal toward the production of healthy fowls and clean breeding stock. 


\section{FOWL CHOLERA (CHOLERA GALLINARUM)}

BY J. WILLEMS

Translated from French by Victor For tier

The readers of ("l'Elevage" of Læken-Belgigue Europe) are well acquainted with the losses caused by the dread disease which we intend to discuss a little in the following lines.

Fowl cholera is the most dreadful and deadly disease that attacks our farm yard feathered tribe.

Chickens, pigeons, ducks, geese, swans, turkeys, guinea fowl, peacocks, rabbits, guinea pigs, all and every one of the dwellers of our roosts and pens may be stricken by the frightful sickness.

The disease is highly infectious and virulent. It is characterized by dullness, stupor, brownish coloring of the comb and visible mucous membranes, ill smelling and profuse diarrhea. The course of the disease is rapid and unfarorable. In the space of a few hours, the animals die in the midst of horrible suffering. For many years the affection caused untold and innumerable losses. The disease appears spontaneously and in a few days causes the greatest devastation. The large and extensive poultry yards are generally the greatest sufferers, and in a very short time the most prosperous establishment is turned into a vast cemetery. The virulence of the disease is such, that one drop of blood taken from an infected fowl and injected into a healthy one causes the death of the latter in a few hours. The disease has such a rapid course, that in a few days all the animals whose blood or organs contain the microbe, perish.

As soon as a hen house, or poultry yard is infected, the healthy animals must be separated from the diseased. Deep buryial in the ground of all dead fowls, is an elementary precaution against further contagion.

For several centuries, fowl cholera filled the human race with a dread and fear equalled only by the shudder of intense horror caused by the black plague. When we read the accounts of ancient poultry raising, we are horrified to find that the dread plague mowed down the harmless fowls by the million and laid waste the finest establishments of the time.

Humanity has made wonderful strides in progress. Admirable and wonderful discoveries are made every day, and man finds new weapons wherewith to carry on the fight against the numerous enemies which surround him.

Pasteur, the wonderful genius to whom we owe so many beneficial discoveries, found and isolated the microbe of chicken cholera and intro- 
duced a successful treatment. In order to study the horrible microbe, the illustrious professor made a "bouillon" with the muscular tissue of a hen and water. He dropped in it a drop of blood taken from a diseased living fowl. He left the whole exposed to the surrounding air for a period of time depending on the noctivity of the virus he wished to obtain. After six or seren months he thus obtained a virus to such an extent attenuated that by inoceulating or vaccinating with this product, he was able to cause a mild form of the disease which generally immunized the fowls against the deadly infection.

Fowl cholera is thus no longer a cause of dread and horror, and we may look with confidence to the future.

Under the influence of the pasteurian treatment the incipient diarrhea is arrested, torpor disappears and life seems to return. The improvement is persistent and lasting. After a short time, the animals run around, scratch and pick; the comb resumes its shape and color; the eye is bright; the animals become lively again and are heard once more; they cackle and crow, they hunt their food with a renewal of vigor and life. There is a complete and sure return to a condition of perfect health.

It has been recommended to give those animals which are not infected, plenty of green food, and grape marc when in season.

The manure should be carted away, and the poultry house or pen properly cleaned and washed with a solution of one per thousand of sulphuric acid, which kills the bacillus. The animals may be brought together again:

1 If the isolation has been sufficient.

2 If there are no more diseased birds.

3 If the hens and poultry in general are kept separate from the other animals on the farm.

To protect their birds and animals against those two most deadly plagues, cholera and anthrax, breeders should have their fowls vaccinated with the Pasteur refractory bouillon.

Diseases of poultry are nearly always the result of bad food, filth in the drinking water, or infection of the ground and houses; consequently the best and most successful remedies are, good food, water renewed daily and kept fresh and clean, and in general proper attention to cleanliness of the poultry house and pen.

J. Willems. 


\title{
PRESENT CONDITION OF EXPERIMENTAL WORK IN FEEDING
}

\author{
BY R. R. SLOCUM
}

In order to understand clearly the status of the experimental feeding work done in this country up to the present time, it is necessary to call to mind the evolution of the poultry departments of the colleges and experiment stations. Activities along this line even at those stations which have the oldest reputation for poultry work are comparatively recent. The beginning of these poultry departments was modest, consisting in most cases, of a few fowls housed in make-shift sheds equipped and cared for with implements and apparatus which found their way to the poultry department only because every other department had discarded them as worthless.

Along with this meager equipment, went in nearly every instance, very small appropriations for carrying on the work. This made it necessary for the poultry to be wholly or in large part, self-supporting. At the same time, as it became known through the respective states that poultry work had been started at the experiment stations, the need was felt of publishing the results of some experimental researches to meet the demand for information. Feeding problems lent themselves readily to fill this need. They could be conducted with equipment but little additional to that needed to keep the fowls under other than experimental conditions; the egg production was not in most cases seriously affected, and the fowls still continued therefore to be self-supporting or nearly so; information along feeding lines was usually greatly sought after and investigations of this nature were consequently popular; results which could be published were obtained in a comparatively short period of time while the technique of the experimental work was not particularly burdensome or time-consuming. More feeding tests than anything else thus came to be undertaken in the earliest work done and many tests of this nature, though more elaborate, have continued to be carried on up to the present time.

The object of the feeding experiments may be said in general to have been one of the following - a comparison of methods of feeding, a comparison of some particular feed or feeds, or a determination of digestive coefficients for poultry. 


\section{Nethod of Procedure}

The general method of procedure in these feeding trials has been as follows: Two or more lots of fowls were selected, some attention being given to equalizing the lots as far as age, condition, etc., were concerned. The different lots were then fed in various ways in accordance with the plan of the experiment and records were kept of the performance, feed, condition, mortality, etc. A fixed unit of time has not been used in all cases, but usually the tests were carried through one year. At the end of the time or as soon as convenient, the records were figured up, summarized, comparisons made, and an account of the experiment and such conclusion, as could be drawn from it, was published.

\section{Comparison of Methods}

A large number of the feeding tests fall under this head. Comparisons were made with a number of objects in view. For example, we find comparisons in which the adaptability of methods of feeding, such as, morning versus evening mash, were made to determine the best way to feed under ordinary conditions and when the general condition of the flock was taken into consideration. In many other cases, the comparisons while concerned with health and vigor were made principally, for determining the effects of the methods on egg yield. Other comparisons of methods have been made for the purpose of determining the best system of feeding for fattening, for growing young stock and for producing broilers. In obtaining data along these lines, records were incidentally and in many cases purposely kept showing the cost of feeding hens, the cost of producing eggs and flesh, and the number of eggs laid by a hen under various conditions.

\section{Comparison of Feeds}

In the feeding tests falling under this head, the first group may be considered as that in which some one particular grain or feed stuff was compared with some other one grain or feed stuff. We find for instance wheat compared with corn, skim milk with meat scrap, clover with cabbage and many others. We find also in this group, certain feeds tested for their stimulating effect on egg yield, as salt, pepper, etc., or for their harmful effect upon the health of the flock, as cottonseed meal. In fattening fowls we find tallow used to determine its effect on weight and on the appearance and finish of the fowls.

We find also tests carried on in which certain combinations of feeds are compared. The most common of such tests is the comparison of the 
effect of carbonaceous and nitrogenous rations on egg yield, fattening and the general health of the fowls. Another test of the same nature is the comparison of a ration rich in vegetable protein with another equally rich in animal protein. Proprietary feeds also have been given considerable attention.

\section{Digestion Experiments}

Few experiments have been carried on with the object of determining the digestion coefficients of feed stuffs for poultry. One of the chief reasons for this is the fact that such experiments are difficult because an operation on the birds is necessary in order to separate the feces and the excreta of the kidneys, which are normally voided together, in order to make analyses of each separately. Other difficulties were the lack of suitable equipment and the need of chemical assistance. It is just possible also that poultrymen have not realized fully the importance and necessity of such work.

As a result of a lack of work of this character, our present feeding standards for poultry are at best rather inexact. It is necessary in figuring poultry rations to use the digestion coefficients established for other classes of animals. This information is fundamental and before any exact feeding tests can be carried on, it must be obtained.

\section{Criticisu of Feeding Work}

The feeding experiments which have been carried on in the past have, in a majority of cases, been open in one or more particulars, to criticism of a rather severe nature. Perhaps the most common weakness has been the failure to recognize the importance of individual variation. As a result conclusions have been drawn from comparisons in egg yield of pens composed of only a few fowls. In using these small numbers it is quite possible that the difference in egg yield has been the result not of the method of feeding or of the feed but of the unequal division of individuals producing either above or below the average. As the numbers used are increased the chance of such unequal distribution of individuals is diminished and the more nearly comparable are the two lots of fowls. Also the use of fowls of unknown history may have been a source of considerable inaccuracy.

Probably the second greatest criticism is the lack of repetition or the use of an insufficient number of pens. A feeding experiment carried only through a single year, or with only one lot of fowls may be affected by climate or other factors which are not readily recognized and which materially change the results. Under these conditions, the results are of 
course attributed to the feed or method of feeding and may lead to considerable inaccuracy. Feeding experiments should be repeated two or three times with the same pens, and with different pens, if possible, in order to be sure of the grounds on which conclusions are drawn. With the acquisition of larger funds and of better equipment for poultry work, there is coming a greater realization of the influence of the factors named, so that the tendency at the present time is to repeat feeding trials and to use a greater number of individuals in the pens compared.

\section{Future Feeding Work}

From what has been said it is apparent that the most urgent need along this line is the determination of digestion coefficients. The equipment for such work is rather expensive and its execution will require considerable patience and skill. The results first obtained may not be suitable for immediate application to practical problems and will scarcely make interesting reading for the majority of poultrymen; but eventually they will be of great value and will move poultry feeding further toward an exact science than it is at the present time. In the meantime, feeding experiments of the same general nature as those of previous years, will yield useful results while many local feeding problems, particularly in regard to the suitability of local products and new feeds for poultry, will constantly arise and require solution. There is at present a tendency to feel that in poultry feeding rations must contain many and rather expensive feed stuffs even though they have to be shipped into that particular section of the country. Probably this is true if maximum egg production or maximum gains are to be obtained, but with the present universally high prices of feeds, it is questionable whether simpler and cheaper rations will not produce eggs and flesh more economically. Feeding tests with this end in view may well be undertaken. 


\title{
FEEDING COLOR-AN AID IN STUDYING PHYSIOLOGICAL DEVELOPMENT ${ }^{1}$
}

\author{
BY C. A. ROGERS
}

The coloring of animal tissues with Sudan III was known as early as 1896 by an Italian Scientist, Daddi. Dr. Oscar Riddle of Chicago University was one of the first to continue with color work. It was through the incentive of an address by him before the zoological meeting at Chicago, $1907-8$, that the feeding of color dyes was begun at Cornell University. Dr. Gage, Professor of Histology and Embryology, with the Department of Poultry Husbandry in co-operation, started several experiments of feeding Sudan III to hens. ${ }^{2}$ The work has since been continued by the writer, using other dyes in addition to Sudan III.

\section{The Nature and Action of the Dres}

Sudan III is a common aniline dye, a compound from Amidoazobenzene and B.-Napthol. It is soluble in alcohol, ether, benzene, petroleum, ether, oils and fats. When fed to fowls it apparently colors the fat deposits only.

In the experiments with Sudan III, $25 \mathrm{mg}$. of the dye were fed to a mature fowl each day. Although smaller amounts produced color, this was not sufficiently intense. Larger amounts may be fed without injuring the fowl. Dr. Riddle has shown, however, that excessive amounts produce fault-bars in the growing feathers of Barred Plymouth Rocks. ${ }^{3}$

Another aniline dye that produces striking results is Rhodamine Red. It is fed to a mature fowl in doses of $100 \mathrm{mg}$. each day. It colors the body muscles, the feathers which are being grown when the dye is in the blood, and the shell and albumen of the egg.

It should be borne in mind that Sudan III colors the yolk of the egg only, while Rhodamine Red colors the albumen strongly and the yolk slightly.

The other dyes used were Auramine Yellow and Saffranine Red. These, as far as the work progressed seemed to act in much the same way as the Rhodamine Red.

There have been no injurious results noticed except in one instance. The fowl fed Auramine Yellow steadily lost in weight, but regained weight

\footnotetext{
${ }^{1}$ Reprinted from the Cornell Countryman.

${ }^{2}$ Science 1908, N. S., Vol. XXVIII, No. 719 , p. 494, "Sudan III Deposited in the Egg and Transmitted to the Chick."

${ }^{3}$ Biological Bul. No. 6, May, 1908, Vol. XIV, "The Genesis of Fault Bars in Feathers and the Cause of Alternation of Light and Dark Fundamental Bars."
} 
as soon as the dye was witheld. Whereas the fowl fed Saffranine Red steadily put on weight as long as the dye was given.

\section{The EgG}

The eggs from the fowls fed Sudan III had as before stated, yolks of a bright red color (Plate I, C). The density of this color, however, varied with the amounts fed and the frequency of the feedings. Daily feeds produced concentric layers of red alternating with yellow yolk. Even with the dye in all the food given no uniformly colored yolks were produced. The eggs laid soon after the first feeding of dye were banded near the outer part only. These two facts show that the yolk is built up by successive layers of fat deposited on the surface of the material already present and is not made by any intermingling of materials deposited at different times.

When the color was fed at stated intervals, the rate of growth within the yolk was obtained. It is not only possible, in this way, to calculate the number of days required to completely develop the yolk, but also to study the relative amount of material added during the stages of its formation. We find that the deposition of yolk material is very slow at first but exceedingly rapid later, the outer bands being much broader as well as greater in circumference. With a particular fowl observed it required fourteen days for the yolk to be fully formed. This observation was taken during the heavy laying season.

It was apparent that the color bands were much thinner than the yellow bands of yolk when the dye was fed daily. This would indicate that the colored food from each feeding remained in the blood less than one-half day -about eight hours, according to the relative thickness of the bands. Even when all of the food was colored, the yolk deposits varied in density of color. An explanation of this condition might be that the rate of deposition of the fat and albumen vary during the day and night and that while one is being deposited heavily, the other is less abundant.

The germ disc, albuminous center and connecting tube were left uncolored, showing that either they contain little or no fat or were a part of the ovary before the dye was fed. Plate I, C indicates the position of the white yolk center, the germinal disc and the white connecting tube. It can be observed also that the yolk layers do not break evenly at the tube but have an upward bend toward the germinal disc.

The Rhodamine Red dye colors principally the albumen of the egg. There is not enough protein in the yolk to make the color show very distinctly in contrast to the yellow. The albumen is colored uniformly throughout Plate I, A, but the density of the color often varies from day to 

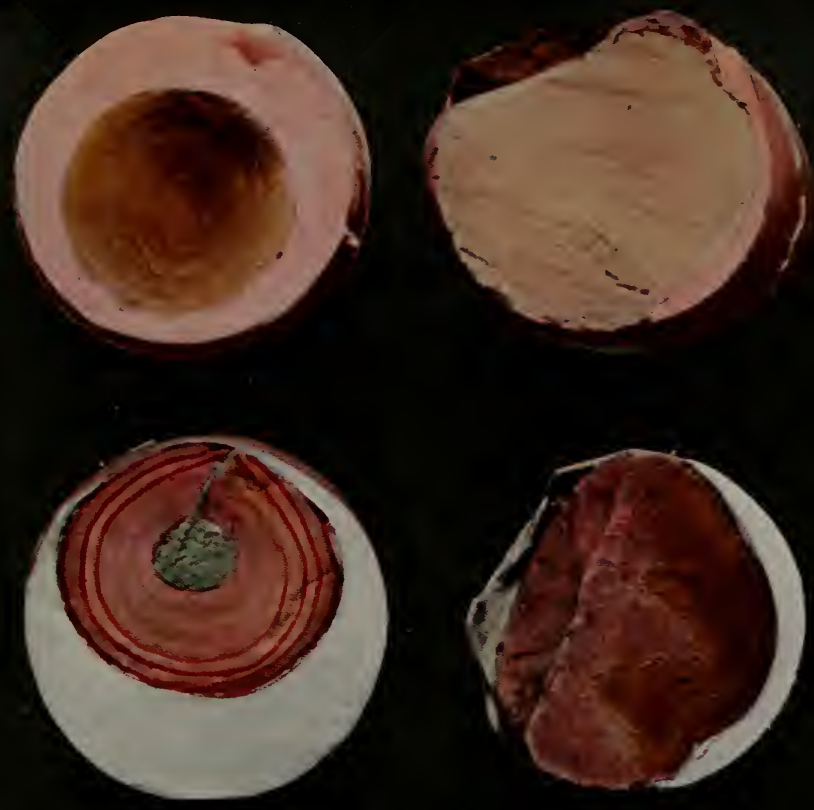

D
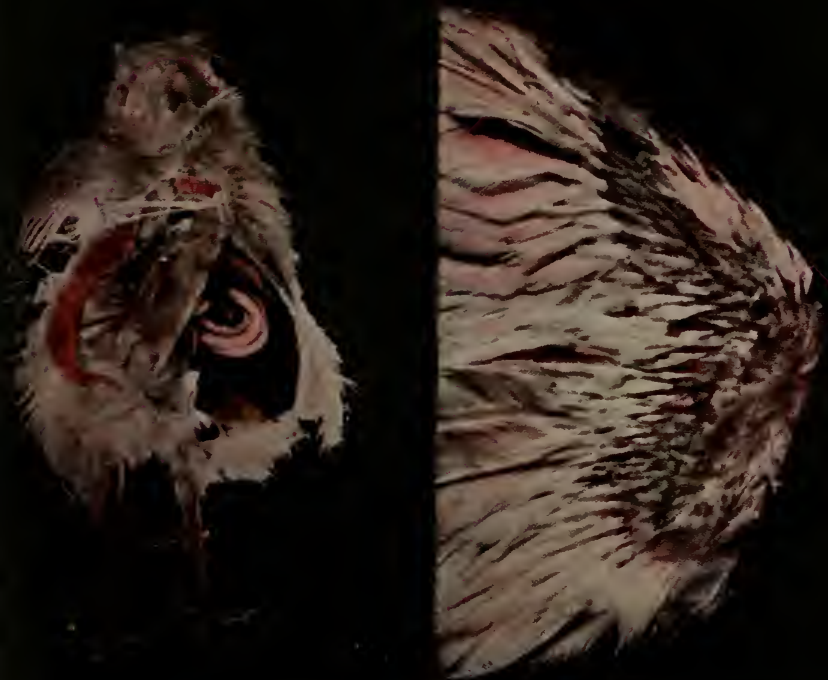

day, depending apparently, upon the state of development of the egg when the dye is fed.

After two days of incubation the fertile eggs colored with Sudan III undergo a change. The outer bands of color break up and intermingle with the yellow bands of the yolk. By the fifth day of incubation, the yolk is quite well mixed so that only a faint resemblance of the banded condition remains. By this time, also, the albumen near the developing embryo has turned pink. The bulk of the albumen, however, is still white. (Plate I, D). Upon boiling the egg, which is necessary in order to make this study the white albumen becomes quite like rubber, while the pink albumen remains very soft; in fact, on the third and fourth, and often on the fifth day of incubation it is impossible to coagulate the pink albumen by boiling. The amount of pink albumen upon which, to all appearances, the embryo directly feeds, remains quite constant. The white albumen gradually decreases until entirely softened and consumed.

The presence of color in the albumen leads one to suspect fat, since Sudan III colors fat only. Analysis does show its presence in a large percentage.

Analyses of the Yolk and Albumen of Fresh and Incubated Eggs

\begin{tabular}{|c|c|c|c|c|}
\hline & & $\begin{array}{l}\text { \%o Protein in } \\
\text { Dry Matter }\end{array}$ & $\begin{array}{l}\text { \% Fat in } \\
\text { Dry Matter }\end{array}$ & $\%$ Moisture \\
\hline \multicolumn{2}{|c|}{ 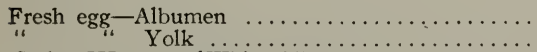 } & $\begin{array}{l}84.5 \\
29.43\end{array}$ & $\begin{array}{r}0.52 \\
65.21\end{array}$ & $\begin{array}{l}90.23 \\
43.67\end{array}$ \\
\hline 'Sudan III & White Albumen $\ldots \ldots \ldots \ldots$ & 86.75 & 0.25 & 69.54 \\
\hline egg incubated & Pink " & 26.31 & 65.50 & $95 \cdot 3^{+}$ \\
\hline five days & Yolk ........ . & 30.44 & 65.67 & 57.50 \\
\hline 'Sudan IIII & White Albumen & 89.19 & 0.17 & 62.03 \\
\hline egg incubated & Pink " & 25.06 & $69.7 \mathrm{I}$ & 76.36 \\
\hline twelve days & |Yolk & 29.87 & 65.24 & $5 \mathrm{I} \cdot 3 \mathrm{I}$ \\
\hline \multicolumn{2}{|c|}{ Day old chick yolk $\ldots \ldots \ldots \ldots \ldots \ldots \ldots \ldots \ldots$} & 48.50 & 43.10 & 47.00 \\
\hline
\end{tabular}

4(Nore-The analytical work was done by Mr. L. J. Cross of the Department of Agricultural Chemistry at Cornell University.

We have already seen in the concentric layers of Sudan III colored yolk, that Sudan III does not stain previous deposits into which there is no circulation or communication. Now, since this albumen is white before being influenced by incubation, how can its fat be colored unless circulation between it and the yolk is begun when the egg is incubated? Also the facts that there still remains after twelve days of incubation practically as much fat as in the fresh yolk and that the yolk still has the same approximate size and moisture content, tend to indicate that the fat in the albumen does not come wholly or even in small part from the yolk itself. The natural explanation of this unexpected condition is that 
the fat is made from the protein in the albumen. Attention is also called to the presence of the small amount of protein in the albumen fed upon by the embryo. This leads us to question whether the bulk of nourishment provided for the embryo is in the form of protein or fat.

An opposite result pointing to the same conclusion occurs when incubating the Rhodamine Red colored eggs. In this instance the soft albumen no longer retains the pink color of the fresh egg but becomes a light yellow, resembling the yolk in appearance, but being fine grained. (Plate I, B). As the colored protein is changed under the influence of incubation it loses its color entirely.

The infertile egg does not change in color or composition. The bands of color in the yolk remain as in the fresh egg even after five days of incubation.

\section{The Chick}

The feeding of these dyes does not impair the hatching power of the eggs. The chicks hatched from Sudan III colored eggs were colored wherever their bodies contained fat, especially along the breast and abdomen, just underneath the skin. (Plate I, E). The yolk in the day old chick still contained color, indicating that some fat remained. In one chick, twenty-four hours old, the coloring of the yolk was concentrated around the outer portion of the yolk sac where it could be most easily digested and assimilated. ${ }^{5}$ Analysis showed that there was a large percentage of fat remaining. Except for a slight increase in the percentage of protein and a decrease in the percentage of fat, the proportion of each remains about constant while the yolk is being absorbed. The moisture content, also, remains practically constant.

Upon withholding food from Sudan III colored chicks till four days of age the fat tissues in the body were used up in developing energy and heat. Consequently, the color passed away and was lost.

Since the color leaves the albumen of the Rhodamine Red colored egg when it is digested for the use of the embryo, one does not expect to see color appear conspicuously in the chick. This is true except for a very slight tint of pink, which shows in the down.

\section{The Flesh}

Sudan III was also fed to fattening fowls. The exact extent and amount of the fat deposits was shown by the pink color. The color did not show up

"Frank R. Lillie explains in "The Development of the Chick" page 225 the feasibility of the contents of the unabsorbed yolk in the day old chick being digested and assimilated by a special glandular and absorbing epithelium surrounding the yolk sac. 
in layers as in the egg, but one large dose served to color all previous deposits of fat presumably because of the circulation within the fat tissues.

The same condition was true with Rhodamine Red. It colored all of muscle tissues a bright pink whether deposited before or during the time of feeding.

\section{The Feather}

After noting the appearance of the pink tint in the chick down, the dye was fed daily to young chicks just growing their first feathers. The result was a decided flesh pink color in the plumage. The red did not stain those parts of the feather already grown but only that portion grown while Rhodamine Red was being given. When the chickens were about four weeks old the dye was withheld for seven days. After this the new feather growth showed no color until the dye was again fed. The result was a reappearance of color at the base of the growing feather. A broad white band, indicating the growth for the days during which the dye was withheld, separated the two areas of color. It also shows by the unevenness of the white band, that different feathers have different rates of growth. (Plate I, F.)

When fed to mature fowls while molting, the new feathers were tinted with pink, varying in density with the amount and regularity of the color feeding.

The work here described is but the beginning of this study. It is hoped, however, that it may serve to illustrate the numerous and varied fields in which color dyes can be employed in the study of physiological development. 


\title{
POULTRY HOUSE CONSTRUCTION AND ITS INFLUENCE ON THE PROGENY OF THE DOMESTIC FOWL'
}

\author{
BY L. C. OPPERMAN
}

Comparisons of different types of Poultry Houses were made at the Maryland Agricultural Experimental Station during 1907 and 1908. Six styles of pens were used: 1. Tight house; 2. Glass front; 3. Cloth front hooded roost; 4. Open front hooded roost; 5 . Cloth front without hooded roost and; 6. Open front without hooded roost.

It is evident from the results of these comparisons that the influence of the type of construction of the Poultry House is not very noticeable during the pullet year of the first generation. Greater differences were noticed between the hatching power of the eggs of different individuals than of different pens. The following points are to be noted.

(1) That all pens except I and III showed an increase in the number of total eggs hatched during the second year. The decrease in pens $I$ and III is not great enough to be of importance and is undoubtedly due to the action of individual hens' eggs.

(2) That the eggs from the fowls in pens $\mathrm{V}$ and VI produced 20 more chicks from every hundred than did those from the fowls in pen I. A result of this kind proves beyond a doubt that an abundance of fresh air, both day and night, and free access to yards or range are essential factors in the production of fertile eggs, which when incubated will hatch a high percentage of vigorous chicks.

It might be well to restate, that the cock birds which were used during the first year were used the second year also, and frequently changed from pen to pen, which would make this factor equal.

\section{The Influence on the Progeny}

The influence of construction on the vitality of the developing embryo and the progeny are the most important phases of the investigation. The success of large or small poultry farms depends largely on the vigor and productive power of the breeding stock. It is, therefore, evident that if a certain type of construction has an influence on the breeders which will tend to increase the number of total eggs hatched, and to produce strong, vigorous chicks, its commercial importance is inestimable.

The comparisons on this basis indicate the following points:

'This article is abstracted from Bulletin No. 146 of the Maryland Agricultural Experiment Station, College Park, Md., July, I910. 
(1) The results of hatches one and two indicate that the influence of environmental conditions were not positive enough to be of significance. The percentage of deaths to total chicks for hatch one would show that the progeny of pen I (tight house) were stronger than those of any other pen. While the above statement may be correct, mention should be made of the fact that the offspring from the six experimental houses were so near alike in the matter of vitality, that it was impossible to say positively which one gave the best results.

(2) That for hatch three there is a noticeable variation in favor of pen 6. It is also apparent, with the exception of pens I and VI, that the mortality was greater than in the previous broods. This increased death rate was due to the intense hot weather, and to placing this hatch in yards which had been used by a previous lot of chicks. These disadvantages, however, were shared alike by all pens.

The variations as mentioned above cannot be associated with the environmental conditions. This point is made clear by comparing the percentage of deaths in hatch two with those of the following hatch. Such a comparison would show that the death rate for pen $I$ in hatch three was identical to that of hatch two. This would indicate that the chicks of this pen were fully as vigorous as were those of pen VI. Even granting that they were not, their percentage of deaths is so much less than that of the chicks from the other fresh-air houses that it is impossible to charge the results of this hatch to housing conditions.

In order to determine, with some degree of certainty, the influence of construction on the offspring of pullets of the first generation, the conditions under which the parent stock are confined would have to be of a more extreme nature than was the case in this experiment.

\section{The Influence on the Progeny During the Second Year}

The important points to be noted in the brooding record of the second year are:

(1) That the progeny of pen VI were more vigorous than those of any other pen.

(2) That the offspring from the tight house were fully as resistant as those of any pen except VI. This would indicate that the parent stock were still vigorous in spite of their abnormal housing conditions. All results point to the fact that the most desirable conditions for maintaining the vigor and productive power of the breeding stock are those found in the open-front house with exposed roost. It cannot be too strongly emphasized, that fresh air and freedom for the breeding stock are very essential if the poultryman is to renew his flock successfully. 


\section{Summary}

The following conclusions are a summary of the data obtained from the work with the first generation. The experiment is in progress at the present time, and will be continued for several generations. Future results will be published from time to time as the work is completed.

(1) The cost of tight double-walled construction is greater than that of any other type. In the experiment here discussed it was found that the fertility and hatching quality of eggs were very much better in fresh-air houses of less expensive construction.

(2) The fertility and hatching quality of eggs is much better in the open and cloth-front houses, where the fowls are allowed free access to yards or range.

(3) The progeny of fowls in fresh-air houses, having free access to yards or range, are more vigorous than those of the fowls which are maintained in houses of other construction, and which do not have the liberty of the yards during the breeding season. 


\section{SOME RECENT EXPERIMENTS IN INCLBATION}

BY JAMES DRYDEN

There are evidently some fundamental differences between natural and artificial incubation.

Believing that the hen held the secret of incubation, our first work was to investigate the hen to discover, if possible, the fundamental differences.

When we began incubation work, the theory was widely prevalent, that the failure of incubators to hatch satisfactorily was due to improper ventilation in the machine. About that time a poultryman in Massachusetts wrote me a letter in which he discussed this point and gave it as his opinion, that an excessive amount of carbonic acid gas in the incubators was responsible for poor results in hatching. He thought better ventilation was needed to carry off the carbonic acid gas. He further stated that where incubators were used for hatching chicks, he knew of no poultry farms in his section of the country that had been successful for more than three years in succession.

We set about investigating this point. This was at the Utah Station. The first thing to do was to find out how much carbonic acid gas accumulated under sitting hens and in incubators during incubation. After the chemist had made a long series of tests, it was discovered that instead of there being an injurious amount of carbonic acid gas in the incubators, there was actually less than was found under sitting hens. This started a new line of investigation. Is there less ventilation under the hen than in the incubator; and is carbonic acid gas a benefit instead of an injury? What is the function, if any, of carbonic acid gas in incubation?

It was demonstrated in the first experiment that carbon dioxide with moisture will decompose the egg shell. Eggs emptied of their contents and sealed up in bottles highly charged with carbon dioxide were kept moist in the incubator, throughout the incubation period. When taken out they were either broken down or readily crumbled to pieces between the fingers. Other eggs under the same conditions, but without any moisture in the bottles, showed no signs of disintegration, the shells being apparently unchanged. They were hard to cut with a pen knife. Another egg emptied of its contents, filled with water and sealed up in a bottle, but with no water in the bottle, was decomposed and dissolved.

The conclusion is that carbon dioxide will weaken or decompose the shell when it comes in contact with water, either on the outside or inside of the shell. It looks as though carbonic acid gas has an important function to 
perform. Is it the hand that liberates the captive chick? Does it break down the prison walls and give life and liberty to the prisoner?

The experiments at the Guelph Station corroborate the Utah tests, showing more carbon dioxide under the hens than in incubators.

The next point to determine was where the excess gas originated. Both at Utah and at Guelph, the experiments seemed to indicate that the excess supply came from the hen herself, though this point was not clearly demonstrated. Apparently the hen was giving off carbon dioxide. Is this the secret of the sitting hen? Is this the missing link?

Following up this lead, we endeavored to show the effect of adding carbon dioxide to the incubators. Varying amounts were added to different machines, but this artificial supply seemed to injure the hatching. Here was a little set-back.

Pursuing this work along another line, the experiments at the Guelph Station showed that the chicks hatched by hens contained more lime than incubator chicks. They showed further that about the eleventh day of incubation, (or when the embryo was eleven days old), there was as much lime in the embryo as there was originally in the contents of the egg, and at the end of the incubation period of twenty-one days the chicks contained many times more lime than was originally in the egg contents. Remembering the Utah tests which showed that carbon dioxide with moisture decomposed the shell, is it possible that while weakening the shell to allow the chick to make its escape, it at the same time liberates the necessary lime for the body of the growing chick? This fact was determined by analysis of the chicks.

Now a German experimenter has analyzed the shell at different stages of incubation, and concludes that the shell is more than a simple protective device. He says: "The egg shell doubtless shares in the exchange of material of the egg contents during the incubation of the chick. The material which disappears from the shell doubtless passes into the interior of the egg. As to what way this "going in" (Absorption) takes place, and what chemical changes render this possible; our investigations offer no explanation. But he intimates the possibility of carbon dioxide abundantly produced in the egg, and penetrating through the shell playing an important part here.

These different experiments show:

First-That there is more carbon dioxide under sitting hens than in incubators.

Second-That carbon dioxide with moisture decomposes the shell.

Third-That lime disappears from the shell during incubation. 
Fourth-That the chick when it emerges from the shell, has more lime in its body than was originally in the contents of the egg.

Fifth-That the hen-hatched chick has more lime than the incubator chick.

Sixth-That supplying artificial carbon dioxide to incubators apparently injures the hatch.

Another point of difference, possibly of great importance, was brought out in recent experiments at the Oregon Station. Chemical determinations showed the presence of oil on egg shells. A small amount was found on fresh eggs. About the same amount was found on eggs that had been incubated artificially for two weeks, while on eggs incubated by the hen for two weeks there was about seven or eight times the amount of oil. What is the function of this oil? Does it hold the secret of sitting hens? We have not been able to determine what part this oil plays in incubation, owing to difficulties in applying oil artificially. We have found further that by taking eggs from under a sitting hen and putting them in an incubator, the oil on the shell disappears in large part.

Let me mention another point where incubators and hens differ. Eight or nine years ago in the Utah Station, we found by weighing a great many eggs at stated periods during incubation, that the incubator eggs lost more weight than eggs under the hen; in other words, incubators dried the eggs more than did the hen. This, I believe, was later confirmed by the Guelph Station. The West Virginia Station reported some results that were contradictory. However, at the Oregon Station it was found that there was a greater loss in incubators than under hens.

This fact led to experiments on the use of moisture in incubators, and as a result, most incubator makers have modified their directions as to moisture. By adding moisture to the machine the evaporation of the eggs was checked and by checking the evaporation with moisture, it was found that the chicks, when hatched, had greater weight.

Now about the oil that the hen puts on the egg. Oil on the shell will check evaporation. It may serve the purpose of moisture so far as evaporation is concerned. This no doubt explains why eggs under hens lose less weight than incubator eggs.

This raises another question. At Guelph there was found what was claimed to be conclusive evidence that there is a greater circulation of air under the sitting hen than in the incubator, but the fact that there was less evaporation from eggs under the hen, could hardly be reconciled with the fact that there was greater air circulation under the hen. It seems to me that the presence of oil explains this point. The hen gives plenty of ventilation and the oil prevents too great evaporation; but the oil may have other important functions about which as yet, we know nothing. 


\section{COMPARISON OF POULTRY-KEEPING IN EUROPE, UNITED STATES AND CANADA}

BY WIL BROWN

Hcad of Department of Poultry Husbandry, West of Scotland Agricultural College; Secretary Departmental Committee on Poultry Breeding in Scotland (1908-9)

All history points to the fact that progress is more rapid in new countries or states than in old whether this be in the direction of commercial enterprise or along other lines.

In comparing the present status of the industry of poultry husbandry in Europe, United States and Canada, in the space at my disposal, it is possible to discuss the subject only in generalities, since to go into detail would necessitate a thorough and complete survey of the whole industry. I want, however, not only to point out the general differences in the method employed, but at the same time to indicate how these differences have arisen and to show that this branch of the great agricultural art is subject to the same laws that regulate the development of any other industry or work.

The real substantial cause for the differences in the methods adopted is summed up in the words "old versus new countries." The conditions prevailing in the Eastern States of America differ from those prevailing in the Western, in that the farms are older, and more general in their croppage. This difference in condition is still more marked between the Eastern States of America and Europe.

The industry of poultry-keeping is centuries old in Europe, more especially in some countries, such as France, Belgium and the United Kingdom and it may be said that the most important factor in the development and advancement of the work has been evolved by a more general distribution among a multitude of producers, the majority of whom are small occupiers of land. Poultry-keeping has been and always will be, as far as one is able to judge at present, a side issue in Europe, except in a few instances as found in France, Belgium and parts of England, where it is in the hands of specialists. This exception is found only in one branch of the work, namely, that of flesh production, but this is only a small proportion of the total poultry production of each country.

With people already on the land, and making their livelihood from the crops they cultivate, progress has been made in poultry-keeping by considering it in the light of an added form of production. Farmers and small holders have been the mainstay in the past and all our endeavors today are 
in the direction of increasing production under these conditions. I hold that farmers will always be able to produce more cheaply than occupiers of special plants. The ideal is to encourage a hundred farmers or small holders to maintain fifty head of stock apiece upon their land, rather than for one worker to keep five thousand. I would remind you that it is the accumulated production of millions of peasants that feeds the great populations of Europe and were we dependent on poultry farms we should starve.

As an indication of the truth of this statement I may mention the fact that Russia is the largest exporting country of eggs and poultry in the world, and that production in her case is entirely in the hands of the peasants. In 1911 Russia exported to Britain poultry produce to the value of $\$ 18,213,258.40$ in addition to the other markets that she supplied.

Large poultry farms have been tried in Europe, but have failed, and this explains why intensification of culture and large plants are ever less in evidence on this side. Not only have such farms proved a failure in Europe, but $I$ have yet to hear of the financial success of any farm in the United States or Canada, run entirely for the production of eggs or flesh for consumption. In every case some other branch is introduced, such as the sale of eggs for hatching, day-old chickens or stock birds. A review of the balance sheets generally shows that the greater part of the profit is derived from these additional sales.

In my work today I use all my influence to prevent the establishment of poultry farms, since I am distinctly skeptical as to the ultimate success of such ventures.

I have given it as my opinion that the future success of the industry in Europe, depends on the rate of increased production on the part of the farmers and small holders, and I would go still farther and say that I believe the same holds good for America and Canada. This can be seen even at the present time in the altered conditions of farming. In the Eastern States general agriculture is taking the place of more specialized cropping as instanced by the northern movement of the wheat belt. This is passing from Minnesota and Dakota into Manitoba and Saskatchewan, and will, if present indications prove correct, eventually travel westward until Alberta and even the Peace River country to the north become the granary of the world. As the farms become more general in their rotation of crops, the industry of poultry-keeping will be developed side by side with other branches of the work.

Any development that has taken place in Europe has been by evolution and is seen in greater numbers and better methods on existing farms, and, 
moreover, any further advancement must, in my opinion, be brought about in a similar way. Much has already been accomplished in this direction, since the Danish and Irish poultry industries have both been built up by the farmers and small holders already in occupation of the land, and followed as a supplementary and not a primary branch of their farm operations.

I have frequently been concerned with the fact that greater provision is made by the Federal and state authorities in America and Canada, for the carrying out of experimental and research work, than is the case in Europe. I may state that practically nothing from public sources is spent on this side and that the industry is bound to suffer on this account. There is one explanation, however, that occurs to me in this connection and it is that there is less need for research work in Europe, since it is the specialist who requires this first of all, and it is only when methods of culture become intensified that the real need arises for the solving of the many problems that result therefrom. I do not mean to infer that the farmer poultrykeeper has no need for this knowledge, which is the outcome of experimental and research work, but only that his need is less great.

I would have you remember that there has always been large production in Europe, and therefore any increase will be brought about slowly and only as the result of considerable labor. Owing directly to this fact we have found that the first work to be performed lay in the direction of organization in marketing. Whenever one is dealing with the accumulated produce from a large number of producers this work must always take precedence. How this has been accomplished I want to explain briefly, using Denmark and Ireland as illustrations. It is only necessary to deal briefly with the past development of the industry in these countries, since a mass of detail with reference to the general management is out of the province of this paper.

\section{DenMark}

Denmark, with its population of nearly $2,500,000$ people, more than half of whom are connected with agricultural pursuits, is a country of small farms, the majority of the holdings being not more than 50 acres in extent. The importance of the industry to the country is indicated by its universality. Poultry is seen everywhere.

The winter climate conditions are unfavorable over the greater part of the country, and labor is scarce, being provided by the members of the family without outside aid, therefore the number of birds maintained on the land is not so great as might be expected. The great majority of farmers do not keep more than 30-50 laying hens and the number of fowls to the acre is small. 
Prior to 1878 when the Danish Poultry Society was formed, the poultry produce was usually bartered for groceries at the village store and the prices were small, two eggs being sold for a cent in the summer and two for five cents in the winter. The primary object of the Danish Poultry Society was to improve the breed of poultry kept, since the Land hen, the native breed of the country, proved unsuitable for the work of increasing egg production. The first exhibition held under the auspices of this Society was at Aarhus, Gutland, in 1879.

This native breed might have been made useful by breeding from selected specimens, but it was thought that results would be obtained more rapidly and easily, by the adoption of a race of higher fecundity. Ultimately the Italian or Leghorn was accepted as best suited to the country.

From 1878 onward the growth of the industry was rapid. Distance from the profitable market-namely, Britain, since, with the exception of Copenhagen, there are no large centres of population in Denmark-made it an essential part of the work to organize the whole system of marketing. It was not until 1894 , however, that the question was taken up in a practical manner, and the Danish Farmers' Co-operative Egg Export Association was formed. To the work of this Society may be attributed the enormous development of the Danish egg trade.

It is estimated that the total poultry crop of the country is in value about $\$ 14,400,000$, annually, or some $\$ 5.75$ per head of the population. Of this total, produce to the value of $\$ 7,200,000$ is exported at present, of which about $99 \%$ is shipped to Britain. Prices have risen from $\$ 1.50$ per 120 eggs in 1890 to $\$ 2.44$ in 1911 .

\section{IRELAND}

The development of the Irish poultry industry is of more recent date than in Denmark, since a commencement was made only some twenty-five years ago. The history of the progress in this instance is even more interesting than in the case cited above. This, too, is a demonstration of the universal keeping of fowls on the farms or small holdings of the country.

It has been estimated that in $\mathbf{1 8 8 7}$ the total export value of eggs and flesh from Ireland amounted to $\$ 7,744,000$ and by 1909 this had increased by over $\$ 10,000,000$ as shown by the total for that year, namely, $\$ 17,878,400$. The total production of the country is reckoned as follows:

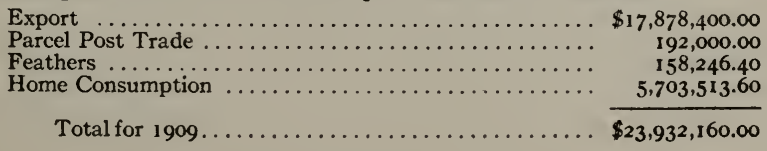


The position in Ireland at present is that the industry has not received the same attention in all parts of the country, as shown by the fact that in County Kildare (Leister) only some 729 birds are kept on the 1000 acres of cultivated land, whereas in County Armagh (Ulster) upwards of 3,300 are maintained on the same area. If the whole country develops to the same extent as County Armagh, it will mean increasing the poultry output by $100 \%$, or allowing that this is not probable in the near future, if I say that if each province came up to the standard of Ulster, with 2,558 birds to the 1,000 acres, it would have the effect of increasing the poultry production by upwards of $50 \%$.

I find that the value of the industry represents $\$ 5.34$ per head of the population, and in all probability this will be advanced to $\$ 8.00$ in the near future and perhaps to nearly $\$ 11.00$ after another decade has passed.

The remarks made concerning marketing in Denmark apply to Ireland, since the success of the work is, in a great measure, the outcome of the endeavors put forward by the Irish Agricultural Organization Society.

\section{Great Britain}

I have referred more or less at length to the present position of the industry in Denmark and Ireland, and in conclusion I desire to say just a few words relative to the state of affairs in Great Britain.

It may be stated that we are today in practically the same position as was Denmark 25 years ago. We are just at the beginning and I can only express my belief that by working along similar lines, we shall be able to develop the industry here as it has been advanced in the countries used as illustrations. With the larger centers of population in England the value of the poultry output per head is not likely ever to reach the figures for Denmark and Ireland. But there is no reason why Wales and Scotland should not take their place as producing instead of consuming countries. The present value stands at $\$ 1.30$ per head of the population.

The following figures in round numbers may prove of interest:

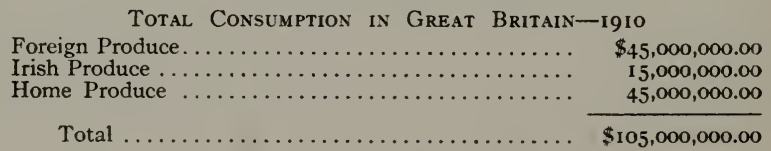

Total Consumption in Scotland-igio

Foreign and Irish $\ldots \ldots \ldots \ldots \ldots \ldots \ldots \ldots \ldots \ldots$

Home

$\$ 10,400,000.00$ $5,000,000.00$

Total $\ldots \ldots \ldots \ldots \ldots \ldots \ldots \ldots \ldots \ldots \ldots \ldots \ldots \ldots \ldots \ldots \ldots$

$\$ 15,400,000.00$ 
The marketing organization is in the hands of the English Agricultural Organization Society, The National Poultry Organization Society and the Scottish Agricultural Organization Society. Conspicuous success has attended their efforts in the past.

All that remains to be said to conclude this brief summary of the poultry industry in Europe, is that I believe the success that has been attained in the past fully justifies the contention that this industry is one that should be worked in conjunction with the general farm operations, not only so that the supplies may be sufficient to meet the demands, but that the agricultural community as a whole may be benefitted by the following of an occupation that is highly profitable. 


\section{AN OUTLINE FOR A COURSE OF STUDY IN POULTRY HUSBANDRY}

\section{PRESENTED BY JAMES E. RICE FOR TIE COMMITTEE ON INSTRUCTION}

The successful teaching of Poultry Husbandry depends upon three factors: the teacher, the method and the facilities. The greatest of these is the teacher. The chief aim of a teacher is to inspire interest on the part of the student, or, as Professor I. P. Roberts has tersely expressed it, "to get the student to want something and to want it badly;" or, as Professor T. F. Hunt expresses it, "interest is the digestive juice of successful teaching;" or, as Director L. H. Bailey has said it "telling is not teaching." Each of these successful, well-known educators has realized the same objective point in teaching and all have been eminently successful in their application of the principle. Their success and my own observation leads to the conclusion that the personality of the teacher is at least of equal and usually of greater importance than the subject matter taught.

It is the teacher's obligation not only to furnish the most reliable information, or to point out the way by which a student can secure the facts and principles on which successful poultry husbandry is based, but also to move him to want to put the acquired knowledge into effective application, to kindle within him the desire for more knowledge. This means that the teacher must arouse personal initiative on the part of the student. When a student studies diligently, persistently and enthusiastically by his own motive power, the teacher's chief purpose has been accomplished. To acquire facts and principles and to know how to apply them is important, but to acquire the ability to go after things independently and to work without being led or driven is still more important in successful teaching.

The method by which the subject is classified, simplified, emphasized and illustrated will, of necessity, play an important part. The fact that Poultry Husbandry, as a subject to be taught and investigated, is so new, and that so little has been done in arranging the known facts so that principles of general application can be made and presented in good teaching form or pedagogical order (to use a more technical term), makes it exceedingly difficult to teach the subject as it should be taught. Each one who is endeavoring to teach Poultry Husbandry is obliged to blaze out his own independent trail and to hew out the principles as best he may while endeavoring to carry on the other strenuous activities of a growing department. 
The nature and extent of the material with which to teach; that is to say, the buildings, the land, the stock and equipment, all have much to do with the effectiveness of teaching and especially with the comfort, peace of mind and satisfaction of the teacher and students. While that famous educator, Elihu Yale, undoubtedly was right in principle when he said that "a good teacher on one end of a log and a good student on the other constitutes a University," he also very likely, fully recognized the importance of adequate buildings and equipments, but desired to emphasize the fact that they are not the chief consideration.

We, who are now engaged in teaching Poultry Husbandry, are not likely to make the mistake of assuming that good land, buildings and equipment are more important than good teachers if we should have the chance to enjoy the refreshing experience of handling a Poultry Department having ample facilities with which to teach and investigate. We are willing to take our chances. We all know from experience, how serious a handicap to our teaching and investigating is the lack of suitable facilities. One item alone, that of land, deserves our thoughtful consideration and vigorous action at this time. Scarcely a Poultry Department, as now organized and equipped, has sufficient land with which to carry on the work successfully. Those in authority must be made to realize that there is a wide distinction between a poultry plant and a poultry farm and that the latter and not the former will provide the kind of object lesson that will make it necessary for us to say to our students, "do as we teach you to do, not as we do ourselves." We must have more positive teaching and less negative teaching; more showing how to do and less telling what to do; more practice and less precept; more affirmation and less apology. Instead of one to five acres of land, a modern poultry department should have from twenty to fifty acres and a good proportion of that amount near the College buildings, where students can come in actual contact with the things about which they are being taught. The poultry farm should be looked upon as an outdoor laboratory of equal or greater importance than our lecture rooms and offices, indispensible though they are to a well organized poultry department. The things that the students do for themselves are the things that they remember. To thoroughly understand a principle the student should apply it. Success lies in the proper application of what we know. The best place for students to apply the principles taught is in connection with the lecture or demonstration.

It should not be inferred, however, that the Poultry Department can provide sufficient technical or practical training to provide expertness. Skill can be acquired only after years of practical application. The Col- 
lege, however, can and slould provide the opportunity for sufficient practice to enable the student to understand the principles involved so that he may put them into application when he has left College.

In presenting for your consideration an outline for a course of study in Poultry Husbandry, it should be understood that the Committee fully realizes the fact that no outline of subjects for lectures, laboratory work, practice courses of advanced courses will meet the requirements of all colleges or schools. A theoretically correct course of study must be varied, more or less, to meet the various existing conditions to be found wherever the subject of Poultry Husbandry is taught.

The personal experience, education and natural qualifications of the teacher; the nature and extent of the land, buildings and equipment; the time of year when the subject is taught; the amount of time that students can profitably give to the subject; the type of poultry farming in the territory from which students are drawn; the age, educational qualifications and experience of the students, all are factors that enter into a consideration of what a course in Poultry Husbandry should consist. A teacher will unconsciously emphasize those divisions of the subject with which he is most familiar or which he is best qualified to teach. One whose experience and qualifications lie in the field of breeding, judging and exhibiting fancy poultry will quite naturally be likely to lay greater stress on these phases of the subject than one whose chief attention has been given to the production of eggs or poultry for market. One who has had much experience as a salesman or bookkeeper will be likely to emphasize commercial aspects of the subject, such as marketing and accounting.

The facilities for teaching frequently determine whether or not certain important subjects shall be taught or how they shall be taught. For example, the lack of proper buildings, equipment, etc., for holding poultry shows; for fitting fowls for exhibition; for brooding; for fattening; for storage of poultry products; for killing, picking and packing poultry, etc., have been the determining factors that have decided whether much or little attention should be given to that particular branch.

A course of instruction must, of necessity, be adapted to the needs of the students. Persons taking a short course in Poultry Husbandry and having constantly in mind the immediate practical application of the principles taught and with only a limited amount of time in which to cover the subject, will enthusiastically give their whole attention to the course. Many regular four year college students desiring to specialize in Poultry Husbandry with the expectation of entering college work will want to go into the subject deeply while others, who elect Poultry Husbandry will do 
so expecting to keep only a small farm flock. Manifestly, the same course or courses cannot be made to fit the needs of each of these three classes of students. Therefore, the factors enumerated and many others must be taken into consideration in determining the scope of a course and the amount of attention that properly may be given to each division of the subject.

One feature of general application to all courses, however, is that they should be symmetrical; that is, well balanced to suit the special needs of the students to be taught, in so far as this is possible under existing conditions.

Another factor of great importance, which should be considered in blocking out a course in Poultry Husbandry, is the arrangement of the topics in a logical order of sequence, or pedagogical order. This works out satisfactorily in theory, but frequently it is impossible of execution, due to the exigencies in administration, entirely beyond the teacher's control. For example, it might be desirable, from the teaching standpoint, to arrange a course so that the students would learn the underlying principles in a progressive order, as follows: (1) The Structure of the Egg; (2) The Development of the Chick; (3) The Anatomy of Poultry; (4) The Physiology of Poultry; (5) The External Characters of Poultry; (6) The Judging of Poultry for the Fancy; (7) The Judging of Poultry for Market, etc.

Howerer, in the actual application of the principle of a logical sequence, other factors must be given full consideration in determining the order in which a subject shall be taught. It is always exceedingly important that the demonstration and handicraft work shall accompany or closely follow the lectures and text book study. If the course is to consist entirely of lectures, text book study and recitations, any arrangement of the subjects which the teacher may prefer generally is possible. However, when the subject is to be taught in part by laboratory and practice courses such disturbing factors as financial expediency, marketing facilities, climatic conditions, etc., frequently nust be taken into consideration. For example, the subject of killing, picking and packing poultry might well come near the close of a course, but a large number of chickens on hand to be killed in the fall of the year and with no room in which to house them until spring and no available funds with which to purchase stock at the prevailing high prices later in the year, may justify the teaching of the subject of preparing poultry for market early in the course. The subject of embryology should, without question, precede incubation, and both of the subjects might, with good reason, come early in a one year course, but 
the practical difficulties of teaching these subjects during the fall and winter months, as regards high cost of eggs, the production of fertile, hatchable eggs, and the difficulties of brooding the chickens, frequently are the determining factors that decide the time when that phase of the subject shall be taught. Poultry Departments, like humans, may be obliged, at times, to follow the lines of least resistance and hatch and rear chickens when they can be reared most economically and advantageously, which, in this instance, fortunately, is the time when the students would be expected, ordinarily in practice on their own farms, to rear them.

The courses here outlined consist of a lecture course and a laboratory course to be taken together; seven practice or handicraft courses which should accompany or follow the lecture and laboratory courses, and six advanced courses which should follow those already named.

It will be observed that equal importance is given to the laboratory and practice courses as compared to the lectures, text book and recitation type of teaching. This has been done because of the belief that theory and practice should go "hand in hand" and should be given in about equal proportion in the teaching of a subject like Poultry Husbandry, where success or failure depends, to so large an extent, upon the skill with which the theory is applied.

The outline of a six hour lecture and laboratory course of study, which is here presented, is intended to carry two lectures and one laboratory exercise each week throughout a college year of about thirty-six weeks. This allows for several days on which preliminary examinations may be held.

The course here presented fits very appropriately a twelve weeks course during which six lectures and three laboratory periods are held each week.

Shorter courses can be arranged satisfactorily by selecting as many of the more important topics as will best meet the requirements.

All that has been said is intended to emphasize the fact that a modern, successful course in Poultry Husbandry must, of necessity, be the result of a series of compromises and adjustments that will best meet the needs of the students and enable a Department to exist within a fixed appropriation. It is clear, however, that in arranging our courses, our constant aim should be the welfare of our students. As our work progresses we will more and more be able to eliminate financial expediency and hew closely to the line of greatest efficiency in teaching. 


\section{THE LECTURE COLRSE}

A. General Considerations.

1. Definitions and classification of the subject and place of poultry in the animal kingdom.

2. Poultry books.

$$
\text { B. Bibliography. }
$$

3. Poultry bulletins.

$$
\text { C. Anatomy and Physiology. }
$$

4. Anatomy and physiology.*

*(Recommended to be preceded or accompanied by course in histology, anatomy, physiology, digestion, etc.) the egg.

5. Anatomy and physiology. Development of the egg and study of

$$
\text { D. Breeds. }
$$

6. Origin, history and characteristics. (Asiatics and Americans.) classes.)

7. Origin, history and characteristics. (Mediterraneans and other

8. Commercial meat and egg types.

9. Selection of fowls for constitutional vigor.

10. Judging systems. (Score card, decimal and comparison.)

\section{E. Exhibition of Poultry.}

11. Methods of organization in conducting poultry shows.

12. Preparing poultry for exhibition.

$$
\text { F. Breeding.* }
$$

*(Recommended to be preceded or accompanied by a course in animal breeding.)

13. Principles of breeding, inheritance, variation, and selection for breeding.

14. Double and single mating and line-breeding.

15. In-breeding and crossing.

16. Pure breeds versus cross-breeds, mongrels, etc.

17. Building up utility strains for egg and meat production.

\section{G. Housing.*}

*(Recommended to be preceded or accompanied by a course in wood working.)

18. Locating and laying out the poultry house.

19. Materials for construction.

20. Principles of poultry house construction, size, shape, walls, roofs, floors and windows.

21. Ditto.

22. Interior arrangements.

23. Types of houses and cost of applying the principles in construction.

24. Auxiliary buildings, feed houses, fattening house, etc. 


\section{H. Feeding.*}

* (Recommended to be preceded or accompanied by a course in animal nutrition.)

25. Principles of nutrition and relation to food of the animal.

26. The foods and their composition and adaptability.

27. Balancing rations and estimating cost.

28. Rations and methods of feeding for egg production.

29. Rations and methods of feeding for egg production.

30. Rations and methods of feeding for fattening.

31. Rations and methods of feeding for growing chickens.

\section{Incubation. ${ }^{*}$}

*(Recommended to be preceded or accompanied by a course in embryology.)

32. The development of the chick.

33. Incubation, artificial and natural.

34. Incubation, artificial and natural.

35. Principles of incubation, temperature, moisture, ventilation, cooling, turning, testing, etc.

36. Principles of incubation, temperature, moisture, ventilation, cooling, turning, testing, etc.

\section{J. Brooding.}

37. Principles of brooding, temperature, ventilation, size, cost, portability, etc.

38. Principles of brooding, temperature, ventilation, size, cost, portability, etc.

39. Brooding systems, natural and artificial.

\section{K. Marketing.}

40. The man and the markets, wholesale and retail.

41. Fixing prices and securing the trade.

42. Preparing for market, killing and packing.

43. Preparing for market, grading and packing.

44. Packages, shipping and preservation.

\section{Sanitation, Parasites and Diseases.*}

* (Recommended to be preceded or accompanied by a course in economic entomology and animal pathology.)

45. Germ life and methods of disease prevention.

46. Methods of sanitation.

47. Contagious and infectious diseases.

48. Digestion and reproduction, respiration and diseases.

49. External and internal poultry parasites.

50. Poultry enemies. 


\section{Poultry Farm Management.* (11)}

*(Recommended to be preceded or accompanied by a course in farm management and farm crops.)

51. Combinations of poultry, and general and other kinds of farming.

52. Extensive versus intensive poultry farming.

53. Types of special egg farming.

54. Types of special broiler farming.

55. Types of special roaster farming, (including capons and caponizing.)

56. Poultry farm crops and rotations.

57. Poultry farm accounting.

58. Poultry advertising, correspondence, etc.

59. Methods of getting started in poultry farming.

60. Extent and importance of poultry husbandry.

61. Personal requirements and opportunities for poultrymen.

N. Turkeys.

62. Breeds and Breeding.

63. Management.
O. Ducks.

64. Breeds, breeding, and management.

\section{P. Geese. (1)}

65. Breeds, breeding and management.

$$
\text { Q. Pigeons. }
$$

66. Breeds, breeding and management.

\section{R. Caponizing}

(Optional in place of one of the above)

Lectures from sixty-two to sixty-six could easily be expanded, condensed or eliminated to suit existing conditions.

\section{The Laboratory Course}

\section{A. Nomenclature.}

1. Naming the parts of poultry from outline and live fowls.* *(Poultry plant inspection can appropriately precede or accompany this practicum.)

\section{B. Anatomy and Physiology.}

2. Dissection of various types and classes of poultry to study internal and external characters and digestive system.

3. Study of the structure of the egg. 


\section{Breeds. (5)}

4. Breed types and variety characteristics.

5. Utility types, for egg production, roasters, fryers, broilers, etc.

6. Judging for constitutional vigor, age, weight, sex, etc.

7. Judging Asiatics and Americans.

8. Judging Mediterraneans and others.

D. Exhibiting.

9. Fitting poultry for exhibition.

10. Cooping and exhibiting.

11. Judging and management.

12. The poultry show, management, institute and journalism and holding a show.

\section{E. Breeding.}

13. Mating up breeding fowls. (Visit near by flocks.)

$$
\text { F. Housing. }
$$

14. Poultry house measurements.

15. Laying out and cutting rafters and estimating materials.

16. Laying out and estimating the foundation.

17. Making concrete foundation floors, walks, posts, etc.

18. Construction of poultry houses.

19. Construction of poultry houses. (Making the poultry house appliances, putting together model for full size poultry house could be substituted for 18 and 19 , depending upon weather, financial and other conditions.)

20. Study of feeds.

$$
\text { G. Feeding. }
$$

21. Mixing to show mechanical condition. (Practice course could be given in addition to the lecture and laboratory practicums, one hour feeding for eggs, one hour feeding for fattening, one hour feeding for growth.)

\section{H. Incubation.}

22. Drawing plans of incubators and answering questions regarding construction or study of the egg and development of the chick as shown by tester.

(Practice course in connection with lectures and laboratory in study of incubators under operation should be taken for one hour.)

\section{Brooding.}

(Practice course in connection with lecture course, one hour study of brooders in operation, including the drawing of plans of brooders and answering questions regarding the principles of construction.)

\section{J. Marketing. (4)}

23. Killing, picking, shaping and packing, drawing, trussing, etc. (Desirable to repeat.) 
24. Judging dressed poultry.

25. Judging eggs.

26. Cleaning, candling, grading and packing eggs for market and hatching.

K. Sanitation .

27. Making and applying lice powder.

28. Making and applying disinfectants.

\section{Poultry Farm Management.}

29. Poultry farm accounting.

30. Poultry farm study and excursion.

31. Poultry farm study and excursion.

32. Laying out poultry farms and estimating capacity, expenditure and capacity.

33. Review and comparison of poultry farm plans and estimates.

(Printed instruction and explanation regarding 32 and 33 should be given to the class several weeks in advance of the time when they are listed.)

\section{Practice Courses in Poultry Husbandry}

Should precede or accompany the three hour lecture and laboratory course. Time required twenty-eight weeks, one and one-half hour each day, total credit seven hours or one hour for each course. To be given morning, noon and afternoon. market.

1. Practice in feeding for egg production and preparation of eggs for

2. Practice in feeding for fattening. Cramming pen or crate fattening and preparation for marketing.

3. Practice in feeding young chickens.

4. Practice in incubation. Operating an incubator, testing eggs, removing chicks, disinfecting the machine etc., or care of sitting hens. hens.

5. Practice in brooding. Operation of a brooder or care of brooding

6. Feeding and handling water fowl.

7. Poultry farm mechanics, operating gasolene engine, bone cutter, grinder, etc.

\section{Advanced Courses in Poultry Husbandry}

For students who have taken the three hour lecture and laboratory course and the seven hour practice courses.

Consisting of two one hour courses, two two hour courses and two one to three hour courses. Total eight hours minimum, twelve hours maximum credit.

1. History of breeds and advance judging. Two hours credit, one lecture or recitation and one laboratory each week, first semester.

2. Poultry Farm Management. Two hours credit, one lecture or recitation and one laboratory each week, second semester. 
3. Poultry Breeding. One to two hours credit, one lecture, recitation or practicum each week, first semester.

4. Poultry nutrition. One to two hours credit, one lecture, recitation or practicum each week, first semester.

5. Poultry Seminar. One to three hours credit, one conference and two or more hours study each week on special problems, and poultry literature.

6. Poultry Research. One to three hours credit, conference by appointment each week, and two or more hours outlining investigations and reporting on special research projects and carrying out a specific investigation.

Other specialized courses can be added to advantage as the subject develops if the teaching enterprise will permit.

\section{Schedule of Courses in Poultry Husbandry and Allied Courage Covering Two College Years of Instruction}

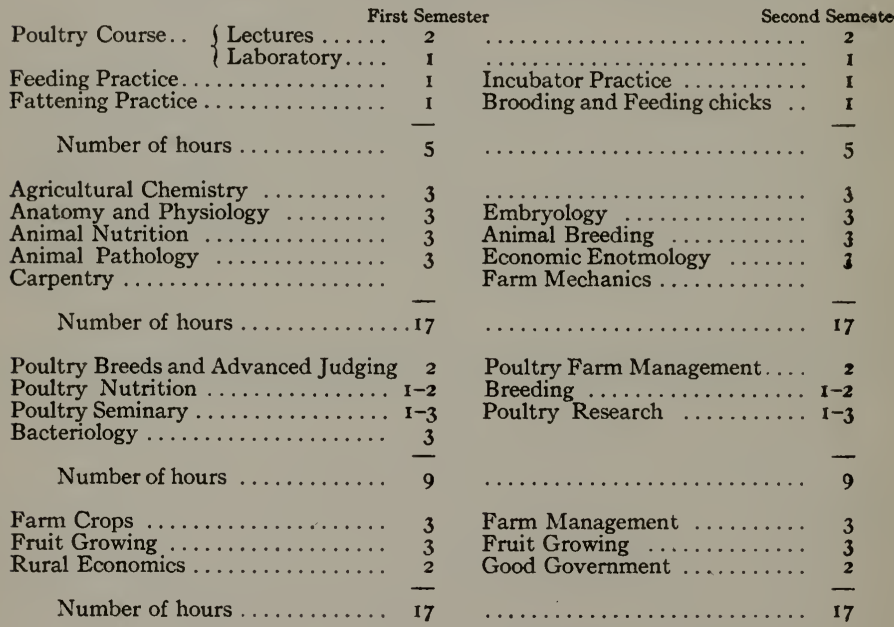

Respectfully submitted, JAMES E. RICE, W. A. Brown, HoMer JACKsON, Geo. B. Morse. 


\section{TEACHING BY FARM TRAINS AND EDUCATIONAL EXHIBITS AT FAIRS}

BY W. A. BROWN

The most striking and important feature of the Modern Farming Special train, which completed on June 25 th a trip of over a thousand miles on the railroads in Maine, was a demonstration of the fact that the farmers of Maine are anxious and willing to learn what they can of the new methods in Agriculture.

All of the departments in the College of Agriculture were represented. Three baggage cars and one flat car were used to carry the exhibits. Onehalf of a 60-foot baggage car was placed at the disposal of the Poultry Department. Three main lines of work were followed out: 1st-a general exhibit of material of interest to farmers and poultrymen, for instance, models of different kinds of poultry houses, a Maine State curtain front laying house, a curtain front colony house, a Tolman house, etc., feed hoppers, nest boxes, egg sorting table, incubators and brooders in operation, nest boxes for setting hens, appliances for fattening, killing, packing, and shipping poultry, and numerous charts giving ideal shapes of the different breeds of poultry, and charts of the different methods of feeding, etc. 2nd-an exhibit of the instructional work in poultry carried on at the University of Maine, showing by means of a series of enlarged photographs the methods used in familiarizing students with the breeds, feeds, houses, etc., on the college poultry plant. 3d-an exhibit of charts and data showing the need of further organization work in poultry in the state of Maine. We have in Maine, as in many other states in the Union a large and influential state poultry association but we have no organization at the present time that will assist the poultrymen to grow a better article, to grow that article more cheaply or that will help them find a better market for that article. The state of Maine needs not only a Poultry Producers' Association that would assist the poultrymen in the state in the growing and marketing of their poultry, but one that would also have for its purpose a collection of data on poultry matters such as the Cow Test Associations are doing for the dairymen.

The Experiment Station also kindly loaned a number of charts setting forth the details of the breeding work they are doing with poultry and also a complete set of the bulletins that they have for distribution. These bulletins were framed and displayed in a prominent place and a book and pencil placed near at hand where persons interested could leave their names and addresses. 
Some twenty thousand people visited the train in its trip over the state. A great proportion of these people receive the Station bulletins; but some do not and to show how great an interest is being evinced in poultry at the present time it might be well to note that over a thousand people put their names down in the book for Station bulletins. Someone was always in charge of the Poultry department exhibit on the train and there was a constant circle of inquirers around him. Questions were asked particularly on the housing, feeding, hatching, and rearing. Probably because the train was operated in the late spring, most of the questions were with regard to hatching and the great mortality that has prevailed among the newly hatched chickens in many sections.

The special train was out fifteen days, stopping at about sixty different places. The regular stop was two hours, one hour of which was given to inspecting the train and the other to three or four short practical addresses on different agricultural topics. In many places the audience was given a chance to select a topic that they wished discussed. It was interesting to note the number of times poultry was asked for.

Four years previous a similar train had been conducted through the state of Maine. It attracted a large number of visitors, but it was regarded much as a curiosity and was visited by numbers of persons who considered only the unusual spectacular features of such an undertaking. Nevertheless, much good was accomplished through disseminating valuable information among the farming communities. This year the situation was entirely changed. The "newness" of farming trains had worn away and the uninterested did not care to look on. Yet the attendance at exhibits and lectures, both day and evening, was larger than in 1906, and ninety per cent of the spectators and auditors were those who are actively engaged in farming. While the first special was regarded by many as a sort of free circus, that of this year was looked on wholly as a school of agricultural demonstration and instruction:

A minor problem has arisen with the trip of the Modern Farming Special in Maine. How is it best to continue this course of instruction? While an occasional "special" may do a vast amount of good, it is apparent that the farmers need more than one lesson to thoroughly understand the principal features of any one branch of farming. It would seem that some plan must be adopted to continue the work so auspiciously begun. Such a plan must possess merits which will result in its having a permanent place in the forwarding of general agriculture. The cause is worthy of the most careful consideration. There is here an opportunity for co-operation at home as well as abroad; co-operation on the part of the railroads, state 
Boards of Agriculture, State Departments of Agriculture, and the various Agricultural Associations. It is hoped that a feasible solution of the problem will be found.

Another form of College extension work similar to the farming train is the educational exhibit at the Fairs. The Poultry Department at the University of Maine has already agreed to furnish educational exhibits at several of the large Fall Fairs in the state, at the state poultry show at Portland in December, and at the Boston Poultry Show at Boston in January. The equipment of these exhibits will be similar to that of the farming train, except that the incubators and brooders will be omitted and such things as practical demonstrations in the killing, dressing and packing of poultry, and the sorting and packing of eggs will be substituted. These exhibits at the poultry shows are especially serviceable in bringing the prominent poultrymen of the state in much closer touch with the work of the College, and also in allowing the College men to get better acquainted with the poultrymen.

I believe that the poultry exhibit at Fairs can be made to have a powerful influence for good. Our poultry shows are doing a lot of good work now; but there is an inmense field to be covered. More attention must be given to the utility side. The fanciers are realizing this, and in many places the show management is willing and glad to have the College Poultry Departments come forward and help them build up their show and Association work in this way. 


\title{
TEACHING BY LECTURES, RECITATIONS AND REFERENCE READING
}

\author{
BY WM. A. LIPPINCOTT
}

I take it that what is implied in my subject is the question "What is the most efficient method of teaching Poultry Husbandry in the class room?" The question of laboratory practice is not included. If recitations imply the use of a text book, the ideal method is one which is a combination of the three methods mentioned. Each has its particular points of strength. It is only when we take advantage of all of them that we have done our best to present facts and principles clearly and fix them in the mind of the student.

The three main advantages of the lecture are: (1) the personal touch with the student and his conditions; (2) the impression of authority which is given by the instructor; and (3) the opportunity for constant revision.

It is impossible for a text book to be so general that it will deal with all conditions without being so vague that it will practically fail to deal with any.

With a lecture an instructor may apply the facts and principles of the text to the particular conditions found in that section of the country.

In dealing personally with any individual, there is a distinct advantage which is difficult to describe. Instead of simply writing letters, a business house sends out salesmen to get orders personally. The truth which is given in a fresh and vigorous way, by a person, makes an impression on a student and takes on a significance that a written or printed statement does not. This quickens the understanding and stimulates the memory. It awakens interest and associates in the student's mind facts which would ordinarily seem to have no connection. Memory depends entirely upon the association of facts. And further, the lecture gives the instructor the opportunity to bring out the connection between the fundamental sciences and practical work. Our work is broader than simply making poultrymen. We are employed by these great institutions, first of all, to develop men and to help them find themselves. We have done a greater thing when we have so presented our poultry work that we have taken hold of the imagination of a student and bridged the chasm that seems to yawn between chemistry, physics and the like on the one hand and practical agriculture on the other and sent him out to be a scientist, (if his tastes and abilities lie in that direction) than we have if we have converted him into a poultryman. We are here primarily to help men get located where their abilities lead them. If they choose poultry we are then to make good poultrymen of them. Such work as this can best be done through the lecture only. 
While the second advantage of the lecture must not be pushed too far, it is a fact nevertheless, that that man who can stand up before a class and tell them things will secure greater confidence from the students than a man who is really better posted but who merely asks questions over a text book assignment. The lecturer gives the impression of authority and inspires confidence.

And lastly, the opportunity which the lecture gives of bringing the subject up to date cannot be over looked. If it is true, as has been said, that any agricultural text book is out of date before it leaves the press it is especially true of a new subject like poultry husbandry. New truth is being brought to light almost daily. New editions could not be brought forward fast enough to keep up with the procession. It can be done only through additional notes.

We need text books because it is impossible to give by word of mouth, all the necessary facts in any course. There is not sufficient time. The student should have the general facts and ideas in mind before attending the lecture. The instructor may then spend his time associating, applying and illustrating them. The recitation has its part only occasionally as a convenient means of finding out whether the student is keeping up his work. Even than the recitation should be a discussion rather than a quiz. Every class room exercise should be conducted with the primary motive to teach not to test. The instructor who cannot find out incidentally, without wasting teaching time by a series of tests, pure and simple, whether a student is working, (provided the classes are of reasonable size) is out of place in the class room.

When one has the facts and principles given in the text, revised, associated and applied by the lecturer, the work will be narrow unless it is viewed from varying angles. In our work this is best done through excursions to practical poultry farms, working on different farms, and what is most available for the college student, reading. Systematic reference reading which is all that its name implies cannot help but broaden the point of view. With the present state of our poultry literature it is difficult to map out a course that is at once progressive and systematic. Our work, however, will be weak until this has been done. 


\section{POULTRY PATHOLOGY \\ Its Place in the Curriculum ${ }^{1}$ \\ BY GEO. BYRON MORSE}

One's answer to a question depends upon the viewpoint. At a Civil Service examination, to the question "What does a perfectly equipped power house need?" a dubious but resourceful candidate answered, "Nothing." His viewpoint was different from that of the examiner. "What position shall the study of disease occupy in the Poultry Husbandry course?" is answered by the writer thus: " $\mathrm{A}$, if not The Most Prominent Place."

Poultry Husbandry should include three groups of studies: Zootechny, Economics and Hygiene. Although naming it third in the list I do not hesitate to affirm that in the most subtle manner Poultry Hygiene assumes first place in the operations of a poultryman.

Poultry Zootechny is that branch of poultry husbandry that has for its object the study of alimentation and reproduction, or, to use an expression that means less and yet is truer to the actual condition of things, the practice of feeding and breeding.

Poultry Economics is that branch of poultry husbandry that is occupied with the commercial aspect of poultry farming, particularly the marketing of poultry and eggs.

Poultry Hygiene is that branch of poultry husbandry that concerns itself with the maintenance of the health of poultry.

Which, now, of these three branches of poultry husbandry is most important? Please do not think me immodest when I tell you that I consider the last named-Hygiene-by far the most important. It is natural for the specialist in each one of these lines to feel that his work is THE work. For him, it is.

If one studies the catalogs of the many different Agricultural Colleges he will be struck with the marked absence of poultry hygiene or poultry pathology from the curriculum. But its absence is not the reason that $I$ believe it is the most important or the most to be sought after.

Hygiene when operating in its widest yet legitimate scope is practically coextensive with Biology. This involves every phase and condition of the living organism; it also includes all those subtle relationships of the physical sciences with what we call the science of life. Biology started out to be the science of the living organism in its normal condition; it was soon apparent,

${ }^{1}$ Reprint from the Ontario Agricultural College Review. 
howerer, that Pathology, the science of disease, must be given a place in its classification. Then it came to be recognized that in the study of disease not only must we include Therapeutics or the science and art of treatment of disease but a most prominent place had to be allotted to Hygiene, the study of the laws of health and its preservation. Any one who has attempted to specialize in Hygiene has found himself face to face with every division of Biology, even classification. In human medicine we have long noted the "diseases of civilization" and the peculiar immunity of uncivilized peoples from the same. Again, there has been recognition of the awful susceptibility of the Negro and Indian races to diseases to which the Anglo-Saxon by centuries of exposure, has acquired a certain amount of immunity. The same is true in poultry husbandry. Who would not prefer to purchase his stock from a flock of "rangers" rather than invest in the third or fourth generation of "back-yard" or "town-lot" poultry. Most observant poultrymen can tell you the differences that exist among their Asiatic, Mediterranean and American breeds as to susceptibility to disease in chickhood and adult life. One of the strong points claimed for certain breeds that are just now being largely exploited is the dominating influence of their diseaseresisting powers.

I referred to the points of contact between the physical sciences and Biology. A man may be, as the result of close observation, an apparently successful feeder, but he cannot be an intelligent feeder today unless he possesses some knowledge of the chemistry of digestion and the chemistry of foods. Permit me to quote from a very recent and most interesting article:" "The animal body is the most complicated and wonderful piece of machinery in the world. It is the only engine which generates its own power, disposes of its waste products and automatically renews its parts. Within the compass of the human frame is an elaborate hydraulic system having not only a double acting force pump but also a suction pump for the purpose of producing a negative pressure in the reins and to assist the return circulation. The nervous system may be likened to the telephone system of a great city for it has all the local call stations and also a central station, which we call the brain, which is so complicated that, elaborate as are the switchboards in our great exchanges, they are simplicity itself compared with the brain. The digestive system forms the furnace in which the fuel is received for the generation of power, while the skin, kidneys and lungs make up a complicated apparatus for getting rid of the waste products of combustion."

(Bristow, Algernon T., M.D.; The Unity of the Medical Sciences. Journal of the American Medical Association, vol. lii. no. II, p. 8+t, opening paragraph, March I3, 1909, Chicago. 
It is this piece of machinery that the poultry husbandman is operating when he is feeding for eggs or breeding to Standard. It is this machine from which the commercial poultryman is planning to turn out a supply of attractive and toothsome table fowl to catch the eye and tickle the palate of the epicure. Hygiene proposes to keep this machine in order, oil all its parts, keep it in repair, tell you how, in the best possible manner, to obtain a new one, lacking all the defects of the old one, possessing features that will place it far away and ahead of the old. It is, in reality, Hygiene that will tell you that your machine is sure to snap and go to pieces if you work it too hard and can explain to you the rationale of the breakdown. Poultry Pathology, as a branch of poultry hygiene will tell you why your 250-egg hen dies before she reaches that fascinating number. It is poultry pathology that explains to you that the 200-egg hen is a monstrosity, an abnormality, and as such is far more susceptible to disease than the average hen of much lower egg laying ability. Not only is this hen peculiarly subject to disease but all the hens that have, as we might say, formed stepping stones up to this much soughtafter product of breeding and commercial enterprise are likewise markedly susceptible to disease because of the abnormal regime to which they have been exposed.

An enterprising poultrywoman brought to the writer a dead hen for autopsy. Examination revealed an hypertrophied ovary, marked congestion and at the same time extreme thinness of the walls of the egg tube. Through this tube an egg had ruptured into the abdominal cavity. There were no other lesions. To my inquiry concerning the use of "forcing" foods, she replied, "I am breeding and feeding my White Leghorns for eggs; I obtain forty cents per dozen all the year round; I could sell one hundred dozen as easily as I now sell fifty dozen. I can afford to lose one of these hens every few months (that had been the record) and keep on forcing. Here was poultry husbandry with Hygiene in the background, that is to say, breeding, feeding and marketing in defiance of Hygiene. It is true, there was a strong appreciation of Hygiene for its general purpose; that woman desired to guard against an attack on her flock by an infectious disease, and she wisely brought the dead bird to a pathologist for investigation. But when it came to a question of the pathology of egg production she allowed the commercial element to overbalance all other considerations. A splendid business capacity suggested that it was better to lose four birds a year from diseased ovaries and oviducts due to excessive functioning than to lose, by cutting out the forcing foods, the large egg production with its generous receipts. As stated above, for her, poultry 
economics was the chief thing. And the writer, as a pathologist, agreed with her. But Hygiene, incarnate in the Poultry Pathologist of an Agricultural College must furnish to poultrymen, who are breeding, feeding and marketing, such data as is contained in Bulletin 166 of the Maine Agricultural Experiment Station. On page 83 of this bulletin, Doctors Pearl and Surface, in their summary, state, "The daughters of '200-egg' hens were in this experiment very much inferior to their mothers in average egg production."

Even though Hygiene may not yet be given a distinctly separate place in the curriculum of poultry studies, still Pathology, as a chief division of that subject, might be allowed to dominate the teaching. Let me show you what I mean. Anatomy and Physiology are taught in the schools at present, but, I think I can safely say, largely with reference to alimentation and reproduction, especially as bearing upon the commercial side of poultry culture. Let it be taught also with reference to disease. Study the anatomy and physiology of the ey'e, nose and throat as being the seat respectively of ocular, nasal, oral and pharyngeal roup. Study the windpipe of chicks as being the seat of gape disease so as to understand why one gape worn might be the cause of death and also to appreciate the difficulties attendant upon some of the proposed instrumental measures recommended for the cure of the disease. Learn the anatomy and physiology of the air sacs so that you may realize better the dangers connected with the air sac mite. Learn all you can about the ceca, their structure and function, and then remember that they are the usual seat of intestinal coccidiosis. Study the cloaca in order that you may be familiar with the locality which you should sometimes carefully investigate and explore with a well-vaselined finger in search for an obstructing egg or fecal concretion.

No more important industry exists today than poultry. Its position among the industries is growing in recognition. The colleges must come to honor it as it deserves. The writer believes that a whole four year course of studies in an Agricultural College could be built up around Poultry. It would be a masterly move on the part of the instructors in poultry husbandry to map out such a course and thus prove to young men and women that in fitting themselves to run intelligently a poultry farm they would be securing a broad training involving not only a fundamental general science course but also a technical agricultural education that would include every phase of farm life, thus enabling the graduate poultryman to meet every requirement for the well-being (health) of his flock. 


\title{
"STUDY OF FEEDS" AND "METHODS OF INSTRUCTION IN FEEDING”. A DEMONSTRATION
}

\author{
BY W. G. KRUM
}

In the study of poultry feeds, students are supplied with half-pint bottles of as many kinds of grain, ground feeds, by-products, meat foods, grit, etc., as can be obtained. At present we have about 60 of the samples, each one labeled and as far as possible, having its analysis given.

Students are allowed to study and familiarize themselves with these for one hour then they are removed and 60 small samples of the same are placed before them in numbered boxes. The student is expected to name each sample recording the name on a numbered sheet.

They are given also a study of mixtures, by having several rations, some good and some poor ones, given them. The students mix these, then note their bulk, coarseness and fiber content. Ground feeds are mixed with water to show crumbliness or stickiness and palatibility.

Directly after a course of lectures on feeds and feeding each student is given a pen of about $\mathbf{4 0}$ fowls to manage for four to six weeks. He takes an inventory of stock and feed on hand, weighs back at the end of each week the amount of feed left, works out a balance sheet showing cost and amount of each kind of food consumed, cost of labor, amount and value of eggs and manure produced, showing loss or profit, and studies to feed according to appetite for best results.

The instructor or assistant should spend as much time as possible with the student at feeding time, as nothing fixes the value of practical work in the mind of the student like personal supervision.

Following is a list of instructions given to students in Poultry Husbandry at the New York State College of Agriculture.

\section{INSTRUCTIONS FOR FEEDING PRACTICE}

Department of Poultry Husbandry,

\section{N. Y. State College of Agriculture at Cornell University}

To be copied into a personal note book by each student and handed to the instructor before commencing the Feeding Practice.

A good poultryman should be $\left\{\begin{array}{l}\text { industrious } \\ \text { careful } \\ \text { orderly } \\ \text { neat } \\ \text { quiet } \\ \text { quick } \\ \text { prompt }\end{array}\right.$


Always knock, whistle or speak before opening a door. It pays to be polite in a hen house. Fright retards egg production.

\section{GENERAL RULES}

In order to insure against mistake or misunderstanding, one person, the Instructor, is responsible for the proper performance of the various kinds of work and the accuracy of the records; therefore, he should always be present when weighings are made. If the Instructor is not available, an assistant will attend to it.

Always carry the "official note book" while doing the poultry practice work and use it.

Leave weekly record sheets and note book in the Dressing room on your locker door.

Copy from the original slips without removing leaves from the book.

Make all notes at the time the observation is made. Do not trust to your memory. Post up records each night. Keep close watch of grit, shell and feed hoppers, - see that they are supplied and feeding properly.

Credit will be turned in as incomplete unless pens are left in perfect order and all records completed.

\section{RULES FOR FEEDING AND MANAGEMENT}

\section{MORNING}

1. Feed whole grain and only as much as the hens will eat eagerly, (unless otherwise directed for special pens in experiments.) Feed much or little according to their appetites. If too much grain is fed in the morning, not enough of the ground feed will be eaten; if too little grain is fed in the morning, too much ground feed will be eaten. To know how much to give is the fine art of feeding. It can only be learned by much practice and careful observation.

2. Scatter the grain over the entire floor space.

3. Keep the straw loose and well toward the front of the house, rake straw to the front once daily.

4. If hens are not hungry enough to work for their living, they are being fed too much.

5. If the litter is not piled up in heaps and full of holes down to the floor, the hens are not working enough.

I. Open feed hopper.

NOON

2. Feed cut bone and vegetables.

3. When the supply cans are empty, they should be weighed, refilled with the ground meal mixture prescribed, weighed again, and the amount of feed charged on the daily food record.

4. Clean and return promptly to their proper places, the pails used for watering and feeding.

\section{NIGHT}

I. Feed all the whole grain scattered in the litter that the hens will eat (unless otherwise directed for special pens in experiment). They should go to roost with full crops. It is better to have a little grain uneaten at night than to have hens go to roost unsatisfied.

2. When the supply cans contain insufficient grain for the next feeding, they should be carried to the feed room, weighed, filled and weighed again, and the weights recorded on the "daily food record sheet."

3. Feed stock in hanging coops three times daily. 
WATERING

I. Rinse and empty all water cans before filling. IThrow waste water in pail provided]. Fill all pans full in the morning.

2. At night add enough water to last until morning. (Except in freezing weather).

3. Fill water cups in the hanging coops both night and morning (when coops are occupied).

4. Never let a water dish get dry. (Except during coldest nights).

5. Relurn water pail to proper place.

\section{Cleaning}

1. Clean the platform each morning. Use a square bladed shovel.

2. Place the droppings in the cleaning pail, then scatter on the platform plaster and coal ashes from the dust box. This will make the platform clean more easily and will absorb the odor.

3. Weigh the total amount of cleanings each day and deposit in the manure shed.

4. Do not forget to replace the perches after the platforms are cleaned.

5. Keep the walls swept free of dust and the windows clean.

6. Shovels should be clean and in their proper places.

\section{Trap Nesting}

1. Examine and work all traps each morning.

2. Release the hen from trap by letting her walk into your hands.

3. Handle the hen gently and stand her on the floor carefully when letting her go.

4. See that all leg bands are properly fastened.

5. Look twice to make sure that you have read the number correctly. The leg band should be right side $u p$ to read when the hen is held in the arm, feet downward and back upward.

6. Mark the egg exactly on the big end and in small distinct figures, first giving the number of the hen then drawing a line underneath, and below it write the number of the pen; thus: $\frac{\mathrm{H} 65}{\mathrm{P}_{4}}$

7. Collect all eggs in the box which is provided, and marked with the number of the pen.

8. If an egg is found on the floor, mark it " $F$;" if, in the nest and no hen is there, mark it " $\mathrm{N}$;" if two eggs are in the nest and only one hen mark one egg with the number of the hen, placing a circle around it, and mark the other egg "N."

9. After gathering the eggs, see that all traps are in proper working order. If you are unable to do this, make a report of your trouble to the assistant in charge, giving the number of the nests and number of the pen.

10. When broody hens are found, their number should be recorded and they should be placed in the hanging coop, and their number entered on the "broody hen" record.

I1. At night, when the last eggs have been collected, wipe them spotlessly clean, and leave in collecting box in the alloted place on the shelf in the egg room. Do not soak eggs unless they are badly soiled. The less water the better. A little sal soda or Bon Ami can be used. The eggs should be dry. Keep your hands clean.

12. Close all traps after the last collection in the evening, if necessary, to prevent hens from roosting in nests. Open in the morning. 
13. Enter the number of each egg on the daily egg record sheet and compute the value of the total number of eggs laid that day, at the price quoted.

14. Before leaving the pen look back and think if anything has been forgotten.

\section{FINALLY}

1. Post your records promptly, accurately and neatly at the end of each period.

2. Remember, you are each day making a record for yourself. The "world is taking your photograph." 


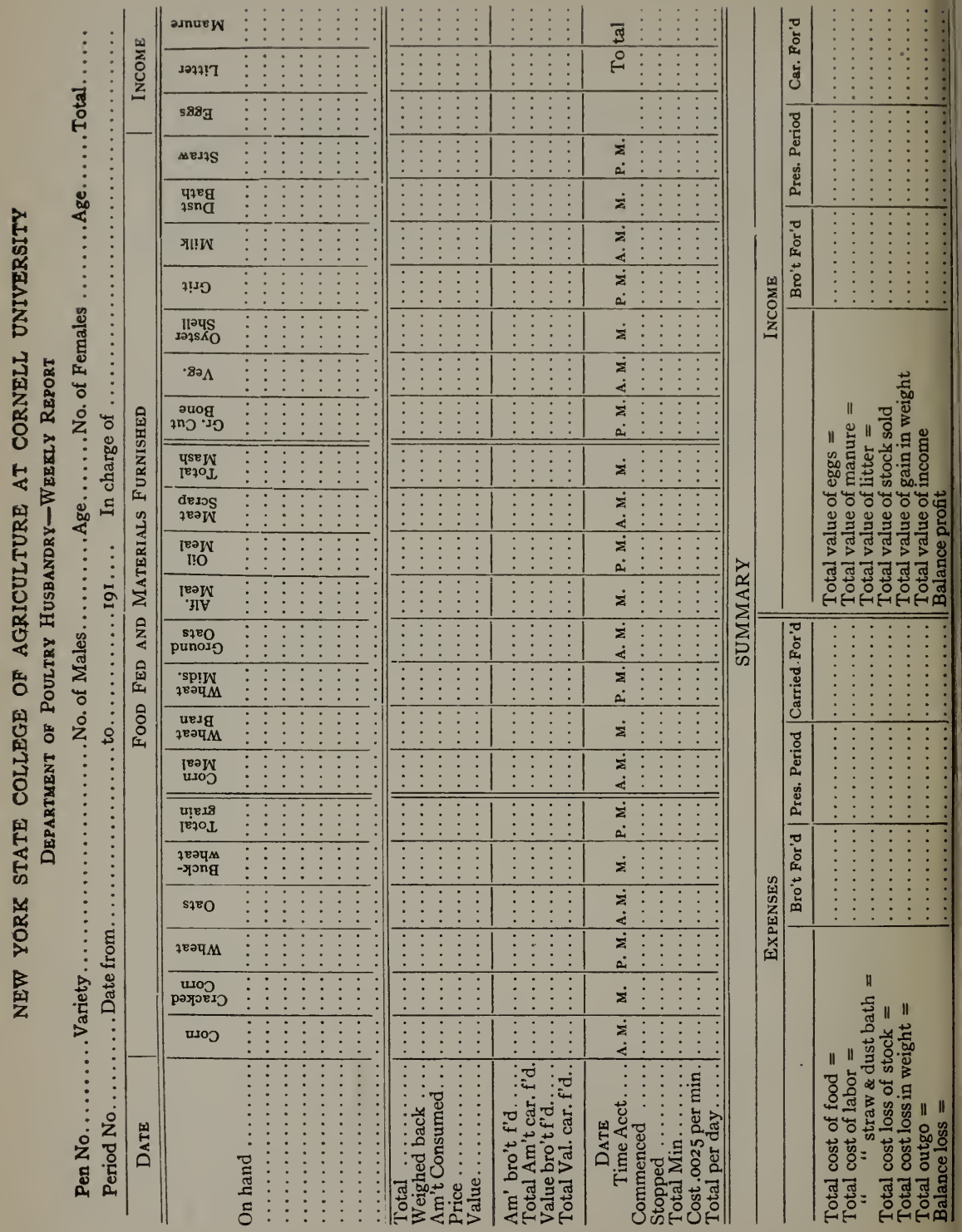




\section{INSTRUCTION IN FEEDING POULTRY}

BY C. A. ROGERS

I can best present my present conception of giving instruction in "Feeding Poultry" by describing my impressions as a student in Poultry and telling how later experiences have altered the original impression.

A good part of the time was devoted to the study of balancing rations. Individual grains and food products were studied principally from their analytical value. Their physical properties also were considered. Later, when the body needs of the fowl were sufficiently understood, these different grains and food products were studied collectively with the object of balancing them; so that, for example, if the ration is for the laying hen, it should provide her with food of such quantity and quality that her digestive system can dispose of it with least effort, giving to her body sufficient nourishment to keep it in healthy physical condition and at the same time giving a surplus of food in a form which the fowl will dispose of in eggs rather than in surplus body fat.

The impression of the importance of balancing rations is enhanced by the fact that one gets this work at some length in at least two courses, Animal Husbandry and Poultry Husbandry. In each course much time is given to this study and it naturally takes correspondingly proportionate importance in one's mind.

The physical properties of the food are also involved in balancing the ration. Experience has shown how easy it is to formulate a ration having the desired nutritive ratio only to discover that its bulk would make it impossible for the fowl to pass enough through her system to supply even her body needs. It is equally inefficient and even dangerous to have the ration too rich or too sticky. The amount and regularity of succulent food also must be carefully proportioned.

Some study was given to the manner of feeding these foods, the time of feeding, amount to be given, etc. However, the full importance of how to feed, was never made so prominent as what to feed. Experience and the observation of the results of others, have done vastly more to impress me with the need of knowing how to feed properly balanced rations.

It is common to find two poultrymen using the same ration under very similar conditions, one obtaining successful results, the other experiencing failure. We assign this difference in results to the personality of the feeder. This is usually the true reason. This difference in personality, however, shows itself in the way in which the ration is fed. It would 
seem then, since such comparisons exist so commonly, that the factors of this personality should be given greater emphasis and the student taught to appreciate the principles of feeding in as important a light as the balancing of the ration.

The instruction on feeding then, based on these facts, would be divided in the following manner:

1. Requirements of the fowl.

2. Balancing the ration.

(a) To obtain the correct proportion of digestible nutrients.

(b) To have the necessary physical properties of bulk, succulence, etc. and (c) To be palatable.

3. Principles of feeding the ration.

(a) To encourage proper exercise.

(b) To provide the fowl with sufficient nourishment each day.

My plea for greater emphasis on the "way to feed" is strengthened by the bulk of our disease correspondence. A large proportion of this correspondence comes from people who are feeding properly balanced rations, but still find that their fowls lay soft shelled eggs, or become weak legged, or die off gradually with no apparent disease, and furthermore, that the chicks hatched from their eggs do the same. Further inquiry usually brings forth the fact that the fowls are either confined in small pens or over-fed in such a way that they do not get proper exercise, thus making it difficult for their bodies to work off the surplus food. This possibility of over-feeding is not so often thought of, especially since it is taught that it is necessary to supply more than the body needs before eggs can be obtained.

The principle of making our fowls exercise for their food does not necessarily interfere with our present methods of feeding. We can use our hoppers for the dry mash provided we keep them closed during the early part of the day or fill them with a bulky mash.

To make a fowl exercise properly, especially in winter, it is necessary only to keep her appetite whetted and partially hide her food. This is most easily done by feeding whole grains scattered in small quantity in a deep litter. If she is forced to work diligently in the morning her exercise will have been sufficient for the day. She may then be allowed to consume all that she desires in the afternoon, and it should be made possible for her to fill her crop before night fall. The digestion of this food keeps her warm and quiet during the night.

I believe also that emphasis should be placed on the "principles involved in feeding" rather than on the "study of individual rations." The prin- 
ciples are applicable everywhere and under all conditions, whereas, an individual ration proves of different value under various conditions. If taught "the principles" a student can interpret the results in a tangible way and more easily solve his own problem, whereas, one will often err and work in the dark when trouble arrives, if one has learned individual rations and methods, instead of principles.

I do not wish to imply by these remarks that I would in any way lessen the value now placed upon the study of balancing rations in relation to the needs of the fowl, but that I would increase the attention given to the "method of feeding." 


\section{BIBLIOGRAPHY}

(A combined report of the committees on Bibliography)

This partial list of books, bulletins and articles on poultry subjects is compiled from many sources; books, bulletins, published list of books, indices of poultry literature, scientific publications, foreign publications, etc.

The material is classified under general topics and arranged under each topic according to the alphabetical order of the Author's name, or of the station from which the publication is issued.

The arrangement of the items is as follows: Name of author or station; title of book, bulletin, or article; date (if known); publisher and place of issuance, or publication in which the article appeared.

The list should be regarded only as a preliminary attempt to classify published information, on poultry subjects and as a foundation on which to build a complete bibliography of poultry literature.

Credit is due to Victor Fortier for translations from the French; to F. M. Surface and G. M. Turpin for references to articles in scientific publications, to R. R. Slocum for the list of publications from the Department of Agriculture at Washington, D. C. and the method of obtaining them, and to Clara Nixon for the list of books and bulletins in English and for the arrangement of the material.

\section{Appliances}

Daves, J. H., Art of Poultry Breeding (1896). Chatham, N. Y.

Dryden, Jas. and Lunn, A. G., A Colony House: A Trapnest. Oregon Exp. Sta., Cir. No. 4.

Ferguson, George, Breeding Poultry (1853). London.

Fiske, Geo. B., Poultry Appliances and Handicraft. Orange Judd Co.

Gowell, G. M., Maine Trapnest.

Gowell, G. M., Hens for One Pen; Trapnests. Maine Report, 1898.*

Rice, J. E., Rogers, C. A., Labor Saving Poultry Appliances. N. Y. (Cornell) Agr. Station Bul. No. 284.

Rice, Jas. E. and Lawry, R. C., New Poultry Appliances. Cornell Bul. No. 248 (1907).

Reliable Poultry Journal Pub. Co., Poultry Houses and Fixtures. Quincy, Ill.

Reprint from "Work." Incubators and Chicken Rearing Appliances; How to Make and Use Them. (1899.) London.

U. S. Dept. Agriculture, Hoppers for Poultry Feeding. Farmers' Bul. No. 316 (Exp. Sta. Work).

ठ. S. Dept. of Agriculture, Catching Hook for Poultry; Water Pan for Poultry, Farmers' Bul. No. 317 (Exp. Sta. Work).

Webb Pub. Co., Poultry Houses, Coops and Equipment. St. Paul, Minn.

*The addresses of the colleges and experiment stations are given at the end of this report. 


\section{Breeding}

Australia, Second Egg Laying Contest. Agr. Gazette, May, 1904.

Barfurth, Experimentelle Untersuchen uber die Vererbung der Hyperdactylie bei Huhner I. Die Einfluss der Mutter. Arch f. Ent'mech. Bd. XXVI. Hf. 4. Taf X u XI. (I909.)

Bateson, W., Poultry-Heredity. Rep. to Evolution Com. Roy. Sec. (London), (1908). No. 4 .

Comyns, Alexander, Breeding and Feeding Fancy Poultry. English.

Davenport, C. B., Characters of Mongrels vs. Pure Breds. Rep. Amer. Breeders' Assoc., Vol. 4 (19II).

Davenport, C. B., Heredity and Mendel's Law. Vol. 9 (1907), pp. 179-187, Washington Academy of Science.

Davenport, C. B., Inheritance in Poultry (1906). Carnegie Institution, Washing. ton, D. C.

Davenport, C. B., Inheritance in Canaries, Pub. No. 95 (1909), Carnegie Inst., Washington, D. C.

Davenport, C. B., The New Views about Reversion. Proceedings of the Amer. Philos. Soc. Vol. 49 (1910), No. 196.

Dryden, Jas., Egg Type; Breeding for Egg Production, etc. Utah Bul. No. 92.

Dryden, Jas., Housing, Fertility of Eggs; Carbon-dioxide in Incubators. Utah Bul. No. 102.

Felch, I. K., Fanciers' Mating of Fowls, Turkeys, Ducks and Geese.

Galloway, A. R., Canary Breeding.

Goodale, H. D., Breeding Expt. in Poultry. Rep. Soc. Exper. Biol. and Med. 7 (1910) pp. 178-179.

Goodale, H. D., Studies in Hybrid Ducks. Jour. Exper. Zool. Io-(1910) No. 3.

Gowell, G. M., Growth of Chickens: Breeding for Egg Production: Effect of Green Food in Fattening. Maine Bul. No. 64 .

Gowell, G. M., Fattening: Breeding for Egg Production: Incubation. Maine Bul. No. 79.

Gowell, G. M., Breeding for Egg Production: Egg Type. Maine Bul. No. 93.

Gowell, G. M., Houses: Breeding for Egg Production: Feeding. Maine Bul. No. 130.

Guyer, M. F., Atavism in Guinea-chicken Hybrids. Jour. Exper. Zool. 7 (1909) No. 4. Cape of Good Hope.

Guyer, Michael F., The Spermatogenesis of the Domestic Chicken (Gallus Gallus Dom.). Anat. Anz. Bd. 34, p. 573-580 (1909).

Hadley, P. B., Sex Limited Inheritance. Science N. S. Vol. 32 (I910) No. 83 I.

Laurie, D. F., Scientific Breeding and Heredity. (I908.) Australia.

New York (Geneva), Males with Laying Stock; Foods and Feeding; Feather Eating. Bul. No. 57 (1893).

Pearl, Raymond and Surface, F. M., Inheritance of Fecundity. Maine Bul. No. I66.

Pearl, Raymond and Surface, F. M., Inheritance of the Hatching Quality in the Eggs of the Domestic Fowls. Maine Agric. Exp. Station.

Pearl, Raymond and Surface, F. M., Selection Index Numbers and Their Use in Breeding. Amer. Nat. 43 (1909) No. 5II.

Pearl, Raymond, Inheritance of the Barred Pattern in Poultry. Maine Agri. Exp. Station. 
Pearl, Raymond, Studies on Hybrid Poultry. Maine Biology Lab. papers No. 21. Rhode Island, Breeding: Crossing: Capons. Rep. 1892.

Rhode Island, Turkey Raising; Goose Raising; Cross Breeding. Rep. I897.

Rice, Jas. E. and Rogers, C. A., Constitutional Vigor in Poultry Breeding. Cornell Reading Course Bul. No. 45 and Rep. 1909.

Surface, F. M. and Pearl, Raymond, Appliances and Methods of Pedigree Breeding. Maine Bul. No. 159.

Tegetmeier, Wm. H. and Boulton, W. W., Breeding for Color, and the Physiology of Breeding (1873). Ward, Beverly \& Co., London, Eng.

Thompson, D. S., 5th Egg Laying Contest. Miscellaneous Pub. (1903), Australia.

Wheeler, W. P., Capons vs. Cockerels; Influence of Male on Egg Production. N. Y. (Geneva) Report 1892.

\section{Breeds and Types of Poultry (Incl. Merit of Breeds)}

American Poultry Assoc., Amer. Standard of Excellence (1883), Buffalo, N. Y.

American Poultry Assoc., Amer. Standard of Perfection (1888), Buffalo, N. Y.

Atkinson, Herbert, Old English Game Fowl.

Ayres, H. F., Game Fowl (1878). Hartford, Conn.

Ayres, F. H., Quest of the Leghorn (1880). Hartford, Conn.

Babcock, Harmon S. and Felch, I. K., Indian Game. Providence, R. I.

Baum, Frank L., Book of Hamburgs (1886). Hartford, Conn.

Biggs, Fred, Minorca Fowls: Their Breeding and Management for Eggs and for the Show-room. Standard of Perfection of the London Minorca Club (1898).

Bowers, J. C., Black Spanish Fowls.

Burnham, G. P., The China Fowl: Shanghae, Cochin and Brahma (1874). Melrose, Mass.

Brown, Edward, Races of Domestic Poultry. Edwin Arnold, London and N. Y.

Brown, Edward, Poultry Classification, Varieties, etc. English.

Brown, Edward, Poultry: With Illustrations (1 889). English.

Caddell, T., Malay Fowl and Malay Bantam with Notes on the Fancy in Australia.

Central Expt. Farms, Fertility of Eggs from Different Breeds; Eggs from Hens in Cold Houses; Egg Production of Different Breeds; Of Old Hens and Pullets; etc. Report 1903.

Clough, W. W., Plymouth Rocks, How to Mate and Breed Them. (1895.)

Clough, W. W., Bantam Book. Medway, Mass.

Clough, W. W., Wyandottes: How to Mate, Breed, Exhibit and Care for Them. ( 1896$)$.

Cook, Wm., Fowls for the Times: The History and Development of the Orpington Fowl (1896). London, Eng.

Corbin, F. H., Plymouth Rocks (1879). Hartford, Conn.

Croad, Miss A. C., Langshan Fowl (1889). London, Eng.

Dixon, Edmund S., Ornamental and Domestic Poultry (1848). Gardeners' Chronicle, London.

Doubleday, Page \& Co., Poultry Book. N. Y. City.

Doyle, Martin, Illustrated Book of Domestic Poultry.

Dryden, Jas., Breeds of Chickens. Oregon R. C. Lesson No. I. 
Dryden, Jas., The Productive Qualities of Fowls. Cir. No. 11, Oregon.

Emery, F. E., Test of Breeds; Feeding (1899). N. C. Bul. No. 167.

Entwisle, W. F., Bantams. English.

"Feathered World," Blue Andalusian: Its Breeding; Management and Exhibition. "Silver Dun," London, Eng.

Ferguson, Geo., Illustrated Series of Rare and Prize Poultry. London, Eng.

Field, J. Penfold, Wyandotte Fowl. "Fanciers' Gazette," London.

Hamilton, Variations of Langshan (1879). London, Eng.

Hansard, T. C., Treatise on the Game Cock. London.

Harrison, T. H., The Minorca Fowl. (I893).

Hesford, Harry, Leghorns of all Varieties (I 896). "Feathered World," London.

Harker, Chas. K., Brown Leghorn Fowl (1879). Rochester, N. H.

Hawes, Theo., Book of Hamburgs. Inland Poultry Jour. Pub. Co., Indianapolis, Ind.

Holt, Charles, Hamburgs up to date. English.

Howard, Geo. E., American Fanciers' Poultry Book. Howard Pub. Co., Washington, D. C.

Howard, G. E., Standard Varieties of Chickens. U. S. Farmers' Bul. No. 5 I.

James, Ed., The Game Cock (1873). New York.

Johnson, W. G., Brown, G. O., and Others. The Poultry Book (1904-5). N. Y.

Johnson, W. G. and Brown, Geo, O., The Poultry Book, Vol. I, II, III.

Jones, R. E. and Hewes, Theo., Wyandottes in Colors and How to Judge Them.

Inland Poultry Jour. Pub. Co., Indianapolis, Ind.

Kansas, Egg Laying Contest. Bul. No. 146 (1906).

Kansas, Egg Laying Contest. Bul. No. I47 (I906).

Laurie, D. F., Egg Laying Contest. Rep. 1907-8 Australia Hawkesbury Agr. Col.

Laurie, D. F., Egg Laving Contest. Australia. Rep. 1908-9, Hawkesbury Agr. Col.

Laurie, D. F., Egg Laying Contest. Australia. Rep. 1909-10, Hawkesbury Agr. Col.

McGrew, T. F. and Howard, G. E., Perfected Poultry of America. Howard Pub. Co., Washington, D. C.

McGrew, T. F., The Feathers' Wyandotte Book. G. E. Howard Pub. Co., Washington, D. C.

McGrew, T. F., The Bantam Fowl. Reliable Poultry Journal Pub. Co., Quincy, Ill.

McGrew, T. F., The Plymouth Rocks. Bul. No. 29, U. S. Bu. Animal Industry.

McGrew, T. F., The Wyandottes. Bul. No. 31, U. S. Bu. Animal Industry.

McGrew, T. F., American Breeds of Fowls. U. S. Bu. Animal Industry Rep. I901.

New South Wales, Dept. of Agr., Egg Laying Competition at Hawkesbury Agr.

College. Farmers' Bul. No. 44.

Nolan, Jas. J., Ornamental, Aquatic and Domestic Fowl and Game Birds (1850). Dublin, Ireland.

Northrup, Geo. H., Minorcas of Every Comb and Color. Raceville, N. Y.

Pierce, B. N., Wyandotte Culture (1886). Indianapolis, Ind.

Raines, H. P., Wyandotte. English.

Reliable Poultry Journal Pub. Co., The Wyandottes. Quincy, III.

Reliable Poultry Journal Pub. Co., The Plymouth Rocks. Quincy, Ill.

Reliable Poultry Journal Pub. Co., The Leghorns. Quincy, Ill.

Reliable Poultry Journal Pub. Co., The Asiatics. Quincy, Ill.

Shaler, N. S., Domesticated Animals and Birds (1895). Chas. Scribner's Sons, N. Y. City. 
Spencer, W. A. and R. F., Wyandottes and All About Them. Stoddard, H. H., Book of Bantams. Hartford, Conn.

Stoddard, H. H., Book of Dorkings (1886). Hartford, Conn.

Stoddard, H. H., Book of Games (1886). Hartford, Conn.

Stoddard, H. H., Brown Leghorns (1893). Hartford, Conn.

Stoddard, H. H., Wyandottes, Hartford. Conn.

Stoddard, H. H., Plymouth Rocks. Hartford, Conn.

Stoddard, H. H., White Leghorns (I884). Hartford, Conn.

Tegetmeier, Wm. B., Poultry Book.

Wallace, Joseph, Plymouth Rock-Barred and White (1888). Albany, N. Y.

Wallace, Joseph, Wyandottes-Silver, Golden, Black and White (189I). Ferris Pub. Co., Albany, N. Y.

Wright, Lewis, Brahma Fowl (1870). London.

\section{Brooding and Chick Rearing}

Boyer, M. K., Little Chicks.

Brigham, A. A., Chick Culture. Torch Press, Cedar Rapids, Ia.

Christy, Thomas, Guide to Poultry Rearing by Artificial Means (1885). Christy, London.

Cobb, Ernest, Feeding and Rearing of Chickens. Incubation Up to Date. "Feathered World," London.

Connecticut (Storrs), Experiments with Chickens. Reports 1882-3.

Connecticut (Storrs), A Successful Brooder House. Report 1904.

Corbett, Adolphe, How to Hatch and Raise any Kind of Poultry with the Aid of Manure, (1874). Hempstead, L. I.

Cypher's Series, Profitable Market Poultry. Cyphers Incubator Co., Buffalo, N. Y. de Reamur, R. A., The Art of Bringing Up Domestic Fowls. (1750). London.

Dryden, Jas., Incubating and Brooding Chickens. Oregon R. C. Lesson No. 5 . England Nat. Poultry Organization Society, Hatching and Rearing. Leaflet No. 5. England (Univ. College), Growth of Chickens and Cost of Rearing.

Field, G. W., Mortality of Incubator Chicks. R. I. Bul. No. 6I.

Gowell, G. M., Growth of Chickens; Breeding for Egg Production; Effect of Green Food in Fattening. Maine Bul. No. 64.

Gowell, G. M., Raising Chickens; "Pioneer House," Feeding Hens. Maine Bul. No. 100 .

Graham, J. C., Facts for Farmers-I (I9II) No. 10. The Feeding and Care of Chicks Hatched Artificially. Mass. Agr. College.

Graham, W. R., Hatching and Rearing Chickens. Ontario Agr. Col. Bul. No. 163 (I908).

Hall, F. H., Feeding Chicks and Capons. N. Y. (Geneva), Bul. No. 126, (1897).

Huffaker, E. C., Artificial Incubation and Brooding. Cornell Inc. Co., Ithaca, N. Y. Ireland Bd. Agr. \& Tech. Instr., Rearing and Management of Chickens. Leaflet No. 43.

Ireland Bd. of Agr. Journal, Dublin, Rearing Chickens in Brooders. (Apr., 1908.)

Johnson, A. T., Chickens and How to Raise Them, (1909.) W. H. \& L. Collingridge, London.

Kirchstein, A., und Sweers, P., Zweite Bericht uber die Vergleiechenden Kuchenaufzuchts Versuche. Deutsche Landw. Geflug.-Ztg. Bd. 12. p. 750. (I909). 
Kirchstein, A., Sweers, P., und Brinkmann, E., Dritte Bericht uber die Vergleichenden Kuchenaufzuchts Versuche Deutshce landw. Geflug.-Ztg. Bd. 12, p. 763. (1909).

Massachusetts Bd. Agr., Poultry Culture. Bul. No. I.

New York, Skim-milk for Growing chicks; Tallow for Hens. N. Y. (Geneva) Bul. No. 39 (1893).

Niles, E. P., Experiments with Chickens. Virginia Bul. No. 96.

Nourse, H. A., Chicks; Hatching and Rearing.

Pernot, E. F., Mortality of Incubator Chicks. Oregon Bul. No. 103.

Plumb, C. S. and Anderson, W. B., Skim Milk for Growing Chicks. Indiana (Purdue) Bul. No. 7 I.

Plumb, C. S. and Anderson, W. B., Skim Milk for Growing Chicks. Indiana (Purdue) Bul. No. 76.

Quisenberry, T. E., The Baby Chick. Quar. Bul. I (I9II) No. I. Missouri State Poultry Expt. Station.

Reliable Poultry Journal Pub. Co., Artificial Incubating and Brooding. Quincy, Ill.

Reliable Poultry Journal Pub. Co., The Chick Book. Quincy, Ill.

Rhode Island, Incubation and Brooding; Poultry Feeding; Goose Experiments. Report 1902.

Rice, Jas. E. and Lawry, R. C., Gasoline Heated Colony Brooder House. Cornell Bul. No. 246. (1907).

Rice, Jas. E. and Rogers, C. A., Principles of Brooding. Cornell Bul. No. 277. (I9II).

Rice, J. E. and Nixon, Clara, Seven Methods of Feeding Young Chickens. N. Y. (Cornell) Bul. No. 282.

Rice, Jas. E., Raising Chickens. (1904). Cornell Reading Course Bul. No. 19.

Stahl, J. M. and Wickey, E. W., Poultry Raising and Artificial Incubation. Champion Mfg. Co., Quincy, Ill.

Stewart, J. H. and Atwood, Horace, Raising Chickens Artificially. West Virginia Bul. No. 98 .

Sweers, P., Erster Bericht uber die vergleichenden Kuchenaufzuchts, Versuche Deutsch. Landw, Geflug. ztg. Bd. 12, p. 739. (1909).

U. S. Dept. Agriculture, Skim Milk for Young Chickens; Gape Disease of Chickens. Farmers' Bul. No. 84 (Exp. Sta. Work).

Von Culin, E. and C., Art of Incubation and Brooding, 1894. Delaware City.

Wheeler, W. P., Oyster Shells for Hens; Skim Milk for Chicks; Tallow for Hens; Salt for Hens; Preserving Eggs. N. Y. (Geneva) Rep. I901.

Williams, H. M., The Chick. Hammonton, N. J.

\section{Capons and Caponizing}

Cushman, S., Production of Capons (1892). R. I. Bul. No. 20.

Cyphers Incubator Co., Capons for Profit. Buffalo, N. Y.

Dipple, Edwin, Pub., Practical Instructions in the Art of Making Capons. London.

Dow, Geo. Q., Capons and Caponizing. Amer. Poultry Advocate, Syracuse, N. Y.

Greeley Bros., Capon Hand Book (1892).

Greiner, T., Capons for Profits (1894). Buffalo, N. Y.

North Carolina, Capons. Bul. No. 62.

Pilling, Geo. P., Complete Guide for Caponizing (1899). Phila., Pa. 
Rhode Island, Breeding; Crossing; Capons. Rep. 1892.

Sawyer, Edward W., Operation of Caponizing (1895). Ferris Pub. Co., Albany, N. Y. Slocum, R. R., Capons and Caponizing. Cir. No. 107, U. S. Bu. Animal Industry.

Slocum, R. R., Capons and Caponizing. U. S. Dept. of Agric., Farmers' Bul. No. 452.

Washburn, F. L., Capons and Caponizing. Oregon Bul. No. 31 .

Watson, O. M., Capons and Caponizing. South Carolina No. 62.

\section{Diseases, Parasites, Enemies and Sanitation}

Banks, Nathan, Lice and Mites of Poultry. Cir. No. 92, U. S. Bu. Entomology.

Barton, Frederick T., Ailments of Poultry, (1896). Dean, London.

Bevan, L. E., Spirochetosis of Fowls in Southern Rhodesia. Jour. Compar. Path. and Ther. 21 (1908) No. I, pp. 43-49.

Boyer, M. K., Farm Poultry's Manual of Poultry Diseases. Farm Poultry Pub. Co., Boston, Mass.

California, Tuberculosis, Fowl Cholera, Chicken Pox, Roup. Report 1903-4.

Carre, C., A Note on Argas Larvae, Which Attack Fowls in Persia. Bul. Soc. Cent. Med. Vet., 86 (1909) No. 8.

Cary, C. A., Chicken Pox or Sore-head in Poultry. Alabama Bul. No. 136.

Chester, F. D., Common Diseases of Fowls. Delaware Bul. No. 47 (1900).

Cole, L. J., Hadley, P. B., Kirkpatrick, W. F., and Others. (1910). Blackhead in Turkeys (Avian Coccidiosis R. I. Bul. No. I4I.

Cole, L. J., The Crow a Menace to Poultry Raising. Rhode Island Report, 1908.

Cooper, G. W., Game Fowls-Diseases. (1869). New York.

Craig, Quinlin and Lyell, Diseases of Poultry and Pigeons. (1895). L. Upcott Gill, London.

Curtice, Cooper, Goose Septicaemia, (1902). R. I. Bul. No. 86.

Curtice, Cooper, Blackhead in Turkeys. Cir. No. 119. U. S. Bu. Animal Industry.

Curtice, Cooper, Blackhead in Turkeys (1907). R. I. Bul. No. 123.

Curtice, Cooper, Blackhead in Turkeys. R. I. Bul. No. 124.

Dawson, Chas. F., Asthenia (Going Light) in Fowls. U. S. Dept. of Animal Ind. Annual Report No. I5 (1898).

Delaware, Asthenia (Going Light), Entero-Hepatitis (Black-Head). Report 1900.

Dorset, M., Some Common Disinfectants. U. S. Farmers' Bul. No. 345.

England, Bd. Agri. \& Fisheries. London. Fowl Cholera. Leaflet No. 28.

England, Bd. Agri. \& Fisheries, External Parasites. Leaflet No. 57.

England, Bd. Agri. \& Fisheries. Nematode or Round-worm. Diseases of Poultry. Leaflet No. 58 .

England, Bd. Agri. \& Fisheries, Fowl Cholera. Leaflet No. 66.

England, Bd. Agri. \& Fisheries, Favus or White-comb. Leaflet No. 67.

England, Bd. Agri. \& Fisheries, London, Tuberculosis. Leaflet No. 78.

Ferguson, George. Roup Among Fowls, (1853). London.

Fleming, (Translator), Newmann's Parasites \& Parasitic Diseases of Domesticated Animals.

Gage, G. E., Notes on Ovarian Infection with Bacterium Pullorum in the Domestic Fowl. Jour. of Med. Research. Series 3, Vol. 24-(June, I9II).

Gage, G. E., Study in Bacterial Organisms in Intestinal Mucosu of Healthy Chickens. Maryland Bul. No. 153. 
Gage, G. E. and Opperman, C. L., Tapeworm Diseases of Poultry. Maryland Bul. No. 139.

Garman, H., Earth Worms a Source of Gapes. Kentucky Bul. No. 74.

Garman, H., Gapes in Poultry. Kentucky Bul. No. 70.

Garman, H., Gape Disease of Young Poultry in Kentucky. U. S. Bur. Animal Industry, 15th Annual Report, (1898).

Graham, C. K., Cause of Death in Young Chickens. Conn. (Storrs) Bul. No. 44 (1906).

Gray, D. J. Thompson, Poultry Ailments and Their Treatment. (1885). "Bazaar" Office, London.

Hadley, P. B., Avian Coccidiosis-I White Diarrhoea of Chicks. II Roup of Fowls. R. I. Agr. College.

Hadley, P. B., Studies in Avian Coccidiosis-3. Coccidiosis in English Sparrow and Other Wild Birds. Centbl. Bakt., Ablt. Oreg. (1910).

Hadley, P. B., Chytodites Nudas (Air Sac Mite) and Haemaphysalis Chordeilis (Fowl Tick), Blackhead, a Coccidial Disease of Turkeys. Div. of Biol. No. 6. Rhode Island Agr. College.

Hadley, P, B., Fowl Cholera (1910). R. I. Bul. No. 144.

Hadley, P. B., Further Studies on Blackhead in Turkeys. Centbl. Bakt., Ablt. IOreg. (1910).

Hadley, P. B., Investigation in White Diarrhoea of Chicks and Blackhead in Turkeys. (1909).

Hadley, P. B., The Use of Carbolic Acid in Fowl Cholera. Centbl. Bakt., Ablt. IOreg. (1911).

Hill, A. J., Chicken Cholera Preventative and Exterminator. 1875 (Worster).

Hill, John W., Diseases of Poultry, (1886). Poultry Office, London.

Homeopathic Pub. Co., Poultry Doctor, Homeopathic Treatment and Care of Chickens, Turkeys and Ducks, etc. London.

Harrison, F. C. and Streit, H., Roup. Ontario Bul. No. 125. (1902).

Harrison, F. C. and Streit, H., Roup. (1902). Ontario Bul. I32.

Ireland, Bd. Agr. and Tech. Instr., Gapes. Leaflet No. 21.

Ireland, Bd. Agr. and Tech. Instr., Fowl Cholera. Leaflet No. 25.

Ireland, Bd. Agr. and Tech. Instr., Fleas, Lice and Mites. Leaflet No. 30.

Jones, F. S., Bacillary White Diarrhoea in Young Chicks. Report 1911. N. Y. State Vet. Coll.

Lantz, D. E., Methods of Destroying Rats. U. S. Farmers' Bul. No. 297.

Lantz, D. E., How to Destroy Rats. U. S. Farmers' Bul. No. 369.

Law, James, Farmers' Veterinary Advisor. Ithaca, N. Y.

Lehman, H. H., Lehman's Poultry Doctor. Ashland, Ohio.

Linfield, F. B., Poultry Management: Poultry Diseases. Montana Bul. No. 50. Louisiana, Preliminary Report of a Disease Fatal to Young Chicks. Report 1907-8. Mack, W. B., Etiology and Morbid Anatomy of Diphtheria in Chickens. Amer. Vet. Rev., (Jan., 1905).

Maine, How to Keep Poultry Free from Lice (1909).

McCarthy, Gerald, Parasite (1897). N. C. Bul. No. 131.

Milks, H. J., Preliminary Report on Some Diseases of Young Chickens. Louisiana Bul. No. 108.

Mississippi Agric. College, The Chicken Mite. Bul. No. 78 . 
Mohler, J. R. and Buckley, J. S., Pulmonary Mycosis in Birds. U. S. Bu. Animal Industry Rep. 1903. Cir. No. 58, U. S. Bu. An. Ind.

Moore, V. A., Infectious Lukaemia in Fowls. U. S. Bu. Animal Industry Rep. I 895-6.

Moore, V. A., Entero-Hepatitis. Cir. No. 5, U. S. Bu. Animal Industry.

Morse, Geo. B., Quail Disease in the United States. Cir. No. 109. U. S. Bu. Animal Industry.

Morse, Geo. B., White Diarrhoea in Chickens. Cir. No. 128. U. S. Bu. Animal Industry.

Nathan, L. V., The Air Sac Mite. 17 (1908) No. 5. Jour. Dept. Agr., West Australia. 1898 .

Nebraska, Fowl Cholera, Anti-toxin for Roup, Destruction of Fleas. Nebraska Rep.

Norgaard, Victor A. and Mohler, John R., Apoplectiform Septicaemia. Bul. No. 36. U. S. Bu. Animal Industry.

Pearson, Leonard and Warren, D. H., Diseases and Enemies of Poultry. (1897). Penna. Dept. of Agr.

Pemot, E. L., Tuberculosis. Oregon Bul. No. 64 .

Pernot, E. F., Infectious Entero-Hepatitis. Oregon Bul. No. 95. (1907).

Pernot, E. F., Diseases of Chickens. Oregon R. C. Lesson No. 4. (I910).

Pierce, H. C. and Webster, R. L., Lice of Fowls. Iowa Press Bul. No. 19.

Pierce, H. C., The Common Chicken Mite. Iowa Press Bul. No. I9.

Poultry Record, One Hundred Formulas and Receipts for Poultrymen. Carey, Ohio.

Ransom, B. H., Tapeworms of Poultry. Bul. No. 12. U. S. Bu. Animal Industry.

Ransom, B. H., A New Nematode Parasitic in the Crop of Pigeons. Cir. No. 64. U. S. Bu. Animal Industry.

Ransom, B. H., Tapeworms of Poultry. Cir. No. 85. U. S. Bu. Animal Industry.

Ransom, B. H., Tapeworms of American Chickens and Turkeys. U. S. Bu. Animal Industry Rep. 1904.

Ravenal, M. P. and Smith, R. W., Disinfection and Commercial Disinfectants. Wisconsin Bul. No. 156.

Reliable Poultry Journal Pub. Co., Reliable Poultry Remedies; Poultryman's Hand Book of Tried and Proved Remedies for Common Diseases of Poultry. Quincy, Ill.

Rettger, L. F. and Harvey, S. C., Fatal Septicaemia in Young Chickens or "White Diarrhoea." Sheffield Lab. of Bact. and Hyg., Yale University.

Rettger, L. F., Further Studies on Fatal Septicaemia in Young Chickens. Bul. Sheffield Lab. of Bact. and Hyg., Yale University.

Rettger, L. F. and Stoneburn, F. H., Bacillary White Diarrhoea. Conn. Bul. No. 60. Agr. College, Storrs.

Rettger, L. F. and Stoneburn, F. H., Bacillary White Diarrhoea. Second Report (I9I0). Connecticut Bul. No. 68.

Rhode Island, Turkeys: Diseases of poultry. Report 1893 .

Rhode Island, Roup. Report 1898.

Rhode Island, Roup. Heredity. Report 1899-1900.

Rhode Island, Investigations in White Diarrhoea in Chicks and Blackhead in Turkeys. Rep. 1909.

Robinson, John H., Common Sense Poultry Doctor. Farm Poultry Pub. Co., Boston, Mass. 
Salmon, D. E., Infectious Diseases Among Poultry. Bul. No. 8. U. S. Bu. Animal Industry, Washington, D. C.

Salmon, D. E., Tuberculosis. Bul. No. $3^{8}$. U. S. Bu. Animal Industry.

Salmon, D. E., A New Parasite of Pigeons. U. S. Bu. Animal Industry Cir. No. 47. Washington, D. C.

Salmon, D. E., Diseases of Poultry. G. E. Howard \& Co., Washington, D. C.

Sanborn, N. W., Farm Poultry Doctor, (1896). I. S. Johnson, Boston.

Schroter, Friedrich, Homeopathic Poultry Physician, 1898. New York.

Shattuck, S. G. and Dudgeon, L. S., Note on the Relationship between Avian and Human Tuberculosis. Lancet (London) 2 (1909) No. 24.

Smith, Theobald, Preliminary Investigation of Unknown Diseases in Young Turkeys.

Spillman, W. J., Spurious Allemorphism in Fowls. Amer. Nat. 42 (1908) No. 501, pp. 610-615.

Stoddard, H. H., Poultry Diseases. Hartford, Conn.

Theobald, F. V., Parasitic Diseases of Poultry. (1896). Gurney \& Jackson, London.

Tyzzer, E. E. and Ordway, T., Tumors on the Common Fowl. Jour. Med. Research. 2 I (1909) No. 3.

U. S. Bu. of Animal Industry, Annual Report 10 and II (1893-4). Work).

U. S. Dept. Agriculture, Healthy Poultry. Farmers' Bul. No. 305. (Exp. Sta.

U. S. Dept. of Agric., Blackhead in Turkeys. Farmers' Bul. No. 334 .

U. S. Dept. of Agric., The Crow as a Menace to Poultry Raising. Farmers' Bul. No. 366. (Exp. Sta. Work).

U. S. Dept. of Agr., Lice on Poultry. Farmers' Bul. No. 435. (Exp. Sta. Work).

U. S. Bu. Animal Industry, Check List of the Animal Parasites of Geese. Cir. No. 14.

U. S. Bu. Animal Industry, Check List of the Animal Parasites of Pigeons. Cir. 2 No. 15 .

U. S. Bu. of Biol. Survey, Hawks and Owls, from the Standpoint of the Farmer. Cir. No. 6r.

Vale, W. W., Roup and Kindred Ailments of Fowls. English.

Vale, W. W., Manual of Poultry Diseases. English.

Ward, A. R., Fowl Cholera (1903). Calif. Bul. No. 156.

Ward, A. R., Tuberculosis in Fowls (1904). Calif. Bul. No. 16r.

Wilcox, E. V., Internal Chicken Mite: Roup. Montana Bul. No. 22. (1899).

Woods, P. T., The Poultryman's Formulary. Middletown, Mass.

\section{Eggs}

Brown, Edward, The Standardization of Eggs. Leaflet No. Io. England. Nat. Poultry Organization Society.

Burrows, Anna H., Eggs. Lathrop \& Co., Boston, Mass.

Connecticut (Storrs), Analysis of Poultry \& Egg. Report I891.

Connecticut (Storrs), Egg Albumen. Report 1898.

Harwood, G. R., The Coloration of Eggs, Nature. Vol. 78, pp. 126-127, (1908).

Indiana, Purdue Univ., How to Detect Bad Eggs. Newspaper Cir. No. 175.

Indiana, Purdue Univ., "Indiana Eggs are Bad." Newspaper Cir. No. 174.

Jaffa, M, E., Food Value of Eggs. Calif. Report 1895-6. 
Jaffa, M. E., Food Value of California Eggs. U. S. Bu. of Animal Industry. Annual Report No. 15 (1898).

Lamon, Harry M., and Opperman, C. L. The Improvement of the Farm Egg. U.S. Bu. of Animal Industry, Bul. No. I4I.

Langworthy, C. F., Eggs and Their Uses as Food. U. S. Farmers' Bul. No. 128.

Maine, Analysis of Eggs; Egg Substitutes and Dried Eggs. Bul. No. 75 .

Middleton, W. J., Eggs in the Diet of Infants. British Med. Jour. (1907) No. 2422.

Pearl, Raymond, Biometrical Study of Egg Production in the Domestic Fowl. Part

1-Variation in Annual Egg Production. U. S. Bu. of Animal Industry Bul. No. I10.

Pearl, Raymond, Biometrical Study of Egg Production in the Domestic Fowl. Part 2-Seasonal Distribution of Egg Production. U. S. Bu. of Animal Industry Bul. 110.

Roger, H., L'amylase des Oeufs de Poules. Jour. de Physiol et de Path. gen. T. X. pp. 797-804. (1908).

Schein, E., Gewicht der Huhnerei Jahresh. Ges. Nat. Gena. Bd. 46-48. pp. 179180. (1906). Rv. Jour. R. Micr. Soc. Vol. pp. 22-23. (1907).

ठ. S. Dept. Agric., Food Value of Eggs. Dept. Farmers' Bul. No. 87. (Exp. Sta. Work).

U. S. Dept. Agric., Selling Eggs by Weight: Flavor of Eggs. Farmers' Bul. No. 122 (Exp. Sta. Work).

U. S. Dept. Agr., Fertility of Eggs, Farmers' Bul. No. 25I (Exp. Sta. Work).

U. S. Dept. of Agric., Fertility and Hatching of Eggs. Farmers' Bul. No. 405. (Exp. Sta. Work).

Willard, J. T. and Shaw, R. H., Analysis of Eggs. Kansas Bul. No. 159.

\section{Embryology}

Barlow, J. H., Daily Progress and Extraordinary Appearance of the Chick in the egg. (1821.) London.

Duesberg, Herr J., Ueber Chrondriosomen und ihre Verwendung zu Myofibrillen beim Huhnerembryo. Anat. Anz. Erganzungsheft zum Bd. 34, pp. 123-126. (1909.)

Du Val, Atlas d'Embryologie.

Fere, Ch.-Note sur l'influence de l'introduction de venim dans l'albumin de l'oeuf de poule l'evolution de l'embryon. C. R. Soc. Biol. Ser. 1o T. 3. pp. 8-9. I896.

Ganfini, Carlo-Sulla presenza di cellule gangliare nell ovaio di Gallus. Biblio. \&nat. Nancy. V. 16, pp. 128-132. (1907). Reb. Zool. Anz. V. 34, p. 352.

Hahn, Hermann-Experimentelle Studien uber die Entstehung des Blutes und der ersten Gefasse beim Huhnchen I Teil. Intraembryonale Gefasse Arch. f. Entw-Mech. Bd. 27, pp. 337-433. (I909). Rev. Biop. Cent. Bd. 4, p. 327.

Kaufmann, Wolf M., Embryologische und Anatomische Beitrage zur Hyperdactylie Houdanhuhn. Leipzig Morph. Jahr. b. Bd. 38. p. 6r. (1908).

Knape, Ernst V., Ueber die Entwickelung der Hornhaut des Huhnchen. Anat. Anz. Bd. 34, pp. 417-424. (1909).

Lillie, F. R., Development of the Chick: An Introduction to Embryology. H. Holt \& Co., N. Y. City.

Lecaillon, A., Sur la segmentation parthen ogenetique de l'oeuf des oiseaux. C. R. Ac. Sc. Paris T. 148 . pp. 52-53. (1909). Rev. Bot. Cent. Bd. I10 p. 98. 
Lecaillon, A., Sur les modifications qui peuvent se produire dans la structure de la cicatricule de l'oeuf non feconde des Oiseaux. Comp. rend. Soc. Biol. Paris. T. 64 . pp. 647-649. (1908).

Lecaillon, A., Sur les changements qui se produisent, apres la ponte, dans l'aspect exterieur de la cicatricule, de l'oeuf non feconde de la poule. Compt. rend. Soc. Biol. T. 64. pp. 1034-1036.

Megoes, Fr., Die Chrondiosomen als Trager erblichen Anlagen Cytologische Studien am Huhner Embryo. Arch. f. Mikr. Anat. u. Entw. Bd. 72, (1908). Rev. Bot. Cent. Bd. I12, p. 162 .

Meves, Friedr., Ueber Neubildungen querstreifen Muskelfassern nach Beobachtungen am Huhner-embryo. Anat. Anz. Bd. XXXIV. (1908).

Michalovsky, J., Zur Frage uber functional Aenderungen in den Zellen des Drusennagens bei Vogeln. Anat. Anz. Bd. 34, pp. 257-275, 1909.

Rabaud, E., Les phenomenes respiratoires et des correlations physiologiques chez l'embryon d'oiseau. Bull. Soc. Philomat. de Par. T. X. pp. 136-143. (1908).

Rabaud, E., La position et l'orientation de l'embryonde poule sur le jaune. Arch. de Zool. exper. et gen. 4 se ser. pt. IX. (1908).

Sonnenbrodt, Die Wachstums periode der Oocyte des Huhnes. Arch. f. Mikr. Anat. u. Entiw'gsh. Vol. 72. pp. 415-480. (I908).

Tralldenier, Missbildung einer Huhnerkopfes. Zeitsch. f. Thiermedizen N. S. 9, pp. 168-169. (1905).

Weber, A., Rapports entre le torsien de l'embryen sur l'axe longitudinal et les phenomenes de dissymetric dans la production de l'amnios chez les Oiseaux. C. R. Soc. deBiol. Paris T. 54, p. 1116.

\section{Exhibition and Judging}

"A Poultry Farmer," Poultry for Exhibition, Home and Market. A Chapter on Pheasants. 1888. Sonnenschein, London.

Archibald, John, American Poultry Fanciers' and Breeders' Directory. (1877). Cambridgeport.

Cobb, Ernest, Preparing Poultry for Exhibition. "Feathered World," London.

Fulton, Robert, Prize Poultry. (1872). Dean, London.

Felch, I. K. and Babcock, H. S., Philosophy of Judging Fowls. W. D. Page, Ft. Wayne, Ind.

Heck, Frank, Secrets of Expert Exhibition and Lessons in Judging. Successful Poultry Journal Pub. Co., Chicago, Ill.

Jones, R. E. and Hewes, Theo., From Shell to Show Room. Inland Poultry Journal Co., Indianapolis, Ind.

Long, Jas., Poultry for Prizes and Profit. (1879). L. Upcott Gill, London.

Slocum, R. R., The Value of the Poultry Show. U. S. Bu. of Animal Industry. Annual Report, 1908.

Stoddard, H. H., Light Brahmas from Shell to Exhibition Room (1892). Hartford, Conn.

Wright, Lewis, Poultry Fancier, (1883-5). New York.

How to Win Poultry Prizes, (188I). Hartford, Conn. 


\section{Feeding}

Allen, Ralph R., Mustard for Poultry. England.

Atwood, Horace, Poultry House Construction: Hopper Feeding Laying Hens (1911). W. Virginia Bul. No. 130.

Author of the "Poultry Kalendar," Poultry as a Meat Supply (1866). Simpkin, London.

Bartlett, J. M., Digestion Expts. with Poultry. Maine Agr. Exp. Station Bul. No. 184 .

Bolte, J. W., Feeding Experiments. R. I. Bul. No. 126, (1908).

Boyer, M. K., Money in Broilers and Squabs (1904). Hammonton, N. J.

Boyer, M. K., All about Broilers and Market Poultry Generally. (189I), Syracuse, N. Y.

Brown, Edward, Housing and Feeding Poultry. Leaflet 114, Bd. Agr. and Fisheries, London, Eng.

Brown, Edward, Poultry Fattening (1895). Arnold, London.

Brown, E. W., Digestion Experiments with Poultry. Bul. No. 56. U. S. Bu. Animal Industry.

Brown, W. A., Timely Helps for Farmers, 3 (I9I0) No. II, Egg Production. Maine Agr. College.

California, Analyses of Meat Meal, Blood Meal, and Fish Refuse-Plump vs. Shrunken Wheat for Poultry. Report 1898-I90I.

California, Jersey Kale for Poultry. Report 1897-8.

California, Corn Cockle Poisonous to Poultry. Report 1902-3.

Central Experiment Farms, Effect of Reduced Rations and Exercise; Cost and Profit of Winter Egg Production; etc. Report 1897.

Cobb, Ernest, Fattening Fowls. Feathered World, London.

Connecticut (Storrs), Poultry as Food; Analysis of Poultry Feeds. Report 1902-3.

Connecticut (Storrs), Digestibility of Fish and Poultry, Report 1905.

Cyphers Series, Profitable Market Poultry. Cyphers Incubator Co., Buffalo, N. Y.

Cyphers Series, Profitable Poultry Feeding. Cyphers Inc. Co., Buffalo, N. Y.

Delaware, Condimental Foods. Report 1901.

Dryden, Jas., Feeding for Eggs. Oregon R. C. Lesson No. 3.

Dryden, Jas., Experiments in Egg Production. U. S. Bu. Animal Industry. Report 1898.

Eckles, C. H., Skim Milk for Poultry. Missouri Bul. No. 57.

England, Journal Nat. Poultry Organ. Soc., 2 (1908) No. 4. Poultry Fattening. Sussex.

England Bd. Agr. and Fisheries, London. Fattening. Leaflet No. 176.

England, National Poultry Organization Society. Winter Egg Production. Leaflet No. 4 .

England, Univ. College, Reading, Housing and Feeding Poultry.

Fields, John and Ford, A. G., Digestion Trials with Chickens. Oklahoma Bul. No. 46. (1900).

Fiske, Geo. B., Poultry Feeding and Fattening. Orange Judd Co., N. Y. City.

Forbes, E. B., Mineral Elements in Animal Nutrition. Ohio Bul. No. 201.

Gowell, G. M., Growth of Chickens: Breeding for Egg Production; Effects of Green Food in Fattening. Maine Bul. No. 64.

Gowell, G. M., Fattening: Incubation; Breeding for Egg Production. Maine Bul. No. 79 . 
Gowell, G. M., Raising Chickens: "Pioneer House;" Feeding Hens. Maine Bul. No. 100.

Gowell, G. M., Feeding, Maine Bul. No. 117.

Gowell, G. M., Houses: Feeding; Breeding for Egg Production. Maine Bul. No. I 30.

Haywood, J. K.; Warren, H. J.; Howard, B. J., Commercial Feeding Stuffs. Bul. No. 108. U. S. Bu. Chemistry.

Ireland, Bd. Agr. and Tech. Instr., Winter Egg Production. Leaflet No. 3 I.

Jackson, H. W., Fattening Experiments: Feeding Chicks (I9II) Penn. Bul. No. 107. Jeffrey, J, S., Feeding and Management of Poultry for Egg Production (I910).

N. C. Agr. Exp. Sta., Bul. No. 2 I I.

Jordan, W. H., More or Less Nitrogenous Rations. Maine Bul. No. I5.

Jordan, W. H., The Feeding of Animals. Macmillan Co., N. Y. City.

Jaffa, M. E., Poultry Feeding and Proprietary Foods (1905). Calif. Bul. No. 164.

Lee, Alfred R., Fattening Poultry. U. S. Bu. Animal Industry, Bul. No. 140.

Lindsey, J. B., Condimental Stock and Poultry Foods. Massachusetts Bul. No. 106 (1905).

Massachusetts, Condition Powders for Egg Production: Feeding. Report I 897.

Massachusetts, Clover vs. Cabbage for Egg Production. Report 1898.

Massachusetts, Condition Powders for Egg Production. Report 1899.

Massachusetts, Morning and Evening Mash. Report I90I.

Massachusetts, Milk Albumen vs. Beef Scrap. Report I903.

Massachusetts, Milk Albumen: Various Grains. Report 1905.

Massachusetts, Milk Albumen; Various Grains. Report 1907.

New Jersey Agr. College, Composition of Feeding Stuffs and the Compounding of Rations. Cir. No. 2.

New Jersey, Egg Production of Virgin Fowls. New Jersey Reports 1905-p. 93; (1906)-p. 355 .

New Jersey Agr. College, Winter Egg Production. Railroad Train Bul.

New York (Geneva), More or Less Nitrogenous Rations; Fattening Capons. Report I889.

New York (Geneva), Feeding Table Fowls. Report I890.

New York (Geneva), Feeding Experiments with Capons. Bul. No. 53. (1893).

New York (Geneva), Males with Laying Stock; Foods and Feeding; Feather Eating. Bul. No. 57. (1893).

New York (Geneva), Moistened Ground Grain vs. Dry Whole Grain for Hens. Bul. No. 90 (1895).

New York (Geneva), More or Less Nitrogenous Rations. Bul. No. 29. (1891).

New York (Geneva), Oyster Shell for Laying Hens. Bul. No. 38. (1892).

North Dakota. Feeding Experiments with Hens; Heating Poultry Houses. N.

Dak. Rep. 1896 .

North Dakota, Feeding for Eggs, etc., N. Dak. Report 1897.

Pennsylvania State Agr. College, Feeding for Winter Eggs, Extension Cir. No. II. Phillips, A. G., Selection and Feeding of Laying Hens. Kansas Bul. No. 164.

Rhode Island, Cross-breeding Geese; Analysis of Foods. Report I 896.

Rhode Island, Turkey Raising; Goose Raising; Cross Breeding. Report 1897.

Rhode Island, Incubation and Brooding; Poultry Feeding; Goose Experiments. Report 1902.

Rice, J. E., Nitrogenous vs. Carbonaceous Rations for Poultry (1890). Cornell Bul. No. 25. Experiment Station, Ithaca, N. Y. 
Rice, Jas. E., Four Methods of Feeding Early Hatched Pullets. Cornell Bul. No. 249. (1907).

Rice, Jas. E., Feeding Laying Hens (1903). Cornell R. C. Bul. No. 17.

Rice, Jas. E., Rations for Poultry. (1904). Cornell R. C. Bul. No. 18.

Robinson, J. H., Broilers and Roasters. Farm Poultry Pub. Co., Boston, Mass.

Salmon, D. E., Wheat for Growing and Fattening. Cir. No. 2. U. S. Bu. Animal Industry.

Stewart, J. H. and Atwood, Horace, Nitrogenous vs. Carbonaceous Rations; Floored vs. Unfloored Houses; Effects of Age on Egg Production; Meat Meal vs. Green Cut Bone. West Virginia Bul. No. 60.

Stewart, J. H. and Atwood, Horace, Warm vs. Cold Houses; Feeding. W. Va. Bul. No. 71 .

Stewart, J. H. and Atwood, Horace, Forcing Molt; Feeding Experiments. W. Va. Bul. No. 83 .

Stewart, J. H. and Atwood, Horace, Feeding Experiments. W. Va. Bul. No. 88.

Stewart, J. H. and Atwood, Horace, Skim Milk. W. Va. Bul. No. 102.

Stoddard, H. H., How to Feed Fowls. Hartford, Conn.

Tegetmeier, Rearing and Fattening Market and Table Poultry (I 885).

U. S. Dept. Agriculture, Kitchen and Table Wastes. Farmers' Bul. No.69. (Exp. Sta. Work).

U. S. Dept. Agriculture, Animal Food for Poultry. U. S. Farmers' Bul. No. 97 (Exp. Sta. Work).

U. S. Dept. of Agric., Weight per quart of Feeding Stuffs. Farmers' Bul. No. 222. (Exp. Sta. Work).

U. S. Dept. Agric., Methods of Feeding Poultry. Farmers' Bul. No. 244 (Exp. Sta. Work).

U. S. Dept. of Agric., Alfalfa Meal as a Feeding Stuff. Farmers' Bul. No. 259.

U. S. Dept. Agric., Digestibility of Fish and Poultry. Farmers' Bul. No. 276 (Exp. Sta. Work).

U. S. Dept. of Agric., Colony Houses for Poultry. Farmers' Bul. No. 374 (Exp. Sta. Work).

U. S. Dept. of Agric., Animal Feeds for Farm Stock. Farmers' Bul. No. 388. (Exp. Sta. Work).

U. S. Dept. of Agric., The Forced Molting of Fowls. Rice and its By-products as Feeding Stuffs. Farmers' Bul. No. 412.

Watson, O. M., Egg Production of Turkeys; Weight of Chickens. S. C. Bul. No. 74 . Wheeler, H. J., Poultry Feeding (1902). R. I. Bul. No. 84.

Wheeler, W. P., Kind and Amount of Food; Proportion of Ash; Analysis of Eggs.

N. Y. (Geneva) Report 1888.

Wheeler, W. P., Capons vs. Cockerels; Influence of Male on Egg Production. N. Y. (Geneva) Report 1892.

Wheeler, W. P., Whole vs. Ground Grain for Egg Production. N. Y. (Geneva) Report I 895 .

Wheeler, W. P., Animal Eood for Poultry. N. Y. (Geneva) Bul. No. I 49. (1898). Wheeler, W. P., Animal Food for Poultry. N. Y. (Geneva) Report. 1898.

Wheeler, W. P., Oyster shells for Hens; Skim-milk for Chicks; Tallow for Hens;

Salt for Hens; Preserving Eggs. N. Y. (Geneva) Report 1901.

Wheeler, W. P., Whole vs. Ground Grain for Laying Hens. N. Y. (Geneva) Bul.

No. 106. (1896). 
Wheeler, W. P., Animal Food for Poultry. N. Y. (Geneva) Bul. No. $171 . \quad$ (1899).

Wheeler, W. P., Importance of Mineral Matter and Grit. N. Y. (Geneva) Bul. No. 222. (1903).

Wheeler, W. P., Animal Food for Ducklings. N. Y. (Geneva) Bul. No. 259. (I904).

Wheeler, W. P., Concentrated By-products for Poultry. N. Y. (Geneva) Bul. No. 271. (1905).

\section{Guineas}

U. S. Dept. Agric., Guinea Fowl: Color of Eggs. U. S. Farmers' Bul. No. 262. Washington, D. C.

Langworthy, C. F., The Guinea Fowl and Its Uses as Food. U. S. Farmers' Bul. No. 234. Dept. Agri., Washington, D. C.

Guyer, Michael F., The Spermatogenesis of the Domestic Guinea (Numida Meleagois Dom.). Anat. Anz. Bd. 34, pp. 502-513 (1909).

Edgerton, J. H., Guinea Culture, Amer. Poul. Pub. Co., Chicago, Ill.

\section{Houses and Construction}

Atlas Portland Cement Co., Concrete Construction, N. Y. City.

Bainer, H. M. and Bonebright, H. B., Construction of Concrete Fence Posts. Colorado Bul. No. 148 .

Baker, W. H., Cement Worker's Hand Book.

Blanchard, H. L., Practical Poultry Buildings. Washington. Spec. Bul. No. 4.

Ireland, Bd. Agr. and Tech. Instr. Portable Poultry Houses. Leaflet No. 5o.

Brown, Edward, Housing and Feeding Poultry. Leaflet No. I14. Bd. of Agr. and Fisheries, England.

Cyphers Incubator Co., Poultry Plant Construction. Buffalo, N. Y.

Cyphers Incubator Co., Profitable Poultry Houses and Appliances. Cyphers Series. Darrow, J. W., Low Cost Poultry Houses. Chatham, N. Y.

Dryden, Jas., Housing, Fertility of Eggs; Carbon-dioxide in Incubators. Utah Bul. No. 102.

Dryden, Jas., Housing Chickens. Oregon R. C. Lesson No. 2.

Dryden, Jas. and Lunn, A. G., A Colony House; A Trapnest. Expt. Sta. Cir. No. 4. Oregon.

Dynes, O. W., Laying Houses. N. Dakota Press Bul. No. 36.

England, (Univ. College), Housing and Feeding Poultry.

Fiske, Geo. B., Poultry Architecture (1907). Orange Judd Co., N. Y. City.

Gowell, G. M., Raising Chickens: "Pioneer House;" Feeding Hens, Maine Bul. No. 100.

Gowell, G. M., Houses: Breeding for Egg Production; Feeding. Maine Bul. No. 130.

Heath, D. C. \& Co., Wood Working Tools: How to use Them. Boston, Mass.

Hodgson, Fred T., Practical Carpentry. Industrial Pub. Co., N. Y. City.

Hodgson, Fred T., Cements, Concretes, Mortars, etc. Fred'k J. Drake \& Co., Chicago, III.

Hodgson, Fred T., Carpenters' Steel Square. Industrial Pub. Co., N. Y. City.

Hodgson, Fred T., Builders' Guide and Estimaters' Price Book. Industrial Pub. Co., N. Y. City.

Howard, Geo. E., The Feather's Up-to-date Poultry House. Howard Pub. Co., Washington, D. C. 
Hunter, A. F., Practical Farm Building. E. Walpole, Mass.

Inland Poultry Journal Pub. Co., Plans for Poultry Houses, Indianapolis, Ind.

International Correspondence Schools, Building Trade's Pocket Book. Scran. ton, $\mathrm{Pa}$.

Kidder, F. C., Building, Construction and Superintendence. Wm. T. Comstock, N. Y. City.

Kuhn, H. A., Poultry Architect (1894). Atlanta, Ga.

Lane, W. J., Poultry Houses. Minnesota Extension Bul. No. 8.

Opperman, C. L. and Patterson, H. J., Part I, Poultry House Construction. Maryland Bul. No. 146 .

Pennsylvania State Agr. College, Poultry Houses. Extension Cir. No. 6.

Radford, Wm. A., Handy Book of Barn Plans. Farm Press Pub. Co., Chicago, Ill. Reliable Poultry Journal Pub. Co., Poultry Houses and Fixtures. Quincy, Ill.

Rice, Jas. E., Building Poultry Houses (1903). Cornell Reading Course Bul. No. 16. Rice, Jas. E. and Lawry, R. C., Poultry House Construction. Cornell R. C. Bul. No. 33 .

Rice, Jas. E. and Rogers, C. A., Building Poultry Houses. Cornell Bul. No. 274. (I9I I).

Robinson, T. R., and Russell, E. J., Ventilation of Poultry Houses. S. E. Agr. Col. Wye, Eng.

Rogers, C. A., Poultry House Plans and Appliances. Circular No. 1. Cornell Dept. Poultry Husbandry.

Rogers, C. A., Working Plans of " $A$ "-shaped Gasoline-heated Brooder House. Cir. No. 3, Dept. Poultry Husbandry, Cornell University.

Rogers, C. A., Working Plans of the Equipment of the N. Y. State Gasoline-heated Colony Brooder House. Cir. No. 4. Dept. Poultry Husbandry, Cornell University.

Sanders, Pub. Co., Farm Buildings. Chicago, Ill.

Sickles, Ivin, Exercises in Wood Working. Amer. Book Co., N. Y. City.

Stewart, J. H. and Atwood, Horace, Warm or Cold Houses; Feeding. West Virginia. Bul. No. 7 r.

Stoddard, Dwight L., Steel Square Pocket-Book. Industrial Pub. Co., N. Y. City.

Stoddard, H. H., Poultry Architecture (1879). Hartford, Conn.

Stoneburn, F. H., Brooder Houses. Conn. (Storrs), Bul. No. 33. (1904).

U. S. Dept. Agricutlure, Construction and Ventilation of Poultry Houses. Farmers' Bul. No. 227 (Exp. Sta. Work).

U. S. Dept. of Agr., Gasoline-heated Colony Brooder House. Farmers' Bul. No. 381. (Exp. Sta. Work).

U. S. Dept. of Agr., Construction of Concrete Fence Posts. Farmers' Bul. No. 403.

Vale, W. W., Fowl Houses. English.

Wormley, P. L., Jr., Cement, Mortar and Concrete. U. S. Farmers' Bul. No. 235.

Webb Publishing Co., Poultry Houses, Coops and Equipments. St. Paul, Minn.

Willis, C. P., The Preservative Treatment of Farm Timbers. U. S. Dept. of Agric. Farmers' Bul. No. 387 .

\section{Incubation and Incubators}

Atkins, W. R. G., Osmotic Pressure of the Egg of the Common Fowl, and the Changes During Incubation. Bio-chem. Jour. 4 (1909) No. 10.

Barlow, J. H., Hatching Eggs by Steam, (1821). London. 
Brill, D. G., Chinese Incubation. U. S. Bu. Animal Industry Report 1900.

Brown, Edward, Practical Artificial Incubation. Cassell, London.

Bucknell, William, Eccaleobion: A Treatise on Artificial Incubation. (1839). Author, London.

Christy, Thomas, Guide to Poultry Rearing by Artificial Means. (I885). Christy. London.

Christy, Thomas, Hydro-incubation. (1877). London.

Cobb, Ernest, Incubation. "Feathered Life" Pub. Co., London.

Connecticut (Storrs), Carbon-dioxide Under Setting Hens. Report 1907.

Corbett, Adolphe, How to Hatch and Raise any Kind of Poultry with the Aid of Manure, (I874.) Hempstead, L. I.

Cyphers, C. A., Incubation and its Natural Laws, (1894). C. C. Du Puy, Syracuse, N. Y.

Day, W. H., Humidity in Relation to Incubation. Ontario Bul. No. I63.

Dryden, Jas., Housing: Fertility of Eggs: Carbon-dioxide in Incubation. Utah Bul. No. I02.

Dryden, Jas., Incubation Experiments. Oregon Bul. No. I00. (I908).

Dryden, Jas., Incubating and Brooding Chickens. Oregon R. C. Lesson No. 5.

Edwards, Chas. Lincoln, The Physiological Zero, and the Index of Development of the Egg of the Domestic Fowl. Biol. Bul. No. I, Trinity Col., Hartford, Conn.

England Nat. Poultry Organization Society, Eggs for Hatching. Leaflet No. 7.

England Univ. College, Artificial Incubation.

Eycleshymer, A. C., Observations and Experiments on the Natural and Artificial Incubation of the Egg of the Common Fowl. Dept. Anatomy, St. Louis, Univ. St. Louis, Mo.

Ferris, Artificial Incubation, (I880). Ferris Pub. Co., Albany, N. Y.

Fulmer, H. L., Chemical Work in Incubation Problems. Ontario Bul. No. 163. (I908).

Gowell, G. M., Fattening: Breeding for Egg Production; Incubation. Maine Bul. No. 79.

Graham, W. R., Hatching and Rearing Chickens. Ontario Agr. Col. Bul. No. 163 (I908).

Halsted, A. M., Artificial Incubation and Incubators. (1883). Albert Metz., N. Y. City.

Harcourt, R., Chemical Work in Incubation Problems. Ontario Bul. No. I63. (I908).

Hawks, E. B., Incubation and Brooding. Author. Clinton, Wis.

Hay, Wm., Incubation and Rearing of Chickens. English.

Hege, F. E., Feeding Experiments, Fattening Ducks; Incubator Tests. N. C. Bul. No. 152.

Huffaker, E. C., Artificial Incubation and Brooding. Cornell Inc. Co., Ithaca, N. Y. Jacobs, P. H., Incubators and Brooders. Fanciers' Review, Chatham, N. Y.

Mareacci, A., Influence du mouvement sur le development des oeufs de poule. C. R. Ac. Sci. Paris. T. I16, pp. 71-73. (1893).

Meyer, Verpackung der Brunteier in Kartons oder Korben. Deutsche landw, Geflug.-Ztg. Bd. 12, p. 764, (1909).

Nisson, C., Nisson on Incubation (for Pacific Coast), (1894). Petaluma, Cal.

Nourse, H. A., Chicks: Hatching and Rearing. 
Pearl, Raymond and Surface, F. M., Fertility and Hatching of Eggs. Maine Bul. No. 168.

Pennsylvania State Agr. College, Hatching Chicks with Incubators. Extension Cir. No. 5 .

Peters, Chas. F., Incubators and How to use Them. (1885). Philadelphia.

Rankin, Jas., The Incubator and its Use. Fanciers' Review. Chatham, N. Y.

Rankin, Jas., Sixteen Years' Experience in Artificial Poultry Raising. (1893). Phelps Pub. Co., Springfield, Mass.

Reliable Poultry Journal Pub. Co., Artificial Incubating and Brooding. Quincy, Ill.

Reprint from "Work," Incubators and Chicken Rearing Appliances. (1899). London.

Rhode Island, Incubation and Brooding; Poultry Feeding; Goose Experiments. R. I. Report 1902 .

Spalding, T. B., Standard \& Commercial Poultry Culture by Artificial Process. (1885). Amer. Poultry Journal, Chicago, Ill.

Stahl, J. M. and Wickey, E. W., Poultry Raising and Artificial Incubation. Champion Mfg. Co., Quincy, Ill.

Stewart, J. H. and Atwood, Horace, Incubation Experiments. West Virginia Bul. No. 73 .

Stewart, J. H. and Atwood, Horace, Factors Influencing the Vigor of Incubator Chicks. West Virginia Bul. No. 124.

Stoddard, H. H., Incubation, Natural and Artificial. Hartford, Conn.

Sutcliffe, J. H., Incubators and their Management. Doubleday, Page \& Co., N. Y. City.

Thorn, C. C., Carbon-dioxide in Relation to Incubation. Ontario Bul. No. 163. (1908).

U. S. Dept. Agriculture, Incubation of Chickens. Farmers' Bul. No. 28I (Exp. Sta. Work.)

Von Culin, E. and C., Art of Incubation and Brooding (1894). Delaware City.

Welch, O. H., Manual of Incubation. Boston.

Wood, R. H., Incubation and Incubators. U. S. Bu. An. Industry Report 1904; also U. S. Farmers' Bul. No. 236.

\section{Management}

Arbuthnot, Hon. Mrs., The Poultry Henwife (8th Ed. 1871). Simpkins, London. Arbuthnot, Hon. Mrs., Popular Poultry Keeping (1891). Menken, London. Arizona, Pin Money from Hens (1909). Timely Helps for Farmers No. 80.

Bacon, Geo. W., How to Succeed in Poultry Keeping for Profit or Exhibition (1876). London.

Bacon, Geo. W., Guide to Success in Poultry Keeping (1882). Bacon, London.

Baily, John, Fowls: A Plain and Familiar Treatise. Huming \& Hollis, London.

Beale, Stephen, Profitable Poultry Keeping (1886). Routledge, London.

Beeton, Saml. O., Book of Home Pets (Domestic Poultry), (1862). London.

Bell, G. A., Hints to Poultry Raisers. Cir. No. 82, U. S. Bu. Animal Industry.

Bell, G. A., Poultry Management. U. S. Farmers' Bul. 287.

Bennett, J. C., Poultry Book. Deff, London.

Biggle, Jacob, Biggle Poultry Book. Wilmer Atkinson Co., Phila., Pa.

Boswell, Peter, Poultry Yard (1848). Putnam, N. Y. City. 
Boswell, Peter, Treatise on the Poultry Yard (1840). Glasgow.

Boyer, M. K., A Living from Poultry, (1896). Farm Poultry Pub. Co., Boston.

Boyer, M. K., Profitable Poultry Farming (1896). Natick, Mass.

Boyer, M. K., Poultry Secrets. Wilmer Atkinson Co., Philadelphia.

Boyer, M. K., Money in Hens. Wilmer Atkinson Co., Philadelphia, Pa.

Brigham, A. A., Progressive and Profitable Poultry Culture (1908). The Torch Press, Cedar Rapids, Iowa.

Brooks, Wm. P., Poultry for Egg Production; Review of Experiments. Massachusetts Bul. No. 122.

Brown, Edward, Pleasurable Poultry Keeping (1894). Arnold, London.

Brown, Edward, Industrial Poultry Keeping (1892). Fanciers' Gazette, London.

Brown, Edward, Poultry Keeping as an Industry for Farmers and Cottagers (1892). Arnold, London.

Brown, Edward, Poultry Industry in Belgium. Brown, Dobson \& Co., London.

Brown, E., Rep. on Poultry Ind. in Denmark and Sweden (1908). London.

Brown, F. C., The Poultry Industry. New Zealand Journal of the Dept. of Agric. I (1910) No. 4 .

Brown, Will, Report of Committee on Poultry Breeding in Scotland. Edinburgh, Scotland.

Browne, D. J., American Poultry Yard, (1850). New York.

Burbridge, O. H., Mrs., California Poultry Culture. Pacific Fancier, Los Angeles, Calif.

Burnham, Geo. P., New Poultry Book. Lee and Shepard, Boston, Mass.

Burnham, Geo. P., New Poultry Book (1877).

Burnham, Geo. P., Walks and Talks about the Poultry Yard (1879). Melrose, Mass.

Burpee, W. Atlee, The Poultry Yard. Burpee \& Co., Philadelphia, Pa.

Burnham, Geo. P., Fowl Raisers' Hand Book. Melrose, Mass.

By an Association of Practical Breeders, American fowl Breeder: Containing full Information on Breeding, Rearing, Diseases and Management of Domestic Poultry. 1850. J. P. Jewett \& Co., Boston.

Central Experiment Farms, Stock and Buildings of the Station; First Production by Pullets of Different Breeds. Report 1888 .

Central Experiment Farms, Gain of Weight in Chickens; First Production of Pullets; Yearly Egg Production (Different Breeds); Weight of Eggs; Management. Report 1889.

Central Experiment Farms, Winter Treatment of Hens; Broodiness; Incubation; Gain of Weight in Chicks, etc. Report 1890.

Central Experiment Farms, Different Breeds in Confinement, Gain in Weight of Chicks, Egg Production after Molt, etc. Report 1892.

Central Experiment Farms, Poultry Houses and Fixtures; Exercise, Winter Egg Production of Different Breeds, etc. Report 1893 .

Central Experiment Farms, Rations; Breeds for Eggs; Gain in Weight of Chicks; Crosses, etc. Report 1894.

Central Experiment Farms, Markets; Egg Production; Gain in Weight of Chicks; First Production after Molt, etc. Report 1895.

Central Experiment Farms, Yearly Egg Yield; Care of Pullets; Fertility of Early Eggs; Molting Period, etc. Report 1898 .

Central Experiment Farms, Production of Pullets and Old Hens; Early or Late Hatched Pullets; Winter Egg Production of Pullets; Fattening, etc. Report 1899. 
Central Experiment Farms, Incubation; Weight of Chicks (gain); Test of Breeds for Eggs; Preservation of Eggs, etc. Report 1900.

Central Experiment Farms, Houses; Feeding; Production after Molt, etc., Report 1896.

Central Experiment Farms, Feeding and Management; Weight of Chicks; Fattening; Molt of Early Pullets, etc. Report 1901 .

Central Experiment Farms, Gain of Weight in Chicks; Winter Egg Production of Different Breeds; of Hens and Pullets; Preservation of Eggs, etc. Report 1902.

Central Experiment Farms, Egg and Poultry Market; Molting; Early Hatched Pullets for Winter Eggs; First Production of Pullets, etc. Report 1904.

Central Experiment Farms, Cost and Profit of Egg Production; Test of Breeds; Fattening; Winter Egg Production, etc. Report 1905.

Central Experiment Farms, Houses; Hopper Feeding; Incubation; Brooding; First Production of Pullets; Yearly Egg Production, etc. Report 1906.

Chamberlain, Jas., Guide to Poultry Keeping. (I18I) Norwich.

Chesney, Jane, Poultry Keeping in Normandy. Macmillan's Magazine.

Chesney, Jane, Poultry Keeping as a National Industry. Macmillan's magazine. Cobb, Ernest, Feeding and Housing Poultry. English.

Cobb, Ernest, Poultry Farming up to Date. Feathered World, London.

Cock, Micajah R., American Poultry Book, (1843). Harpers, N. Y. City.

Cole, L. J., Method of Keeping Pedigree Records. Div. of Biol. Papers No. 3 (1909). Rhode Island Agr. College.

Collingwood, H. W., The Business Hen. Rural New Yorker, N. Y. City.

Comyns, Alexander, Poultry for the People. English.

Contributors to the Cottage Garden and Poultry Chronicle, Poultry Book for the Many. (1857). Winchester, London.

Cook, Wm., Practical Poultry Breeder and Feeder. (1883) London.

Corbett, Adolphe, Raising of Poulty; Diseases. Orange Judd, N. Y.

Craig, Francis D., Complete Poultry Manual. (1886) Author. No. Evanston, Ill. Cypher's Series, Profitable Egg Farming. Cypher's Incubator Co., Buffalo, N. Y. Cypher's Series, Profitable Poultry Keeping in all its Branches. Cypher's Incubator Co., Buffalo, N.Y .

Darrah, H. C., Poulterers' and Farmers' Guide. (1874) Dubuque, Iowa.

Darrow, J. W., 500 Questions and Answers in Poultry Keeping; A Book of Practical and Authentic Information in the Form of Questions and Answers on Various Subjects, as Feed and Care, Diseases, Eggs, Incubators, Buildings, etc., with a Chapter on Turkeys, Geese, and Ducks. (1891-1894). Fanciers' Review, Chatham, N. Y.

Davidson, W. R., Practical Poultry Culture.

de la Bere, Kinard Baghot, "A I" Poultry Book. Houlston \& Sons, London.

de la Bere, Kinard Baghot, How the French Make Fowls Pay (1871). Bosworth, London.

De Salis, Harriet A., Mrs., New Laid Eggs (1892). Longmans, Green \& Co., London.

Dickson, W. B., Poultry: Their Breeding, Rearing, Diseases and General Management.

Dodge, J. A., The Poultry and Egg Industry of the United States. U. S. Bu. An. Ind. Report 1891-2.

Donaldson, Hon. M. L., Poultry Raising (1909). S. Carolina Bul. No. 3. 
Doubleday, Page \& Co., Poultry Book. New York City.

Doyle, Martin, Illustrated Book of Domestic Poultry (1892). Philadelphia, Pa. Dryden, Jas., Old Hens vs. Pullets; Exercise; Breeds, etc. Utah Bul. No. 5I.

Dryden, Jas., Year-old Hens vs. Pullets; Exercise; Cost of Food, etc. Utah Bul. No. 60.

Dryden, Jas., Hens vs. Pullets; Exercise, Cost of Food, etc. Utah Bul. No. 67.

Editors of the "Poultry Book," Poultry Keepers' Pocket Almanac and Diary of Proceedings (1854-87). London.

Eliot, James (Mrs.), Profitable and Economical Poultry Keeping. (1885). Ward, Locke \& Co., London.

Elkington, W. M., Egg and Poultry Raising at Home. Doubleday, Page \& Co., New York City.

English, Eggs all Year Around at 4d. per Doz. Chickens at 4d. per lb.; Containing Full and Complete Information for Successful and Profitable Keeping of Poultry. (1875). Macmillan, London.

English, Poultry for the Many; Selection, Breeding and Management. May, London.

English, Poultry Keeping; Hints for Mistress and Maid (1877). Houlston, London.

English, Poultry Maid (1857), Houlston, London.

English, Profitable Fowls and Eggs, and How to Make Money of Them. (1866). London.

Erf, Oscar, Farm Poultry. Kansas Dept. Agr. Report 1907-8.

Felch, I. K., Amateur's Manual, (1877). Boston Photo Electrotype Co.

Felch, I. K., Breedings and Management of Poultry, (1877). Norfolk Co., Gazette, Hyde Park, Mass.

Felch, I. K., Poultry Culture (1886). W. H. Harrison, Jr., Chicago, Ill. IIl.

Felch, I. K., Standard American Perfection Poultry Book, Donohue \& Co., Chicago,

Foley, A. W., Methods, Poultry Bul. No. I (1907). Dept. of Agr. Education, Alberta.

Fortey, W. S., Poultry Keeper's Guide (1890). London.

Fossum, Andrew, Poultry and Egg Industry in Europe. Bul. No. 65. U. S. Bu. Animal Industry.

Gardiner, H. C., Poultry Raising. Montana Bul. No. 26.

Gardiner, H. C., Poultry Experiments. Montana Bul. No. 32.

Geyelin, G. K., Poultry Breeding in a Commercial Point of View (1867). A. Williams \& Co., Boston.

Gilbert, A. G. and Fortier, Victor, Breeding, Feeding, Management. Ottawa Bul. No. 54 .

Gilbert, A. G., Experiments with Poultry. Central Expt., Farms Report, 1909.

Glasby, W. P., Poultry Pension.

Gowell, G. M., Management, Housing, Feeding. Maine Bul. No. 144.

Gowell, G. M., Hens to One Pen; Trapnests. Maine Report 1898 .

Graham, C. K., Suggestions to Amateurs. Conn. (Storrs) Bul. No. 36. (1905).

Graham, C. K., Poultry Culture. Conn. (Storrs) Bul. No. 52. (1908).

Graham, W. R., Farm Poultry (1903). Ontario Bul. No. I27.

Graham, W. R., Farm Poultry (1907). Ontario Bul. No. 15I. 
Greene, C. S., Poultry in Minnesota. Minn. Bul. No. 91 .

Haig, J. P., Common Sense in the Poultry Yard, (1885). Industrial Pub. Co., New York City.

Halpin, Jas. G., Poultry Raising (1907). Michigan Bul. No. 245.

Harrison, T. H., Suburban Poultry Keeping. London.

Hastings, Milo M., The Dollar Hen (1909). Arcadia Press, New York City.

Hawkins, H. V., Journal Dept. of Agr. (I910) Part I, Poultry Farming in Small Holdings. Proceedings of the South Australian Poultry Conferences (1910).

Hawks, E. B., Science and Art of Poultry Culture (1909) Author, Clinton, Wis.

Heck, Frank, Nine Hundred, Ninety-Nine Questions and Answers. (1903).

Hege, F. E., Poultry Keeping for Profit. North Carolina Bul. No. 130. (1896).

Henderson, J. A., Poultry and Eggs for Market and Export (1896). Wellington, N. 2 .

Hicks, Reese V., Tricks of the Poultry Trade. Poultry Pub. Co., Topeka, Kan.

Hodson, R. W., Practical Poultry Raising. Dept. Agr., British Columbia.

Hunter, A. H., Profitable Poultry Raising. Maine Report 1894-5.

Husselman, Cal., Southern Poultry Guide, Forty Years with Poultry.

Indiana, Purdue University. How to Produce Good Market Eggs. Newspaper Cir., No. 176.

Jacobs, W. S., Farm Poultry. Arkansas Bul. No. 99, (1908).

Jacoby, F. S., A Poultry Primer (1911). Kansas, Agr. Col.

Jennings, Robert, Swine, Sheep and Poultry (1864). J. E. Potter, Philadelphia, Pa.

Johnson, W. G. and Brown, Geo. O., The Poultry Book, Vols. I, II, III.

Johnson, G. M. F., Poultry for Pleasure and Profit (1885). Binghamton, N. Y.

Johnson, G. M. F., Practical Poultry Keeping (5th Ed. 1886). Binghamton, N. Y.

Kansas, Profitable Poultry Report, 1908.

Kansas, Farm Poultry. Report for Quarter ending March, I9Io.

Laurie, D. F., Hints and Advice on the Breeding and Rearing of Poultry (1895). Adelaide, S. Aus.

Laurie, D. F., Poultry Expert. Australia Report 1907-8. Hawkesbury Agr. Col. Laurie, D. F., Poultry Manual. Australia (1909). Hawkesbury Agr. Col.

Lawler, P. H., Poultry Industry of Petaluma, Calif. Cir. No. 92 and U. S. Report 1904, U. S. Bu. Animal Industry.

Lee, J. Henry, Some of Lee's Ideas. Hammonton, N. J.

Lewis, W. M., The People's Practical Poultry Book (1871). Rural New Yorker, New York City.

Linfield, F. D., Poultry Management: Poultry Diseases. Montana Bul. No. 50. Mairs, Thos. L., Poultry Experiments. Pennsylvania Bul. No. 87 (1908).

Major, B., Poultry Chitchat. (1888). Eyre and Spottiswoode, London.

Martin, J. D., Key to Successful Poultry Keeping (1887). Progress Pub. Co., Sullivan, Ill.

Martin, Wm. C. L., Our Domestic Fowls, (1847). Religious Tract Society, London. Martin, Wm. C. L., Poultry Yard (1853). Roultledge, London.

Mascall, Leonard, Husbandlye Ordering and Government of Poultry (1581). London.

McGrew, T. F., Egg Question Solved. G. E. Howard Pub. Co., Washington, D. C. Michigan, Poultry at the Michigan Station. Report 1895.

Michigæn, Poultry Experiments. Michigan Report 1896. 
Miner, T. D., Domestic Poultry Book, (1853). G. F. Fisher, Rochester, N. Y. Minnesota (Crookston), "Poultry," Bulletin No. II9.

Missouri State Poultry Ex. Sta., "Poultry Pointers and Possibilities." Third Annual Report.

Mitchell, E. Pryce, Practical Poultry Plant for Southern California.

Moffatt, John M., Domestic Poultry, (1870). Dean, London.

Myers, John A., Breeds and Management. W. Va. Bulletin, No. 45. (1896).

Opperman, C. L., Poultry Industry in Maryland. Maryland Bulletin, No. 138.

Ontario Agric. Col., Water Fountains; Poultry Houses, and Appliances; Poultry Diseases. Ontario Agric. Col. Report I896.

Ontario Agric. Col., Diseases and Parasites; Incubation; Feeding; etc. Report, 1897.

Ontario Agric. Col., Egg Preservation; Fertility of Eggs; Cross-breeding. Report 1899.

Ontario Agric. Col., Feeding for Egg Production; Incubation; Rearing Broilers and Ducks; Fattening. Report 1900.

Ontario Agric. Col., Cost of Summer Eggs (different breeds); Fattening. Report 1901.

Ontario Agric. Col., Early or Late Hatching; Fattening; Care of Breeding Stock. Report 1902.

Ontario Agric. Col., Early or Late Hatching; Incubation; Fattening. Report 1903.

Ontario Agric. Col., Early or Late Hatching; Houses; Forced Molt; Fattening. Report 1904.

Ontario Agric. Col., Care of Breeding Stock; Incubation Houses; Fattening (gain of different breeds). Report 1905.

Ontario Agric. Col., Incubation; Brooding; Fattening; Weed Seeds for Poultry; Growth of Ducks. Report 1906.

Ontario Agric. Col., Selecting Laying Hens; Trapnesting; Incubation; Brooding; Vitality. Report 1906-7.

Ontario Agric. Col., Houses; Trapnesting; Brooding; Fattening. Report 1907.

Orange Judd Co., Profits in Poultry; Useful and Ornamental Breeds, and their Profitable Management (1887). New York City.

Orr, T. E., Poultry in Pennsylvania. Pennsylvania Dept. Agric. Bul., No. 143, (1906).

Pearl, Raymond and Surface, F. M., Poultry Notes. Maine Bul. No. 165.

Pearl, Raymond, Methods of Poultry Management at the Me. Agric. Sta., (1909). U. S. Farmers' Bul. No. 357.

Pendergast, N. R., Fifteen Years of Poultry. City.

Pettingill, Bates \& Co., Hearth and Home Handbook of Poultry (1870). New York

Phillips, Sampson \& Co., Poultry Book; A Treatise on the Breeding and Management of Domestic Fowls. Boston, Mass.

Pope, W. J., Poultry of the Farm. (I88I) London.

Powell, E. C., Making Poultry Pay. Orange Judd Co., New York City.

Purvis, Miller, Farm News Poultry Book. Author, Peotone, I11.

New South Wales Dept. of Agric., Conference of Poultry Farmers. Farmers' Bul. No. 39 .

New York Bu. Farmers' Institutes, Report 1901. Building Poultry Houses; Feeding; Management; Incubation and Brooding; Turkeys; Egg-laying type. 
New Yor's Bu. Farmers' Institutes, Report 1905. Poultry Industry; Construction; Discases; Preserving Eggs; Roup; Embryology; Comparative Physiology; Parasites; Avian Tuberculosis.

New York Bu. Farmers' Institutes, Report 1906. (Normal Institute) and Report 1907. Recent Investigations; Poultry Culture; Poultry Shows; Running a Squab Plant.

New Zealand Dept. Agric., Report of the Poultry Div., 1907.

New Zealand Dept. Agric., Report of the Poultry Div., 1908.

New Zealand Dept. Agric., Report of the Poultry Div., 1909.

Niles, Wm., Illustrated Pacific Coast Poultry Book. (1880). S. E. Wurst, Elyria, O. N. Carolina, Farm Poultry, (1907). N. C. Bul. No. 195.

Norys, Myra V., Egg Poultry Keeping for Invalids.

Norys, Myra V., Pocket Money Poultry. (1899), Washington, D. C.

Pearl, Raymond and Surface, F. M., Poultry Notes. Me. Agric. Ex. Sta., Bul. No. 179 .

Reliable Poultry Journal Pub. Co., Eggs and Egg Farms. Quincy, Ill.

Reliable Poultry Journal Pub. Co., Successful Poultry Keeping. Quincy, Ill.

Report of Meeting of Breeders and Experts, Raising and Management of Poultry. (Mch. 7-I4, I885), Cuppers, Boston.

Rhode Island, Visits to Poultry Plants; Buildings; Breeding; Roup; Ventilation of Poultry Houses. Report I891.

Rhode Island, Narrow vs. Wide Rations; Preservation of Eggs; Blackhead; Mortality of Incubator Chicks; Nest Boxes; Rations. Rhode Island Reds, Report I90I.

Rice, J. E., Poultry Farm Management. New York Dept. Agric., Bul. No. II.

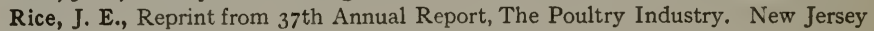
Agric. Col.

Rice, J. E., Poultry Problems. Pennsylvania Dept. of Agric., Bul. No. I5I.

Rice, J. E., Recent Experiments in Poultry Husbandry. Report Bu. Farmers' Institutes, (I906).

Richardson, H. D., Domestic Fowls, (1846). Jas. McGlasham, Dublin.

Robinson, J. H., First Lessons in Poultry Keeping; First and Second Year Courses. Farm Poultry Pub. Co., Boston, Mass.

Robinson, J. H., Poultry Craft. Farm Poultry Pub. Co., Boston, Mass.

Robinson, J. H., Winter Eggs and How to Get Them. Farm Poultry Pub. Co., Boston, Mass.

Rogers, Geo., Poultry and Pets. Fort Wayne, Ind.

Rogers, J. J., Directory for Management of Poultry, (1858). Dean, London.

Roland, Arthur, Poultry Keeping (1879). London.

Routledge, Lady Housekeeper's Poultry Yard. London.

Salmon, D. E., Poultry Raising on the Farm. U. S. Farmers' Bul., No. I41.

Schureman, J. F., Poultry Lessons for the Amateur.

Salmon, D. E., Poultry Raising on the Farm. U. S. Bu. Animal Industry. Report, 1900.

Sanborn, N. W., One Year's Work with Money Making Birds.

Sando, R. B., American Poultry Culture.

Saunders, Simon M., Domestic Poultry, (1865). Orange Judd Co., New York City. Shackleton, Jas., System in Poultry Practice (1904). Milburn, N. J.

Sheppers, J. H. and Dynes, O. W., Poultry Experiments (1907). N. Dak. Bul. No. 78. 
Shinooka, C., Poultry Keeping in Japan. (Govt.) Tokio, Japan.

Smith, C. D. and Brooks, W. P., Housing; Incubation; Feeding; Eggs. Mich. Bul., No. 158 .

Stoddard, H. H., The New Egg Farm. Orange Judd Co., New York City.

Stoddard, H. H., Poultry Compendium. Hartford, Conn.

Stewart, J. H. and Atwood, Horace, Poultry Management. W. Va. Bul. No. Ir5. Sutcliffe, J. H., Poultry Farming Profitable. Doubleday, Page \& Co., New York City. Taggart, John, New American Poultry Book, (1884). Crawford, Philadelphia, Pa. Taylor, (Mrs.) May, The Hen Business.

Tegetmeier, Wm. B., Poultry Book. Routledge \& Son, London, Eng.

Tegetmeier, Wm. B., Poultry for Table and Market vs. Fancy Fowls. (1892), Horace Cox, London.

Thorne, C. E., Complete Poultry Book. (I 882), Springfield.

Tilson, Sewall, Poultry Manual. Doubleday, Page \& Co., New York City

No. 5 .

Titlow, C. B., Hints on Poultry Raising (I9II). Ohio Extension Bul. Sup. No. 4,

Tweed, J., Poultry Keeping in India (I894).

U. S. Dept. Agric., Best Number of Hens to One Pen. U. S. Farmers' Bul. No. I I 4, (Exp. Sta. Work).

U. S. Dept. Agric., Rations for Laying Hens; Early Molting Hens; Evaporation of Incubator eggs. U. S. Farmers' Bul. No. I86 (Exp. Sta. Work).

U. S. Dept. Agric., Cost of Eggs in Winter; The Chicken Mite. Farmers' Bul., No. 190.

U. S. Dept. Agric., Amateur Poultry Raising. Farmers' Bul., No. 237. (Exp. Sta. Work).

U. S. Dept. Agric., Incubation of Eggs; Snow for Poultry; Causes of Death in Chicks. Farmers' Bul. No. 309, (Exp. Sta. Work).

Vale, W. W., Chickens and Fowls. English.

Vale, W. W., Profitable Poultry. English.

Valentine, C. S., How to Keep Hens for Profit. MacMillan Co., New York City.

Van Benschoten, W. H., How to Raise Poultry on a Large Scale. (1880), H. H. Stoddard, Hartford, Conn.

Valpon, W. E., Poultry Raising (1910). Colorado Bul., No. I64.

Voltz, W., Studien über den Stoffwechsel des Haushuhnes Fütterungs-versuche mit Kartoffeln, Roggen und Hafer, Landwirt, Jahrb. Bd. 38, pp. 553-592, (I909.)

Walnut Pub. Co., How to Make $\$ 500$ a Year Keeping Poultry. (1894) Boston.

Warren, Edgar L., 200 Eggs a Year per Hen and How to Get Them. C. C. Du Puy, Syracuse, N. Y.

Warren, Edgar L., Two Dollars a Day from Poultry and Egg. C. C. Du Puy, Syracuse, N. Y

Watson, G. C., Fowls; Care and Feeding. U. S. Farmers' Bul., No. 41.

Watson, Geo. C., Farm Poultry. MacMillan Co., New York City.

Weir, Harrison, In the Poultry Yard (1878). Religious Tract Society, London.

Wheeler, W. P., Experiments with Poultry (Summary of Expts. 1888-1907). Geneva, N. Y.

Wilcoxon, Mrs. B. F., Common Sense in Poultry Raising.

Wing, H. H., Cost of Egg Production (1902). Cornell Bul., No. 204.

Wing, H. H., Yearly Egg Production (1903). Cornell Bul., No. 2 Ir. 
Wing, H. H., Cost of Producing Eggs, (1903). Cornell Bul., No. 212.

Witbycomb, Jas., Poultry under Confinement. Oregon Bul., No. 84 .

Wittman, W. Theo., Cream from a Poultry Scrap Book, Parts I and II. Amer. Poultry Journal Pub. Co., Chicago, Ill.

Wittman, W. T., Twelve Months' Work in the Poultry Yard. Poultry Item Pub. Co., Sellersville, Pa.

Woods, C. D. and Gowell, G. M., Poultry at the Me. Station. Bul. No. 90. U. S. Bu. Animal Industry.

Woods, C. D., Review of Work at Me. Station. Maine Bul. No. 157.

Wright, Lewis, The Illustrated Book of Poultry, (1886). London, Eng.

Wright, Lewis, New Book of Poultry (1901). Cassell \& Co., London and New York City.

Wright, Lewis, Practical Poultry Paper, (1867, 1874, 1879). Cassell \& Co., London.

American Poulterers' Companion, (1845). New York.

Practical Poultry Book for Both Farmer and Fancier, (1884) Pennsylvania.

Poultry; How to Manage. Ward \& Lock, (1880) London.

Two Years with Poultry (1909), Mt. Morris, Ind.

\section{Markets and Marketing}

Alvord, Henry E., Foreign Markets for Eggs and Poultry. U. S. Bureau Animal Industry Rep. 1899.

Arizona, Preserving Eggs. Bul. No. 60.

Bickel, M. V., Poultry Packers' Guide (1909). Pool Pub. Co., Mason City, Iowa.

Boos, W. F., Chemical examination of Drawn and Undrawn Poultry. 39 (1907), pp. 263-283. Am. Rep. Mass. Bd. Health.

British Columbia, The Marketing of Eggs. Jour. Dept. Agr. 7 (1909), No. 9.

Brown, W. A., The Poultry Industry. Maine Dept. Agr. Bul. No. 3. Vol. 9.

Cavana, M., Danger of Undrawn Poultry and Game. Oneida Despatch, Oneida, N. Y.

Central Experiment Farms, Preservation of Eggs. Report 1907. Ottawa, Canada.

Cooper, Madison, Practical Cold Storage. Wickerson \& Collins, Chicago, Ill.

Emmett, A. D. and Grindley, H. S., Chemistry of Flesh-A Preliminary Study of the Effect of Cold Storage on Beef and Poultry. Jour. Indus. and Engine. Chem. I (1909) nos. 7 and 8.

England, Bd. Agr. and Fisheries, Preservation of Eggs. Leaflet No. 83 .

England, Bd. Agr. and Fisheries, Coōperative Egg and Poultry Societies. Leaflet No. 110.

England, Bd. Agr. and Fisheries, Sale of newly-hatched Chicks. Leaflet No. 157.

England, Bd. Agr. and Fisheries, Marketing Poultry. Leaflet No. 201.

England, National Poul. Organization Society, Equipment for Eggs and Poultry Depots. Leaflet No. 6.

England, National Poul. Organization Society, Marketing Eggs and Poultry. Leaflet No. 8.

England, National Poul. Organization Society with Agr. Organization Soc., Formation of Egg and Poultry Societies. Joint Leaflet No. I. bia.

Hart, A., Poultry Export Trade. Jour. Dept. Agr. 6 (1908) No. 1. British Colum- 
Hastings, Milo, Egg Trade of the United States. Cir. No. I40. U. S. Bu. Animal Industry.

Hastings, Milo, A Cold Storage Evaporimeter. U. S. Bu. of Animal Industry. Cir. No. 149.

Hendrick, J., Preservation of Eggs in Water Glass. Bul. No. 8. Aberdeen and No. Scotland Col. Agr., Scotland.

Higley, H., Bacteriology of the Drawn Poultry Question. N. Y. Poultry and Game Trade Assoc., N. Y. City.

Hill, Geo. G., Marketing Farm Produce. U. S. Farmers' Bul. No. 62.

Hyde, D. D., Poultry and Eggs for Market. N. Z. Agr. Dept. (1908).

Indiana, Purdue University, Improving Indiana Egg Conditions. Newspaper Cir. No. 177.

Ireland, Bd. of Agr. Journal, Marketing Eggs and Poultry. (Apr., 1907).

Jeffrey, J. S., Preservation of Eggs: Bibliography (1895). N. C. Bul. No. 191.

Ladd, F. E., Preservation of Eggs. North Dakota Bul. No. 35 and 44.

Lamson, G. H., Jr., Infection and Preservation of Eggs. Conn. (Storrs) Bul. No. 55 .

Lamson, G. H., Water-Glass as an Egg preservation (19ro). Conn. (Storrs) Bul. No. 67.

Morvier, F. R. and Skinner, R. R., Poultry and Eggs. Daily Cons. and Trade, Rep. U. S. (1909), No. 3400. U. S. Dept. of Agr.

Pennington, M. E., Changes in Cold Storage Chickens. Year Book (1907) of U. S. Dept. Agr.

Pennington, M. E., How to kill and Bleed Market poultry. U. S. Bu. of Chemistry, Cir. No. 6r.

Pennington, M. E., Studies of Poultry from the Farm to the Consumer. U. S. Bu. of Chemistry. Cir. No. 64.

Pennington, M. E., Comparative Rate of Decomposition in Drawn and Undrawn Poultry. U. S. Bu. of Chemistry. Cir. No. 70.

Pierce, H. C., Knife for Killing Poultry. U. S. Dept. Bu. of Chemistry. Miscellaneous.

Pierce, H. C., Home Preservation of Eggs. Iowa Press Bul. No. 17.

Phillips, A. G., The Marketing of Eggs. Kansas Bul. No. 162.

Plumb, C. S., The Marketing of Eggs. (1911) Ohio Extension Bul. No. 8.

Rice, Jas. E., Marketing Poultry Products-(1904). Cornell Reading Course. Bul. No. 20.

Riddell, S., Dietetic Value of Refrigerated Foods. Cold Storage and Trades Jour. 36 (1908) No. 4.

Salmon, D. E., Foreign Markets for Eggs and Poultry. Cir. No. 147, U. S. Bu. Animal Industry.

Slocum, R., Marketing Eggs Through the Creamery. U. S. Dept. of Agr. Farmers' Bul. No. 445.

Stoddard, H. H., How to Preserve Eggs. (1885) Hartford, Conn.

Stoneburn, F. S., Marketing Poultry Products. Conn. (Storrs) Bul. No. 38 (1906). Thatcher, R. W., Preserving Eggs. Washington Bul., No. 71 .

Thomas, S. V., How to Dress Poultry. A. D. Hosterman \& Co., Binghamton, N. Y.

U. S. Dept. of Agr., Improved Egg Preservation. Con. and Trade Rep. (Ig09) No. 3377. 
U. S. Dept. Agr., Preserving Eggs. Farmers' Bul. No. 103. (Exp. Sta. Work.)

U. S. Dept. of Agr., Cold Storage on the Farm. Farmers' Bul. No. I19. (Exp. Sta. Work.)

U. S. Dept. Agr., Dressing and Packing Poultry. Farmers' Bul. No. 144. (Exp. Sta. Work).

U. S. Dept. Agr., Preserving Eggs. Farmers' Bul. No. 273. (Exp. Sta. Work.)

U. S. Dept. Agr., Preserving Eggs. Farmers' Bul. No. 296. (Exp. Sta. Work.)

Wheeler, W. P., Oyster Shells for Hens; Skim-milk for Chicks; Tallow for Hens; Salt for Hens; Preserving Eggs. N. Y. (Geneva) Rep. (190I).

Wiley, H. W., A Preliminary Study of the Effects of Cold Storage on Eggs, Quail, and Chickens. U. S. Bu. of Chemistry Bul. No. 115.

\section{Miscellaneous}

Abel, Mrs. Mary Hinman, Care of Food in the Home. U. S. Dept. of Agric. Farmers' Bul. No. 375 .

Atwater, Helen, Poultry as Food. U. S. Farmers' Bul. No. 182.

Aunt Chloe, One Hundred Methods of Cooking Poultry, (I 888).

Beal, W. H., Barnyard Manure. U. S. Farmers' Bul. No. 192.

Brigham, A. A., Instruction in Poultry Culture. R. I. Bul. No. 72 (1900).

Brown, Edward and W., Value of Poultry Manure. Jour. Bd. Agric. (Mar. 1907). London.

Burnham, Geo. P., History of the Hen Fever. J. French \& Co., Boston, Mass.

Byam Printing Co., Poultry Breeders' Egg and Poultry Record. North Adams, Mass.

Clark, W. H., Poultry on Farms. Govt., N. S. Wales, Farmers' and Fruit Growers' Guide, pp. 399-415 (1897).

Connecticut, (Storrs), Poultry as Food; Analysis of Poultry Feeds. Reports 1902-3.

Cooper, J. M., Treatise on Cooking (1895). Media, Pa.

Cushman, A. S., Corrosion of Fence Wire. U. S. Farmers' Bul. No. 239.

Dearborn, Ned., How to destroy English Sparrows. Farmers' Bul., No. 383. U. S. Dept. of Agr.

Dorsey, W. R., Fowls and Eggs in China. U. S. Daily Cons. and Trade Rep. (1909) No. 3637 .

Duerden, J. E., Egg Laying Records of Ostriches. 32 (1908) No. 4. Agr. Jour. Cape Good Hope.

Duerden, J. E., Experiments with Ostriches. 32 (1908) No. 6 Agric. Jour. Cape Good Hope.

England, Bd. Agric. and Fisheries, Mutual Insurance of Live Stock. Leaflet No. 221. English, Poultry Keepers' Account Book and Hand-Guide (1871). Letts, London.

Gould, W. B., Poultry Keepers' Complete Account Book. London (1886).

Houssay, F., Variations experimentales Etudes sur six generations de poules carnivore. Arch. Zool. Exper. et Gen. IV, Ser. T. VI. pp. 137-332. (1907).

Ireland, Bd. of Agr. Journal, 9 (1908) No. I. Egg Records.

Katz, D. und Revesz, G., Versuche uber das Gedachtnis der Huhner. Ztschr f Psychol u Physiol. D. Sinnesorg. Leipzig. Bd. I pp. 93-110. 1908.

Kuns, H. A., Egg Record and Poultry Account Book. Atlanta, Ga.

Langworthy, C. F. and Hunt, Caroline L., Economical use of meat in the Home.

U. S. Farmers' Bul. No. 39r. 
Lee, Alfred R., The Ostrich Industry in the U. S. U. S. Bu. of Animal Industry Cir. No. 172.

Maine, Work of Dept. of Biology of Expt. Sta. (1908).

McDowell, R. H., Burning Dead Animals. Nevada Bul. No. 53 .

Milner, R. D., Poultry as Food, (1903). Conn. Bul. No. 27.

Montana College of Agr., Announcement of School of Agri. Bul. of State Col. of Agr. 7 (1910) No. 4.

Mulligan, Catherine A., Plain cookery, (Eggs, meats, Poultry, etc.). Normal and Industrial College Bul. No. I (1907), North Carolina.

New York, Bu. Farmers Institute. Rep. 1900 Poultry Discussions.

Pearl, Raymond and Surface, F. M., Use of Atropine Sulphate in Anasthetizing Birds for Surgical Operations. Jour. Animal Ind. Assoc.

Pickerell, Watson, Ostrich Farming in America. U. S. Dept. of Agric. (1905).

Slocum, R., A System of Poultry Accounting. U. S. Dept. of Bu. of Animal Industry. Cir. No. 176.

South Dakota. Poultry Progress. South Dakota (Correspondence course).

South Dakota Agric. College, Correspondence Courses. Bul. 8 (I9ro) No. 2.

U. S. Dept. Agr., Hen Manure. U. S. Farmers' Bul. No. 210 (Exp. Sta. Work).

U. S. Dept. of Agr., Preservation of Fence Posts. Farmers' Bul. No. 320.

ठ. S. Dept. Agr., Poultry Manure. U. S. Farmers' Bul. No. 384 (Exp. Sta. Work.)

U. S. Bu. of Biol. Survey, Wild Animals and Birds Which May be Imported without Permits. Circular No. 30.

U. S. Office of Experiment Stations, Syllabus of Illustrated Lecture on the Production and Marketing of Eggs and Fowls. Farmers' Institute Lecture No. 10.

Weiss, H. F., Preservative Treatment of Fence Posts. Cir. No. 117. U. S. Div. Forest Service.

\section{Pheasants and Game Birds}

A Poultry Farmer, Poultry for Exhibition, House, and Market. A Chapter on Pheasants. (1888). Sormenschein, London.

Cook, Wm., Pheasants, Turkeys, and Geese. (1892) Author, London.

Darlington, C. L., Pheasants.

Oldys, Henry, Pheasant Farming in the U. S. U. S. Farmers' Bul. No. 390.

Oldys, Henry, Introduction of the Hungarian Partridge into the U. S. Year Book 1909 of U. S. Dept. of Agric.

Oldys, Henry, Introduction of the Hungarian Partridge into the U. S. Year Book 1909 of U. S. Dept. of Agr.

Palmer, T. S. and Oldys, Henry, Importation of Game Birds and Eggs for Propagation. U. S. Farmers' Bul. No. 197.

Simpson, G. M., Pheasant Farming. R. P. J. Pub. Co., Quincy, IU.

Sudow, F. J., Reliable Pheasant Standard. Poughkeepsie, N. Y.

\section{Physiology}

Basch, K., Zur Thymusextirpation beim jungen Hunern, Monatsch. fur Kinderheilkunde Bd. VII. No. 9, 1908.

Butler, Arthur G., Feathers Changing Color. Avicult. Mag., Vol. 8 (1902) pp. 132135 Rev. Zool. Anz. Bd. 34, p. 302. 
Brunotte, C., Greffe animale chez un coq domestique. Bull. Soc. Sc. Nancy T. 8. pp. 140-143, (1907). Rev. Zool. Anz. Bd. 34, p. 352.

Curtis, M. R., Biganieuts of the Oviduct of the Domestic Fowl. Maine Bul. No. 176.

Davenport, C. B., The Factor Hypothesis in its Relation to Plumage Color. Amer. Br. Assoc. Rep. No. 5 (1909).

Davenport, C. B., The Transplantation of Ovaries in Chickens. Jour. of Morphol. Vol. 22 (1911) No. 1.

Drew, G. A., Hens That Have Laid Two Eggs a Day. Science (N Ser) 26 (I907) No. 656 .

Durski Staneslaw, P., Die pathologishen Veranderungen der Eies und Eileiters bei den Volgeln. Dissertation, Bern. (1907).

Dwight, Jonathan, Jr., Plumages and Molts of the Passerine Birds of New York. Annuals N. Y. Acad. Scr. 13 (1900) Oct. 3I.

Edgeworth, F.H., The Development of the Head Muscles of Gallus Domestieus, and the Morphology of the Head Muscles. O. J. Micr. Sci. Vol. 51, pp. 511-556 Rev. Zool. Anz. Bd. 34, p. 216.

Fischl, Rud., uber die Folgen der Thymusexstirpation beim jungenlHühnern. Jahrb. Kinderkeilk. Bd. 66, p. 475, (1907). Rev. Anat. Anz. V. 34, p. 351.

Gadeau de Kerville, H., Note sur un oeuf double de poule domestique. Bull. Soc. Amer. Sc. nat. Rouen T. 42, pp. 299-300. (1907). Rev. Zool. Anz. Bd. 34, p. 352.

Gage, S. H. and Susanna P., Sudan III Deposited in the Egg and Transmitted to the Chick. Science (N. Ser.) 28 (1908) No. 719. pp. 494-5.

Goodale, H. D., Results of Castration in Ducks. Biol. Bul. (Dec., 1910).

Grosser, T. C., Ein vierbeiniges Wünder-Huhnchen. Der Geflugel-Zuchter. Bd. 2 I. P. 189. (1909).

Hadley, P. B., Notes on the Behavior of the Domestic Fowl. Div. of Biol. No. 5 . Rhode Island Agr. Col.

Heidrich, K., Anatomisch-physiologische Untersuchungen über den Schlundkopf des Vogels, mit Berücksichtigung der Mundhöhlenschleimhaut und ihrer Drüsen bei Gallus Domesticus. Giessen, p. 82. (1906).

Houssay, F., Sur un poulet ayant vecu 7 jours apres l'eclosion avec un second jaune inclus dans l'abdomen. Compt. rendu. T. ${ }_{134}$, (1709).

Hugues, Albert, Couleur des yeux d'oiseaux albinos. Bul. Soc. Zool. France. V. 32. pp. 108-1 10. (1907). Rev. Zool. Anz. v. 34, p. 300.

Jones, Bynds, Development of Nestling Feathers. Lab. Bul. No. 3. Oberlin College.

Kunster, J., Les beufs anormaux. Bibliogr. Anat. Bd. I6. pp. 262-272. (I907). Rev. Zool. Anz. Bd. 34, p. 301.

Lefeuvre, Sur une anamolie assez rare de l'oeuf un cas d'oeuf inclus chez le cane. Bull. Soc. Scient. Med. Onest. Rennes T. 15. p. 239-241. Also Trav. Scient. Univ., Rennes. T. 6, pp. 60-62. (1906-7). Rev. Anat. Anz. Bd. 34.

Lichtenstadt, S., Ein Vierbeiniges Kuchen Natur u. Haus. Jahr. 12, p. 29. Rev. Biblio. Zool. Bd. 9, p. 132.

M'Aldowie, Alexander, The Development and Decay of the Pigment Layer in Birds' Eggs. Jour. Anat. u. Phs. Vol. 20 (1 886) pp. 225-237.

Marshall, T. H., Another Monster Egg. V. 31 P. 718, 1907 Rev. Zool. Anz. 34 Agric. Journ. Cape Good Hope.

McNair, H., Structure and Function of the Digestive Tract of the Chicken. N. Y. State Veterinary College Laboratory Bul. No. 3 . 
Meitzner, M., Zur Kenntnis der Morphologie und Histologie des hautigen. Labyrinthes von Gallus domesticus. Marburg pp. 118 (1908).

Pearl, Raymond and Pearl, Maude H., Data on Variation in the Comb. Biometrika, 6 (1909), No. 4.

Pearl, Raymond, Morphogenetic Activity of the Oviduct of the Domestic Fowl. Jour. Exper. Zool. 6 (1909) No. 3.

Pearl, Raymond and Surface, F. M., Nature of the Stimulus which Causes the Shell to be Formed on a Bird's Egg. Science (N. Ser.) 29 (1909) No. 741.

Pearl, Raymond and Surface, F. M., Resection and End-to-end Anastomosis of the Oviduct of the Hen, Without Loss of Function. Biol. Papers of the Maine Agr. Exp. Sta. No. 5.

Pearl, Raymond, A Triple Yolked Egg. Maine Biology Lab. Paper No. 15.

Reihl, H. A., Ueber den Bau des Augenlides beim Vogel. G. Thieme p. 82 (I908).

Rice, J. E., Nixon, Clara and Rogers, C. A., The molting of Hens. (1908) Cornell Bul. No. 258.

Riddle, Oscar, Cause of Production of Down and other Down-like Structures in the Plumages of Birds. Biol. Bul. I4 (1908) No. 3.

Riddle, Oscar, Genesis of Fault-bars in Feathers and Cause of Light and Dark Fundamental Bars. Biol. Bul. 14 (1908) No. 5.

Riddle, Oscar, Rate of Growth of the Egg Yolks in the Chick and Significance of. the White and Yellow Yolk in the Ova of Vertebrates. Science (N. Ser.) 27 (1908) No. 703 P. 945.

Shattuck, S. G. and Seligman, C., An example of Incomplete Hermaphroditism in the Domestic Fowl. Proc. Roy. Soc. Med. London. (1908). Vol. 1 path. sec.: pp. 3-7.

Simpson, Sutherland, Observations on the Body Temperature of the Domestic Fowl During Incubation. Trans. Royal. Soc., Edinburgh (I911).

de Sower, Eugene, Les premiere stades de la vitellogenese dans l'ovule de la poule. Ann. Soc. Med. de Gand. T. 85 pp. 55-62. (1905). Rev. Zool. Anz. Bd. 34, p. $35^{2}$.

Strong, R. M., Development of Color in the Definitive Feather. Bul. Museum of Comp. Zool. Harvard College Vol. 40 (1902) No. 3.

Szielasko, A., Die Bildungsgesetze der Vogeleier bezuglich ihrer Gestalt. GeraUntermhaus 80. p. 23 (1902) Rev. Biblio. Zool. Vol. 8, p. 45.

Vaughan, Victor C., Osteology and Myology of the Domestic Fowl (1876).

Walker, C. E., Influence of the Testes on the Secondary Sexual Characters of Fowls. Proc. Royal Ser. Med. (London) I (1906) No. 6.

Willey, A., Dwarf Eggs of the Domestic Fowl. Spolia Zeylanica Vol. 1, pp. 76, 77 (1903) Rev. Zool. Anz. 34, p. 353.

— Quelques faits concernant le developement l'intestin moyen et de ses glandes annexes chez les oiseaux. loc. cit. p. 1268.

Beeton, S. O., Poultry and Pigeons. Ward \& Bowden, London.

Brice, F. B., Jr., Successful Pigeon Raising.

Cox, W. E. and Rice, W. E., Squabs for Profit. Orange Judd Co., N. Y. City.

English, Poultry and Pigeons, Engravings and Designs by H. Weir. (1862) Bickers \& Bush, London.

Fly, E. A., Poultry and Pigeon Raising.

Fulton, R., Book of Pigeons. Cassell \& Co., London.

Gilbert, F. L., Pigeons and all about them. American Poultry Jour. Pub. Co., Chicago, Ill. 
Graham, C. K., Squab Investigations. Conn. (Storrs) Bul. No. 50. (1907).

Howard, G. E. \& Co., Poultry and Pigeon Fancier's Companion and Breeder's Directory. (1897). Washington, D. C.

Meersch, A. V., Pigeons: Care and Management for Pleasure and Profit.

Rice, E, C., National Standard Squab Book. American Poultry Jour. Pub. Co., Chicago, Ill.

Rice, Wm. E., Squab Raising. U. S. Farmers' Bul. 177.

Selby, P. J., Natural History of Pigeons. W. H. Lizars, Edinburgh.

Sotter, F. A., Breeding for Squabs. (1908). Douglasville, Pa. III.

Summers, J. A., Diseases of Pigeons. American Poultry Jour. Pub. Co., Chicago,

Summers, J. A., Successful Pigeon Breeding. Frecks, Pa.

Tegetmeier, W. B., Pigeons: Their Structure, Varieties, Habits and Management. Routledge \& Son, London.

Twombly, C. E., Pigeon Standard. American Poultry Jour. Pub. Co., Chicago, IIl.

Walters, John, The Jacobin. (English).

Webber, J. A., The Working Homer.

Wright, Mr., Practical Pigeon Keeper.

Wright, Mr., The Feather's Practical Squab Book. Geo. E. Howard Pub. Co., Washington, D. C.

Wright, Mr., The Feather's Practical Pigeon Book. Geo. E. Howard Pub. Co., Washington, D. C.

\section{Statistics}

England National Poul. Organization Society, Consumption of Eggs and Poultry. Leaflet No. I.

Ontario Agr. College, Starting the Poultry Dept. at the College. Report 1894.

Slocum, R. R., Poultry Work of the Animal Industry, Washington, D. C. U. S. Bu. An. Ind. Rep. 1907.

Thompson, G. F., Distribution and Magnitude of the Poultry and Egg Industry. U. S. Bu. Animal Industry Rep. 1902.

Wisconsin, Organization of Poultry Dept. Report of Director, Bul. No. 193.

\section{Systems of Poultry Keeping}

Hosterman Pub. Co., The Briggs System. Binghamton, N. Y.

Philo, E. R., The Philo System. Elmira, N. Y.

Potter, T. F. \& Co., Don't Kill the Laying Hen.

\section{Turkeys}

Blanchard, H. L., Hatching and Rearing Turkeys. Washington Bul. No. 96.

Corbett, Adolphe, Raising of Turkeys and how the Queen of England Manages.to Avoid Death by the Red. English.

Cushman, S., Turkeys. R. I. Bul. No. 25 (1893).

Doubleday, Page \& Co., Turkeys. Care and Management. N. Y. City. Eng.

England (Univ. College), Rearing and Feeding Turkeys. Pamphlet. Reading,

Field, Fanny, Practical Turkey Raising. E. R. Mitchell, Chicago, Ill. 
Harris, Wm. W., The Turkey (1893). Puldoro, Sussex, Eng.

Johnson, G. M., The Turkey, Duck and Goose. Binghamton, N. Y.

Jouett, W., Epizootic Pneumo-pericarditis in the Turkey. 34 (1909) No. I Agr. Jour. Cape Good Hope.

McGrew, T. F., Turkeys: Standard Varieties and Management. U. S. Farmers' Bul. No. 200.

Meyrick, Herbert, Turkeys and How to Grow Them. Orange Judd Co., N. Y. City.

Reliable Poultry Jour. Pub. Co., Turkeys; Their Care and Management for Exhibition and for Market. Quincy, Ill.

Rhode Island, Turkey Raising; Goose Raising, Cross-breeding. Report I897.

Rhode Island Agr. College, Turkey Breeding. Report 1907.

U. S. Dept. Agr., Experiments with Turkeys; Grit and Ash for Growing Chicks; A Successful Brooder House. U. S. Farmers' Bul. No. 225 (Exp. Sta. Work.)

Watson, O. M., Egg Production of Turkeys; Weight of Chickens. South Carolina No. 74 .

\section{Waterfowl}

Brown, W. and E., Cost of Rearing Ducklings. University College, England.

Cook, Wm., Ducks and How to Make Them Pay. (1895) London.

Corbett, Adolphe, How to Raise Ducks.

Digby, H., How to Make 5o Pounds a Year Keeping Ducks. Treatise on Geese. English.

Digby, H., Standard for Waterfowl. English.

Donald, J., Indian Runner Duck. English.

England, Bd. Agr., Cost of Rearing Ducklings. Jour. Bd. Agr. 15 (1908) No. 9.

England, Bd. Agr. and Fisheries, Ducks. Leaflet No. 167.

England, Bd. Agr. and Fisheries, Rearing and Marketing Geese. Leaflet No. 198.

Flagg, Chas. O., Goose-breeding. R. I. Rep. 1897.

Howard, Geo. E., Ducks and Geese. U. S. Farmers' Bul. No. 64.

Ireland, Bd. Agr. and Tech. Instr., Geese. Leaflet No. 198.

Johnson, G. M. F., The Turkey, Duck, and Goose. Binghamton, N. Y.

Lewis, J., Some Notes on the Hybridizing of Ducks. Bonbote. Orvis-Vol. 14 (1905) pp. 235-264. Zool. Anz. 34, p. 343 .

Pound, C. J., Infectious Leukaemia in Ducks. Queensland Agr. Jour. 20 (1908) No. 3-pp. 136-138.

Rankin, Jas., Natural and Artificial Duck Culture (1889), Daniel Gunn, Boston, Mass.

Reliable Poultry Jour., Pub. Co., Ducks and Geese. Quincy, Ill.

Rhode Island, Blackhead, Cross-breeding Geese. Rep. I894.

Rhode Island, Experiments with Geese. Rep. 1895 .

Rhode Island, Cross-breeding Geese; Analysis of Foods. Report 1896.

Rhode Island, Incubation and Brooding. Goose Experiments. Rep. 1902.

Spencer, A., Duck Rearing in the Vale of Aylesbury. Eyre \& Spottiswoode, London.

Stoddard, H. H., Domestic Waterfowl. Hartford, Conn.

Sutcliffe, J. H., Duck Farming. English.

U. S. Dept. Agr., Geese for Profit. Farmers' Bul. No. 65. Exp. Sta. Work.

U. S. Dept. Agr., Feeding Ducks. Farmers' Bul. No. 107. Exp. Sta. Work. 

Work.)

U. S. Dept. Agr., Animal Food for Ducks. Farmers' Bul. No. 233. (Rxp. Sta.

Vale, W. W., Profitable Ducks-English.

Weber Bros., How we Make Ducks Pay. Amer. Pekin Duck Co., Boston, Mass.

How to Secure Publications of the Department of Agriculture

Publications of the Department of Agriculture may be divided into two classes, those of a popular nature and intended for wide circulation, and those of a more technical nature and intended for a more restricted circulation. The first class includes Farmers' Bulletins, Circulars of the various Bureaus, and certain other periodical publications, such as the Crop Reporter and the Monthly List of Publications issued by the Department. The second class includes the bulletins of the various bureaus, the annual. reports of the bureaus and the Year Book of the Department, besides special publications and reports.

Any publication, whether of the first or second of these classes, of which a supply is in the hands of the Department is for free distribution. Application for these publications should be made to the Editor and Chief of the Division of Publications, United States Department of Agriculture. As the editions of many of these publications are necessarily limited, and no funds are available for securing additional copies, the list of those in the hands of the Department is constantly changing. Where the Department's supply is exhausted, application must be made to the Superintendent of Documents, Government Printing Office, who has them for sale at a nominal price. Remittance should be made by Postal Money Order, Express Order or New York Draft. Currency may be sent at owner's risk. Postage stamps, foreign money, uncertified checks, defaced or sleek coin will not be accepted.

Applications by residents of foreign countries for Farmers' Bulletins should be sent to the Superintendent of Documents, Government Printing Office, Washington, D. C., and should be accompanied by six (6) cents, the price per copy including postage. Applications from foreign countries for other publications must be accompanied by the price of the publication plus the regular rate of postage. No charge is made for postage on documents forwarded to points in the United States, Guam, Hawaii, Philippine Islands, Porto Rico, or to Canada, Cuba or Mexico.

Senators, Representatives and Delegates in Congress, each have a quota of several thousand copies of Farmers' Bulletins and of certain other publications such as the Year Book of the Department. These publications are 
supplied them for distribution among their constituents. It is often possible, therefore, to secure these publications by direct application to one's Representative or Senator.

\section{Addresses of Colleges and Experiment Stationg}

Academy of Sciences, Washington. D. C.

Arizona, Experiment Station, Tucson.

Arkansas, Experiment Station, Fayetteville.

Alabama, Experiment Station, Auburn.

California, State College, Berkeley.

Colorado, Experiment Station, Fort Collins.

Connecticut, Agricultural College, Storrs.

Delaware, Experiment Station, Newark.

Indiana, Purdue University, Lafayette.

Iowa, Agricultural College, Ames.

Kansas, Agricultural College, Manhattan.

Kansas, Department of Agriculture, Topeka.

Kentcuky, Experiment Station, Lexington.

Louisiana, Experiment Station, Baton Rouge.

Maine, Agricultural College and Experiment Station, Orono.

Maine, Department of Agriculture, Augusta.

Maryland, Agricultural College, College Park.

Massachusetts, Agricultural College, Amherst.

Massachusetts, Board of Agriculture, Boston.

Michigan, Experiment Station, Agricultural College.

Minnesota, University of Minnesota, St. Paul.

Mississippi, Agricultural College, Agricultural College.

Missouri, Experiment Station, Columbia.

Missouri, Poultry Experiment Station, Mountain Grove.

Montana, Experiment Station, Bozeman.

Nebraska, Experiment Station, Lincoln.

New Jersey, Agricultural College, New Brunswick.

New York, Agicultural Experiment Station, Geneva.

New York, Cornell Experiment Station, Ithaca.

New South Wales, Department of Agriculture, Victoria.

New Zealand, Department of Agriculture, Wellington.

Nevada, Experiment Station, Reno.

North Carolina, Experiment Station, Raleigh.

North Dakota, Experiment Station, Agricultural College.

Ohio, Agricultural College, Columbus.

Oklahoma, Experiment Station, Stillwater.

Oregon, Agricultural College, Corvallis.

Pennsylvania, Agricultural College, State College.

Pennsylvania, Department of Agriculture, Harrisburg.

Rhode Island, Agricultural College, Kingston.

South Dakota, Agricultural College, Brookings. 
South Carolina, Experiment Station, Clemson College.

Utah, Experiment Station, Logan.

Virginia, Experiment Station, Blacksburg.

Washington, Experiment Station, Pullman.

West Virginia, Experiment Station, Morgantown.

Wisconsin, Agricultural College, Madison.

United States Department of Agriculture, Washington, D. C.

United States Bureau Animal Industry, Washington, D. C.

United States Bureau Chemistry, Washington, D. C.

United States Bureau Entomology, Washington, D. C.

United States Office Experiment Stations, Washington, D. C.

United States Division Forest Service, Washington, D. C.

Australia, Hawkesbury Agricultural College, Roseworthy, S. Australia.

British Columbia, Department Agriculture, Victoria.

Canada, Alberta, Dep't Agriculture, Edmonton.

Canada, Ontario Agricultural College, Guelph.

Canada, Central Experimental Farms, Ottawa.

England, Board Agriculture and Fisheries, London.

England, University College, Reading.

England, National Poultry Organization Society, London.

Ireland, Board Agriculture and Technical Instruction, Dublin.

Japan, Government, Tokio.

Respectfully submitted,

Clara Nixon,

Victor Fortier,

Frank Surface,

R. R. SLOCUM,

J. M. TURPin. 


\title{
CONSTITUTION AND BY-LAWS
}

\author{
Article I-NAME
}

SECtion 1. The name of this organization shall be the International Association of Instructors and Investigators in Poultry Husbandry.

\section{ARTICLE 2-OBJeCts}

Section I. The objects of this Association shall be the advancement of poultry husbandry throughout the United States and the Dominion of Canada, and especially as it relates to the profession of teaching and research.

\section{ARTICLE 3-MEMBERSHIP}

SECTION 1. The members of this Association shall be persons engaged in instruction or investigation in poultry husbandry in any educational institution or experiment station in the United States or the Dominion of Canada, who, upon recommendation by one or more members, shall be elected by a majority vote of the Executive Committee.

\section{ARTICLE 4-EXPULSION OF MEMBERS}

SECTION I. Any member who shall be found guilty of an offence not in keeping with the dignity and honor of a teacher or investigator may be expelled by a two-thirds vote of the members of the Executive Committee, who shall receive and weigh evidence for and against the member accused. The member shall have the right of appeal to the Association.

\section{Article 5-Initiation Fee and Dues}

Section I. The initiation fee of this Association shall be two dollars (\$2), payable with the application for membership; and the dues shall be one dollar $(\$ 1)$ annually thereafter, payable on or before the date of the annual meeting.

SECTION 2. Members whose dues have not been paid within one year after the date of the last annual meeting shall be considered as having forfeited their membership.

SECTION 3. Persons who have been dropped from membership because of non-payment of dues may be re-instated by a majority vote of the Executive Committee upon receipt of a written statement from the Secretary-Treasurer that all back dues have been paid.

\section{ARTICLE VI-OFFICERS}

Section I. The officers of this Association shall be a President, First and Second Vice-Presidents, Secretary-Treasurer and five directors who shall constitute an Executive Committee of nine members.

SEction 2. The term of office for all officers shall be one year, or until their successors shall be elected, except the directors, whose term of office shall be for two years. At the first election three directors shall be elected for two years and two for one year.

Section 3. The office of President shall not be filled by the same person for more than one year in succession.

Section 4. Neither the President, the Vice-Presidents nor any two members of the Board of Directors shall be chosen from the same State or Province. 


\section{ARTICLE VII-ELECTION OF OFFICERS}

Secrion 1. The officers shall be elected by ballot at the annual meeting. The first ballot shall be informal.

SECTION 2. It shall require a majority of all ballots cast to elect any officer. Should there be three or more candidates for any office after the second informal ballot, the lowest one on the list shall be dropped after each succeeding ballot until some one gets a majority.

SECTION 3. The newly elected officers shall asume the duties of their office immediately at the close of the annual meeting.

SEction 4. Vacancies in office shall be filled by a majority vote of the Executive Committee.

\section{ARTICLE VIII-DUtIES OF OfFICERS}

Secrion I. The duties of the President shall be to preside at all meetings of the Association and of the Executive Committee and to perform the usual duties of that office. He shall appoint all committees not otherwise provided for, and sign all checks, drafts or orders on the funds of the Association.

Secrion 2. The duties of Vice-Presidents. In the event of the absence of the President or his inability to act, the first Vice-President shall perform the duties of the President In case of the absence or inability to act of the first Vice-President, the second Vice-President shall perform the duties of the President.

Section 3. The Duties of the Secretary-Treasurer shall be:

(a) To keep the records of all transactions of the Association.

(b) To have charge of all the correspondence of the Association.

(c) To collect all money due the Association.

(d) To be custodian of all properties belonging to the Association.

(e) To prepare and distribute notices of all meetings.

(f) To deposit all funds of the Association in such bank or banks as may be designated in writing by the Executive Committee.

(g) To pay out of the funds of the Association only by check countersigned by the President and accompanied by itemized bills, which shall later be receipted and filed.

(h) To make a financial report at each annual meeting.

(i) To make a report of the minutes of all meetings.

(j) To edit an annual report in the event of the authorization of a report by the Executive Committee.

SEction 4. The Secretary-Treasurer shall give a bond which shall be effective when approved by the Executive Committee.

Section 5. The duties of the Executive Committee shall be to have general charge of the affairs of the Association when not in annual session.

\section{ARTICle 9-Committees}

Secrion r. At the annual meeting the President shall appoint

(a) A Legislative Committee of three whose duty it shall be to promote legislation which shall safeguard the interests of poultry husbandry.

(b) A Committee on Investigational Work.

(c) A Committee on the Systematizing of instruction in Poultry Husbandry.

(d) A Committee on the Advancement of the Principles of Breeding Poultry.

(e) A Committee on the Progress in the knowledge of the Feeding of Poultry. 
(f) A Committee on the Development of the Science of Incubation and Brooding.

(g) A Committee on Poultry Diseases and Parasites.

(h) A Committee on Bibliography.

\section{ARTICle 10-MeETINGS}

Secrion I. The annual meeting shall be held at such time and place as shall be designated by the Executive Committee.

Section 2. Special meetings of the Executive Committee may be called by the President and must be called upon the written request to him of five members of the Executive Committee or of one-fifth of the membership of the Association.

SEction 3. Notice of all meetings of the Executive Committee shall be mailed to each member of the Executive Committee by the Secretary Treasurer at least ten days before they are held.

\section{BY-LAWS}

Roll call.

\section{ARTiCle I-ORder OF BUSINESS}

Minutes of the last meeting.

Election of new members.

Report of Executive Committee.

Report of other standing committees.

Report of special committees.

Unfinished business.

Election of officers.

New business.

\section{ARTICLE 2-FundS}

Section 1. The President and Secretary-Treasurer shall not pay out the funds of the Association for any extraordinary expense without the authority of the Executive Committee.

No committee shall render the Association liable to an amount exceeding that appropriated by the Executive Committee.

\section{ARTICLE 3-TELLERS}

Secrion I. At the annual meeting the president shall appoint three tellers whose duties it shall be to have charge of the election.

\section{ARTICle 4-AMENDMENTS}

The constitution and by-laws may be altered or amended only by a two-thirds vote at an annual meeting after each members of the Association has had a thirty-day notice in writing of the proposed amendment.

\section{ARTIClE 5-QUORUM}

Section 1. One-fifth of the members of the Association shall constitute a quorum. 


\section{MEMBERS}

Atwood, Horace, (charter), M.S. in Agr., Asst. Agriculturist, W. Va. Agr. Expt. Station, Morgantown, W. Va.

Barto, D. O., (1909), Extension Department, University of Illinois, Urbana, Ill.

Blanchard, H. L., (I910), Asst. Supt. In charge of Dairy and Poultry Investigation, Puyallup, Wash.

Brigham, A. A., (1909), B.S., Ph.D., Principal School of Agriculture; Supt. South Dakota State College Summer School; Director South Dakota College Extension, South Dakota State College, Brookings, S. D.

Brown, C. E., (1908), Poultryman, University of Minnesota, North West Expt. Farm and School of Agriculture, Crookston, Minn.

Brown, W. A., (charter), B.S.A., M.S., Poultry Expert for the Dominion, Department of Agriculture, Ottawa, Canada.

Campbell, S. T., (charter), Secretary American Poultry Association, Mansfield, Ohio.

Chapman, N. E., (1909), A.B., B.D., A.M., Poultry Specialist, Extension Division of State Agricultural College, University of Chicago, Denison University, Owatonna, Minn.

Clark, J. W., (charter), Cainsville, Ontario, Canada.

Cole, L. J., (1909), Ph.D., Associate Professor of Experimental Breeding, Wisconsin Agr. College and Expt. Station, Madison, Wis.

Coleman, W. E., (1909).

Crane, Otis, (I908), Lebanon, Ind.

Davenport, C. B., (charter), Ph.D., Director, Carnegie Institution of Washington, Cold Spring Harbor, L. I.

Drew, James M., (1908), Registrar, College of Agriculture, University of Minnesota, St. Anthony's Park, St. Paul, Minn.

Dryden, James, (charter), Professor Poultry Husbandry, Oregon Agri. College and Expt. Station, Corvallis, Oregon.

Dynes, O. W., (charter), B.S., Associate Professor of Agronomy, N. Dak. Agri. College, Agricultural College, N. D.

Edwards, S. F., (1910), Professor Bacteriology, Ontario Agri. College, Guelph, Canada.

Elford, F. C., (charter), Cypher's Incubator Mfg. Co., Buffalo, N. Y.

Foley, A. W., (1909), Edmonton, Alberta, Canada.

Fortier, Victor, (I908), M.S. N.A., de F., Poultry Manager, Central Experimental Farm, Ottawa, Canada.

Gage, Geo. Edward, (1909), M.A., Ph.D., Asst. Professor of Animal Pathology, Massachusetts Agri. College, Amherst, Mass.

Gilbert, A. G., (1909), Supt. Poultry Division, Central Experimental Farm, Ottawa, Canada.

Graham, C. K., (charter), Director of Agricultural Department, Hampton Normal and Agricultural Institute, Hampton, Va.

Graham, W. R., (charter), B.S.A., Professor of Poultry Husbandry, Ontario Agricultural College, Guelph, Canada.

Hadley, P. B., (charter), Ph.B., Ph.D., Biologist, Experiment Station of the R. I. State College, Kingston, R. I. 
Halpin, James G., (charter), B.S.A., Associate Professor of Poultry Husbandry, University of Wisconsin, Madison, Wis.

Jackson, Homer W., (1909), Cyphers Incubator Mfg. Co., Buffalo, N. Y.

Jacobs, W. S., (1908), Fayetteville, Ark.

Jacoby, F. S., (1910), B.S.A., Instructor in Poultry Husbandry, Ohio State Agri. College, Columbus, Ohio.

Jaffa, M. E., (1909), Ph.B., M.S., Professor of Nutrition, Director Pure Food and

Drug Laboratory, University of California, Berkeley, Cal.

Jeffrey, J. S., (1908), Cyphers Incubator Mfg. Co., Buffalo, N. Y.

Jull, M. A., (1909), B.S.A., W.H. Gunn \& Co., 135 Water St., Vancouver, B. C.

Kempster, H. L., (1909), B.S., Asst. Professor Poultry Husbandry, University of Missouri, Columbia, Mo.

Kerr, J. P., (charter), Agricultural College, Miss.

Kirkpatrick, Wm. F., (1908). B.E., B.Agr., Professor of Poultry Husbandry, Conn. Agr. Col. Storrs, Conn.

Krum, Walter G., (charter), Supt. of Poultry Plant, New York State College of Agriculture at Cornell University, Ithaca, N. Y.

Lambert, D. J., (1908), Instructor in Poultry Husbandry, R. I. State College, Kingston, R. I.

Lamson, G. H., (1909), Storrs, Conn.

Landry, J. P., (I909), Manager and Lecturer, Poultry Department, Nova Scotia Agri. College, Truro, Nova Scotia, Canada.

Lane, D. J., (1909), University of Minnesota, St. Anthony's Park, St. Paul, Minn.

Lawry, R. C., (charter), B.S. in Agr., Vice-President, Yesterlaid Egg Farms Co., Pacific, Mo.

Lee, A. R., (1909), B.S., Junior Animal Husbandman, U. S. Dept. of Agriculture, Washington, D. C.

Lippincott, Wm. A., (1909), A.B., B.S. in A. H., Professor of Poultry Husbandry, State Agri. College, Manhattan, Kas.

Lunn, A. G., (1909), Asst. Poultryman, Instructor in Poultry Husbandry, Oregon Agri. College, Corvallis, Oregon.

McAleer, H. A., (I909), Investigator in Poultry and Egg Handling, Food Research Laboratory, Bureau of Chemistry, U. S. Dept. of Agr., 1833 Chestnut St., Philadelphia, $\mathrm{Pa}$.

McGrew, T. F., (1909), Principal of the School of Poultry Husbandry, International Correspondence Schools, Scranton, Pa.

Morse, G. B., (charter), Bureau of Animal Industry, U. S. Dept. of Agri., Washington, D. C.

Nixon, Miss Clara M., (charter), Asst. in Poultry Husbandry, N. Y. State College of Agriculture at Cornell University, Ithaca, N. Y.

Opperman, C. L., (charter), Junior Animal Husbandman, U.S. Dept. of Agriculture, Washington, D. C.

Pearl, Raymond, (charter), A.B., Ph.D., Biologist, Maine Agri. Expt. Station, Orono, Me.

Phillips, A. G., (1908), B.S. in Agr., Instructor in charge of poultry in Purdue University and Associate in Experiment Station, Lafayette, Ind.

Pierce, H. C., (charter), B.S.A., Investigator in Poultry and Egg Handling, Food Research Laboratory, Bureau of Chemistry, U. S. Dept. Agr., 1833 Chestnut St., Philadelphia, $\mathrm{Pa}$. 
Quisenberry, T. E., (1909), Director, Missouri State Poultry Experiment Station, Mountain Grove, Mo.

Rice, James E., (charter) B.S. in Agr., Professor of Poultry Husbandry, at Cornell University, Ithaca, N. Y.

Rider, Wm. M., (1909), B.S., Professor of Animal Husbandry and Dairying, Winona College of Agriculture, Winona Lake, Ind.

Rogers, C. A., (charter), M.S. in Agr., Asst. Professor of Poultry Husbandry, N. Y. State College of Agriculture at Cornell University, Ithaca, N. Y.

Schoppe, W. F., (1909), B.S., Asst. Professor of Animal Industry in Poultry Husbandry, Col. of Agr., Orono, Me.

Schreiner, T. E., (1910), Asst., N. Y. State College of Agriculture at Cornell University, Ithaca, N. Y.

Slocum, R. R., (charter), B.S.A., Ithaca, N. Y.

Spear, A. E., (I9I0), Teacher of Poultry Husbandry, Hampton Normal and Agricultural Institute, Hampton, Va.

Stoneburn, F. H., (1909), care of the McGuckin-McDevitt Co., Morris Building, Philadelphia, $\mathrm{Pa}$.

Surface, F. M., (1908).

Turpin, Geo. M., (1909), B.S. in Agr., Asst. Professor of Poultry Husbandry, Utah Agri. College, Logan, Utah.

Vaplon, W. E., (1909), Poultryman, Colorado Agri. College, Fort Collins, Colo.

Waite, Roy H., (1909), B.S., Associate Poultryman, Maryland Agri. Expt. Station, College Park, Md.

Wheeler, W. P., (charter), First Asst., N. Y. Agri. Expt. Station, Geneva, N. Y.

Wilkins, S. D., (charter), Instructor in Poultry Husbandry, University of California. Davis, $\mathrm{Cal}$. 



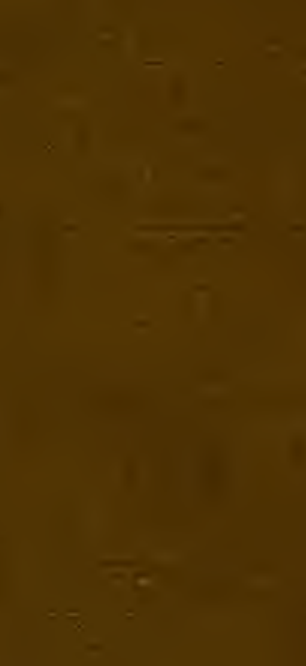

- 